\title{
IMPACTS OF PLUG-IN ELECTRIC VEHICLE ON RESIDENTIAL ELECTRIC DISTRIBUTION SYSTEM USING STOCHASTIC AND SENSITIVITY APPROACH
}

\author{
A Thesis \\ presented to \\ the Faculty of California Polytechnic State University, \\ San Luis Obispo
}

\author{
In Partial Fulfillment \\ of the Requirements for the Degree \\ Master of Science in Electrical Engineering
}

by

Henry Chigozie Ureh

October 2011 
(C) 2011

Henry Chigozie Ureh ALL RIGHTS RESERVED 


\section{COMMITTEE MEMBERSHIP}

TITLE:

AUTHOR:

DATE SUBMITTED:

COMMITTEE CHAIR:

COMMITTEE MEMBER:

COMMITTEE MEMBER:
IMPACTS OF PLUG-IN ELECTRIC VEHICLE ON

RESIDENTIAL ELECTRIC DISTRIBUTION SYSTEM USING STOCHASTIC AND SENSITIVITY APPROACH

Henry Chigozie Ureh

October 2011
Dr. Ali Shaban, Professor

Dr. Ahmed Nafisi, Professor

Dr. Taufik, Professor 


\begin{abstract}
IMPACTS OF PLUG-IN ELECTRIC VEHICLE ON RESIDENTIAL ELECTRIC DISTRIBUTION SYSTEM USING STOCHASTIC AND SENSITIVITY APPROACH Henry Chigozie Ureh
\end{abstract}

October 2011

Plug-in Electric Vehicles (PEVs) are projected to become a viable means of transportation due to advances in technology and advocates for green and eco-friendly energy solutions. These vehicles are powered partially, or in some cases, solely by the energy stored in their battery packs. The large sizes of these battery packs require large amount of energy to charge, and as the demand for PEV increases, the increase in energy demand needed to recharge these PEV batteries could pose problems to the present electric distribution system. This study examines the potential impacts of PEV on a residential electric distribution system at various penetration levels.

An existing residential distribution network is modeled up to each household service point and various sensitivity scenarios and stochastic patterns of PEV loads are simulated. Impact studies that include voltage drop, service transformers overload, energy loss, and transformer thermal loss-of-life expectancy are analyzed. Results from the study are reported and recommendations to mitigate the impacts are presented.

Keywords: Electric Vehicle, Stochastic, Sensitivity, Residential, Electric Distribution, Voltage Drop, Transformer Thermal Loss-of-Life Expectancy, Overloads, Energy Loss. 


\section{ACKNOWLEDGEMENTS}

I wish to thank my family for their encouragement and support for my education. They taught me the value of college education and instilled in me the importance of hard work and perseverance.

I wish to express my appreciation to my advisor Dr. Shaban, and my committee members, Dr. Taufik and Dr. Nafisi. I credit them for teaching various courses that helped develop my passion for power systems and power electronics.

I wish to express my gratitude to San Diego Gas and Electric for providing Advanced Metering Infrastructure (AMI) data and distribution network data used for this study.

I am grateful to Bill Torre for the resource and support that he provided during the course of my thesis. And thanks to EPRI for providing training and support for the OpenDSS software.

Disclaimer:

SDG\&E does not endorse or accept the conclusions or results of this study. 


\section{Table of Contents}

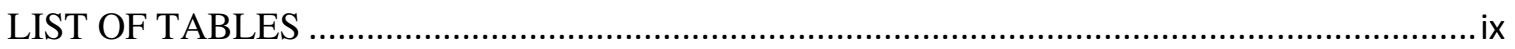

LIST OF FIGURES ..........................................................................................................

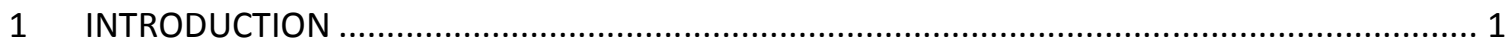

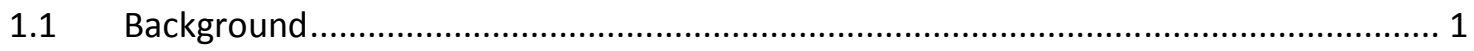

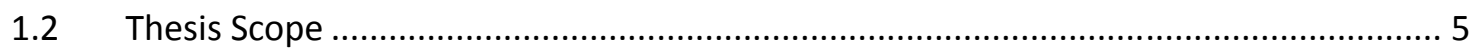

$1.3 \quad$ Thesis Organization ....................................................................................... 5

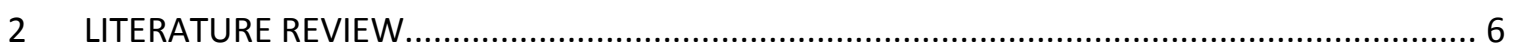

$2.1 \quad$ PEV Characteristics ................................................................................... 6

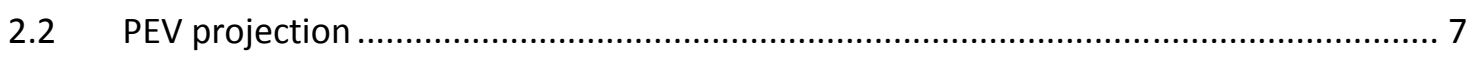

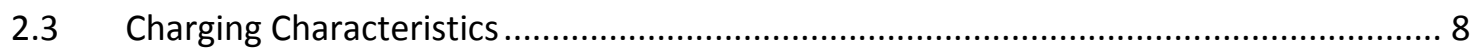

2.3.1 Levels of PEV Charger............................................................................. 8

3 OVERVIEW OF MODELED RESIDENTIAL ELECTRIC DISTRIBUTION SYSTEM USING EPRI

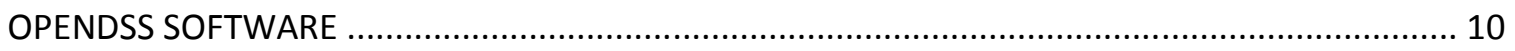

3.1 OpenDSS Simulation Software ……………………............................................ 10

3.2 Modeled Residential Electric Distribution System ………......................................... 10

3.2.1 Transformers.................................................................................... 14

3.2.2 Overhead Conductors and Underground Cable ……………………………….... 18

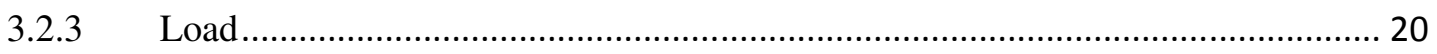

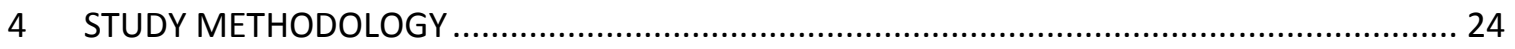

$4.1 \quad$ Overview of PEV Parameters........................................................................... 24

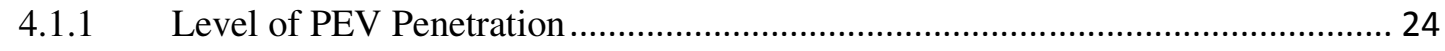

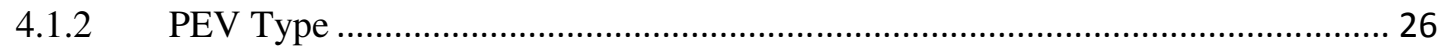

4.1.3 Charger Type …………………………………………………………. 29

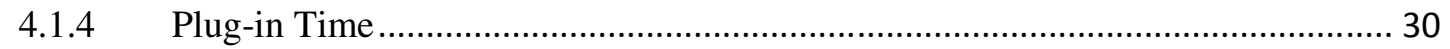


4.2 Overview of Analyzed Parameters

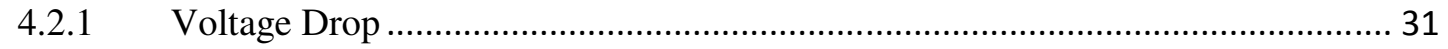

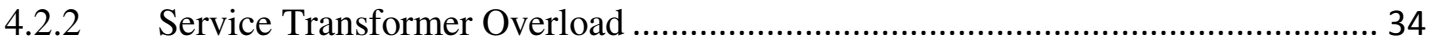

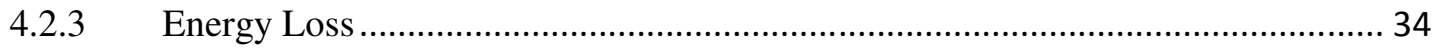

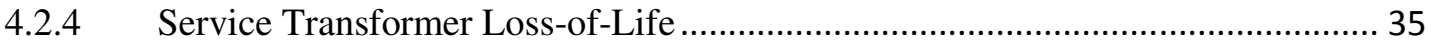

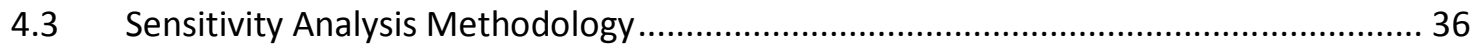

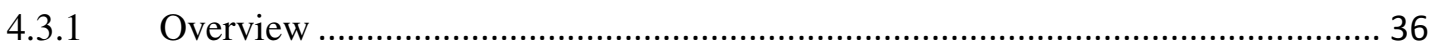

4.3.2 Proposed Methodology for Sensitivity Approach .............................................. 37

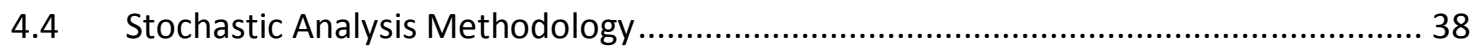

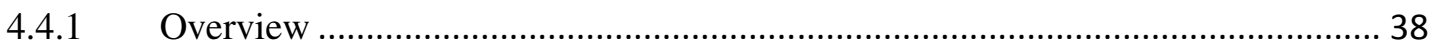

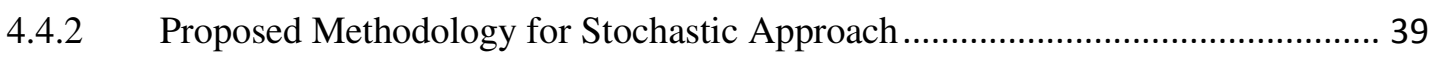

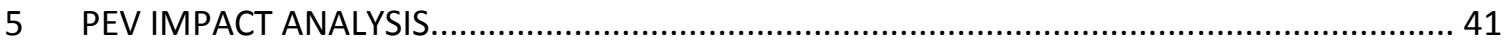

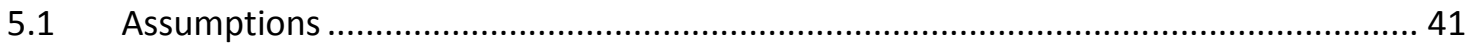

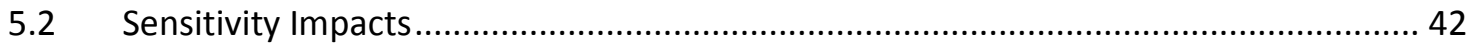

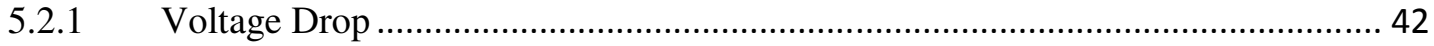

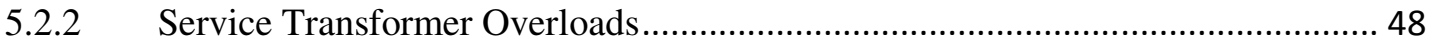

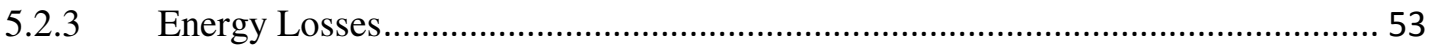

5.2.4 Service Transformer loss-of-life expectancy ..................................................... 55

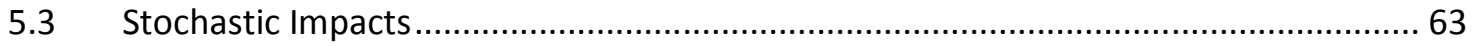

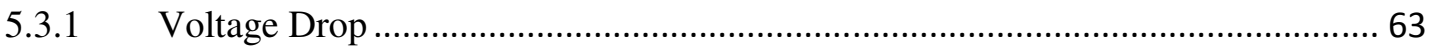

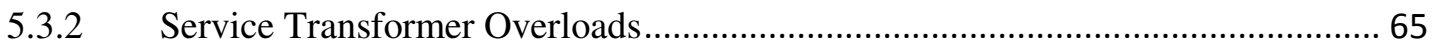

5.3.3 Service Transformer Loss-of-Life Expectancy ................................................. 67

6 SUMMARY OF FINDINGS, RECOMMENDATIONS, FUTURE STUDIES ................................. 70

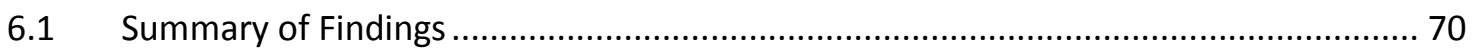

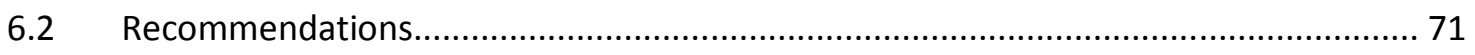




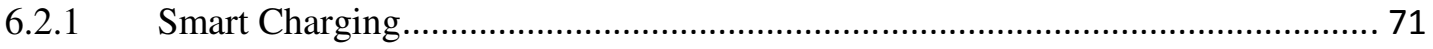

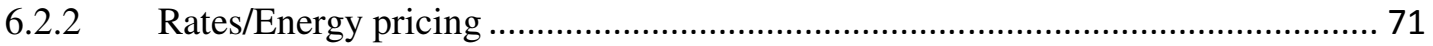

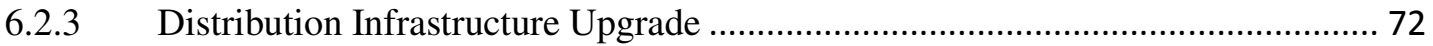

6.2.4 Effective Interaction between Utilities and Customers ...................................... 72

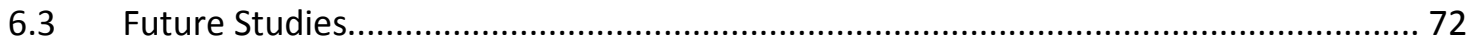

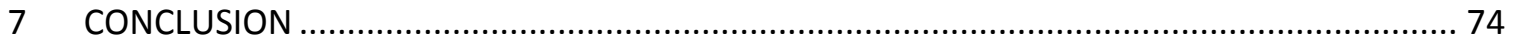

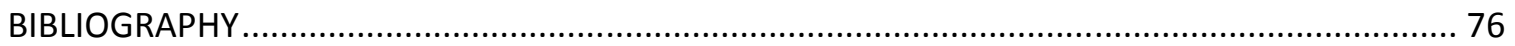

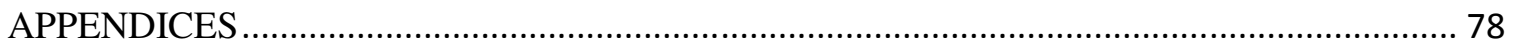

Connected PEV to each Service Transformer at Increasing PEV Penetration Level................... 78

PEV Location on the Electric Distribution Circuit at Increasing Penetration level ................... 80

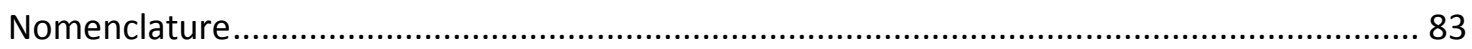

Service Transformer Loss-of-Life Calculation Using IEEE "Classical Thermal Model” ............... 85 


\section{LIST OF TABLES}

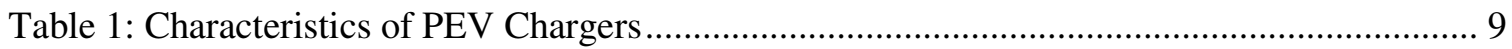

Table 2: OpenDSS Single Phase Mid-Tap Service Transformer parameters.............................. 15

Table 3: Current Ratings of Service Transformers (Primary Side) ........................................... 17

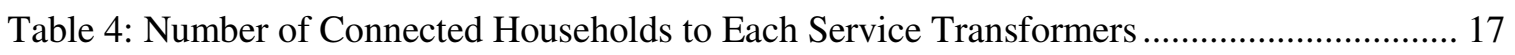

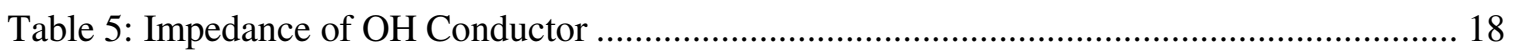

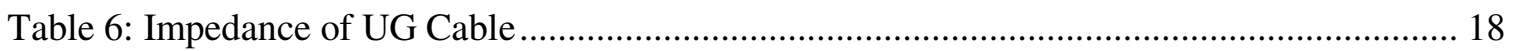

Table 7: Normal and Emergency Current Ratings of UG Cable and OH Conductors .................. 19

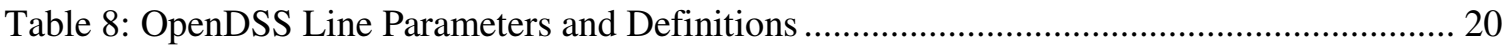

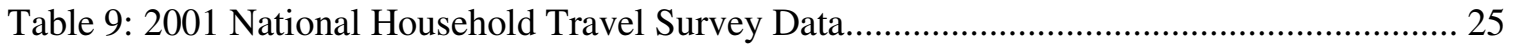

Table 10: Probability of Number of PEVs per Households ....................................................... 26

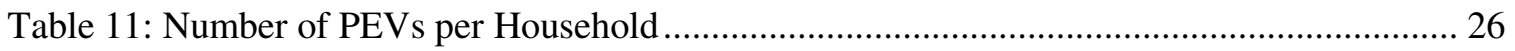

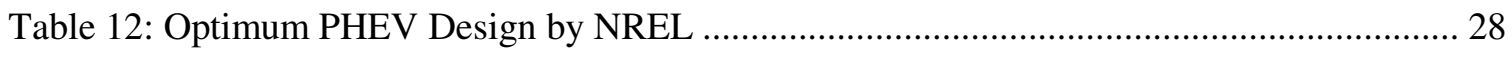

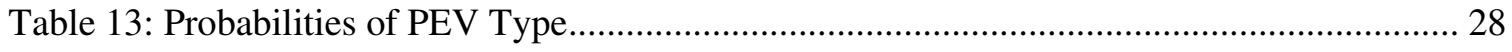

Table 14: Probabilities of PEV Charger Type (Stochastic Approach) ......................................... 29

Table 15: Charge Time for PEV Chargers and PEV Type ….................................................... 29

Table 16: Optimal and Tolerable Voltage Ranges for Service Point ......................................... 32

Table 17: Optimal and Tolerable Voltage Ranges for Utilization Point ....................................... 32

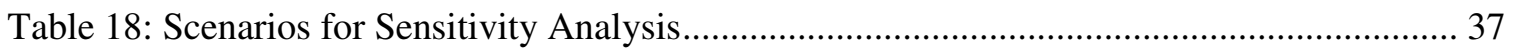

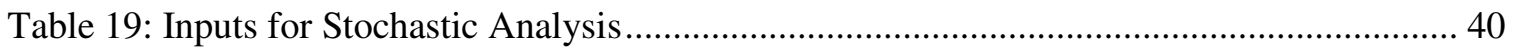

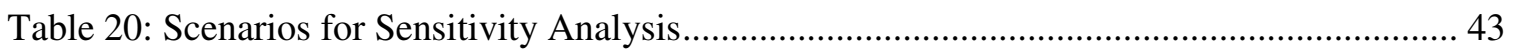

Table 21: Number of Households with Voltage Levels within Tolerable Voltage Range ............ 43

Table 22: Number of Households with Voltage Levels below Tolerable Voltage Range ............ 44

Table 23: Number of PEV Households with Voltage Drop Issues for all Sensitivity Scenarios .. 46

Table 24: Number of Service Transformers at risk of Overload for all Sensitivity Scenarios...... 49

Table 25: Number of Overloaded Service Transformers for all Sensitivity Scenarios ................. 50 
Table 26: Percent of Overloaded Transformers by kVA for Scenarios 1 and 2.......................... 51

Table 27: Percent of Overloaded Transformers by kVA for Scenarios 3 and 4 .......................... 51

Table 28: Percent of Overloaded Transformers by kVA for Scenarios 5 and 6 ........................... 52

Table 29: Percent of Overloaded Transformers by kVA for Scenarios 7 and 8 ........................... 52

Table 30: Table showing Number of Transformers Sizes and Connected PEV ............................ 52

Table 31: Average Hours of Service Transformers at Risk of Overload as a Percent of Base

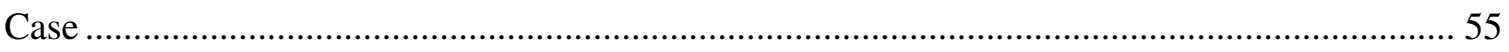

Table 32: Average Hours of Overloaded Service Transformers as a Percent of Base Case ......... 57

Table 33: Loss-of-life Expectancy for each transformer for scenarios 1 and 2 as a percent of

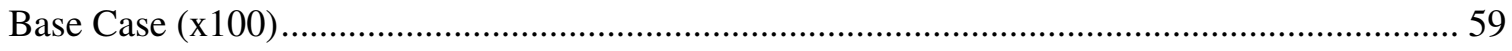

Table 34: Loss-of-life Expectancy for each transformer for scenarios 3 and 4 as a percent of

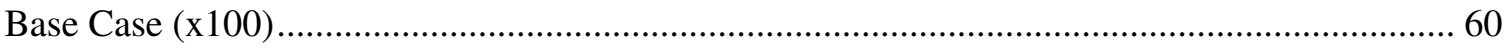

Table 35: Loss-of-life Expectancy for each transformer for scenarios 5 and 6 as a percent of

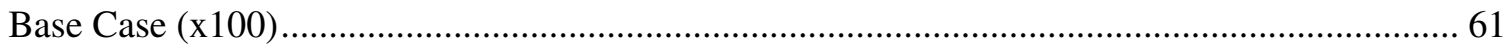

Table 36: Loss-of-life Expectancy for each transformer for scenarios 7 and 8 as a percent of

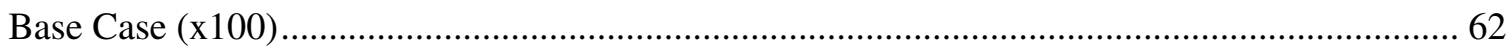

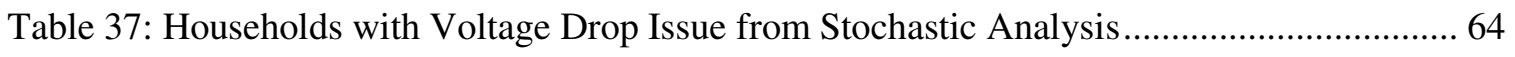

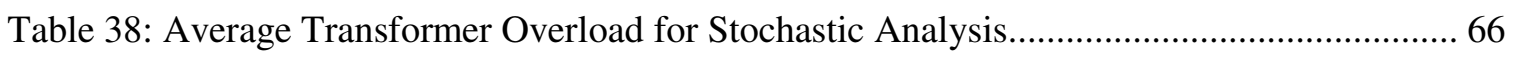

Table 39: Percent of Service Transformer Overload by kVA rating for Stochastic Analysis....... 67

Table 40: Average Hours of Service Transformers Overload or at Risk of Overload (For 7

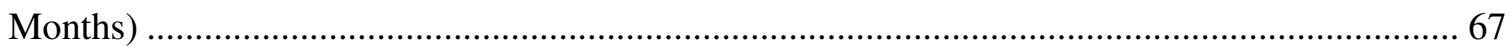

Table 41: Transformer Loss-of-Life Expectancy for Stochastic approach................................... 69

Table 42: Number of Connecter PEV to each Service Transformer at increasing PEV

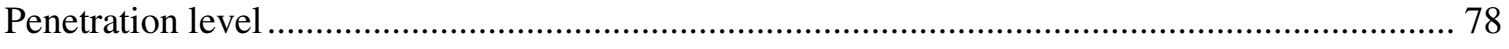

Table 43: Number of Connected Household to each Service Transformer.................................. 79 


\section{LIST OF FIGURES}

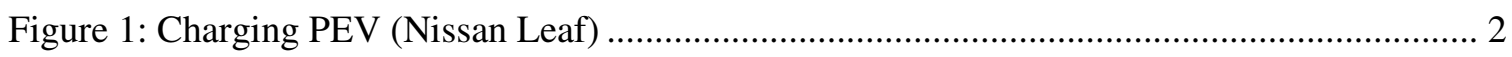

Figure 2: Load Profile of a Residential Home with PEV Charging between 1:00am and 6:30am . 2

Figure 3: Load Profile of PEV Charging between 1 am and 6:30am .......................................... 3

Figure 4: Voltage Profile of Residential Home with PEV charging from 1am to 6:30am.............. 3

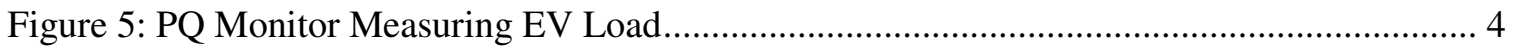

Figure 6: Household with PEV next to the Service Transformer .................................................... 4

Figure 7: Projected New Vehicles Market Share Categories ..................................................... 7

Figure 8: Example of J1772 Plug (Left) and PEV Receptacle (right) [13] ................................. 9

Figure 9: Modeled Residential Electric Distribution Circuit...................................................... 12

Figure 10: 12kV 3-Phase Feeder and 120/240V Single Phase Service/Secondary Lines ............. 13

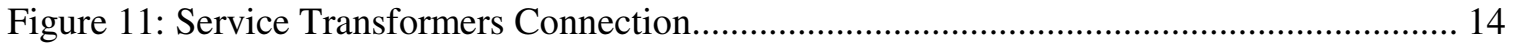

Figure 12: Center Tapped Single Phase Transformer Model ...................................................... 16

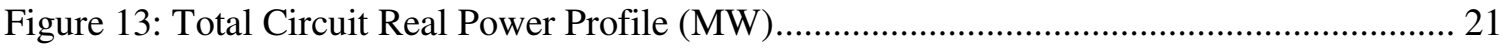

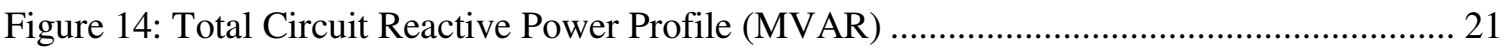

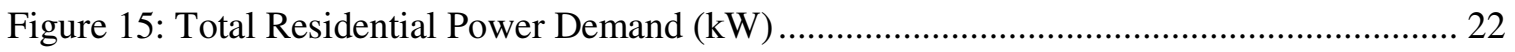

Figure 16: Daily Average Residential Load Profile ................................................................ 22

Figure 17: CDF of Daily Commuter's Miles Based on NHTS Data .......................................... 27

Figure 18: CDF of Commuters' Last Trip Arrival Time Based on the NHTS Data ..................... 31

Figure 19: PEV Charging at Service and Utilization Point. (1) PEV (2) EVSE (3) Residential

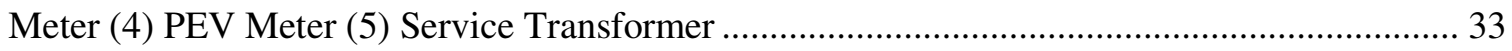

Figure 20: Simulation Algorithm for Sensitivity Analysis...................................................... 38

Figure 21: Monte Carlo Simulation Algorithm for Stochastic Analysis ..................................... 40

Figure 22: Percent of Households that Experienced Voltage Levels Below Tolerable Voltage

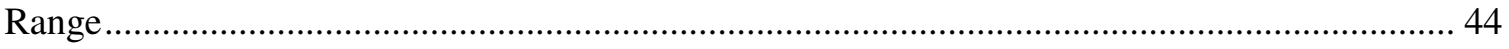

Figure 23: Number of PEV Owners with Voltage Drop Issues for all Sensitivity Scenarios ....... 46 
Figure 24: Percent of PEV Owners with Voltage Drop Issues for all Sensitivity Scenarios

Figure 25: Percent of Service Transformers at Risk of Overload .............................................. 49

Figure 26: Percent of Overloaded Service Transformers for all Sensitivity Scenarios ................. 50

Figure 27: Percent increase in total Circuit Losses (As multiple of Base Case) ........................... 53

Figure 28: Percent Increase in Service Lines Losses (As multiple of Base Case) ........................ 54

Figure 29: Percent Increase in Service Transformer Losses (As multiple of Base Case) ............. 54

Figure 30: Average Hours of All Service Transformers within Risk of Overload (As a percent

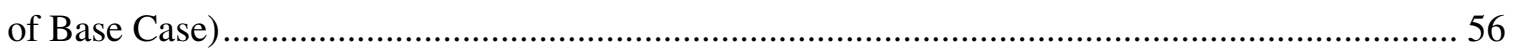

Figure 31: Average Hours of Overloaded Service Transformers (As a percent of the Base

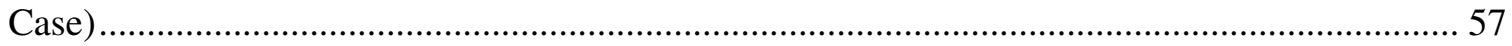

Figure 32: Percent of Households with Voltage drop issues from stochastic analysis.................. 64

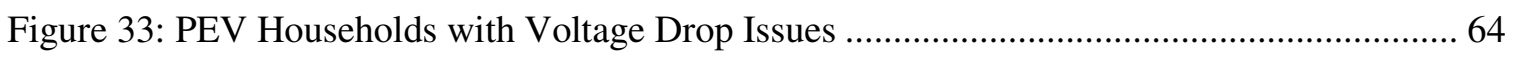

Figure 34: Percent Transformer Overloads from Stochastic Analysis ........................................ 66

Figure 35: Average Hours of Service Transformers Overload or at Risk of Overload as a

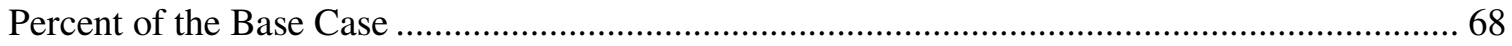

Figure 36: PEV Locations on the Distribution circuit at 2\% and 5\% Penetration Level .............. 80

Figure 37: PEV Locations on the Distribution Circuit at 10\% and 20\% Penetration Level.......... 81

Figure 38: PEV Locations on the Distribution Circuit at 50\% Penetration Level........................ 82

Figure 39: Transformer's Temperature profile for IEEE classical thermal model [14] ................ 85 


\section{INTRODUCTION}

\subsection{Background}

The transport sector relies heavily on fossil fuels and therefore accounts for a significant part of greenhouse emissions. The passenger car is the major consumer of energy, accounting for more than half the total transportation energy. Therefore, one of the main future technologies to combat greenhouse gas emissions is the battery powered plug-in electric vehicle (PEV). PEVs present a promising direction in the transportation section for decreasing both reliance on fossil fuels and emission of greenhouse gases. In

addition, driving on electricity has been found to be less expensive per mile compared to fossil fuel [1]. A range of passenger electric vehicles is currently being developed or already developed by different auto manufacturers. Some of the existing PEVs include TESLA Roadster, Chevy Volt, and Nissan Leaf. Other automakers including FORD, Toyota, Mercedes, and Volvo have plans to offer PEVs. While the roll-out of PEVs presents both environmental and financial benefits, the potential impacts on the electric grid, especially the distribution system, could be an issue if PEV charging is totally uncontrolled. 


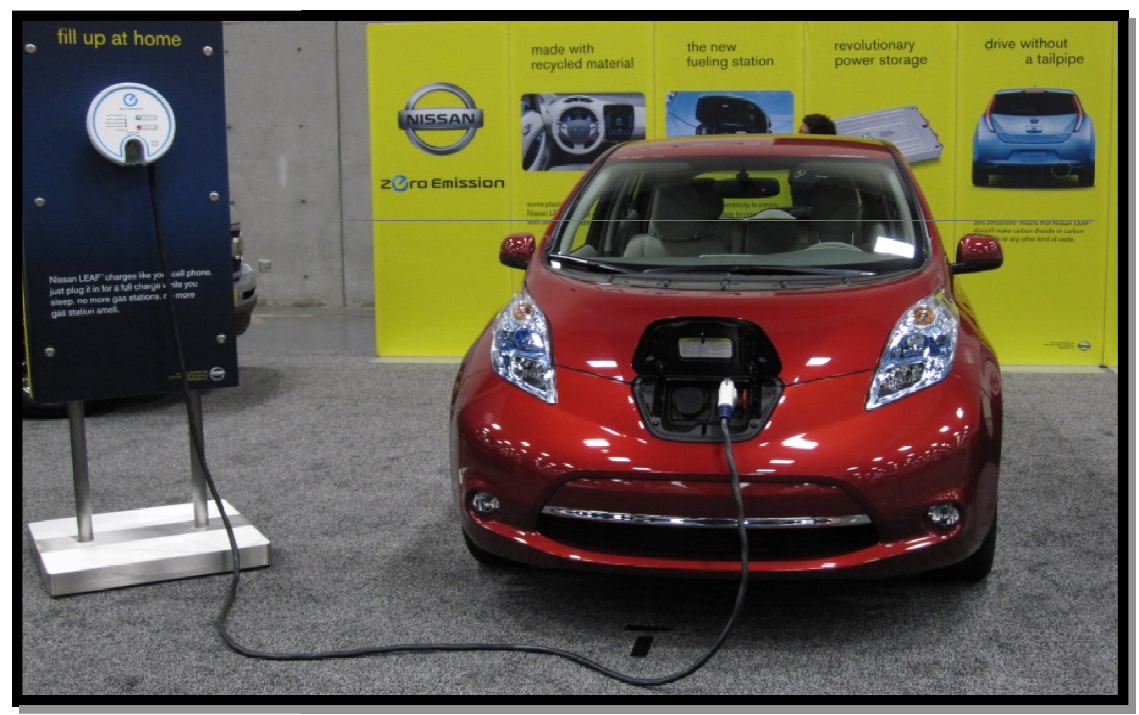

Figure 1: Charging PEV (Nissan Leaf)

The power demand for a PEV charger could double, or in some cases, more than double the power demand for a whole household. Figure 2 below shows an actual metered load profile of a residential home with PEV charging between 1am and 6:30am. Figure 3 illustrates the load profile of the PEV charger only. Clearly, the PEV load only, about quadruples the entire household load.

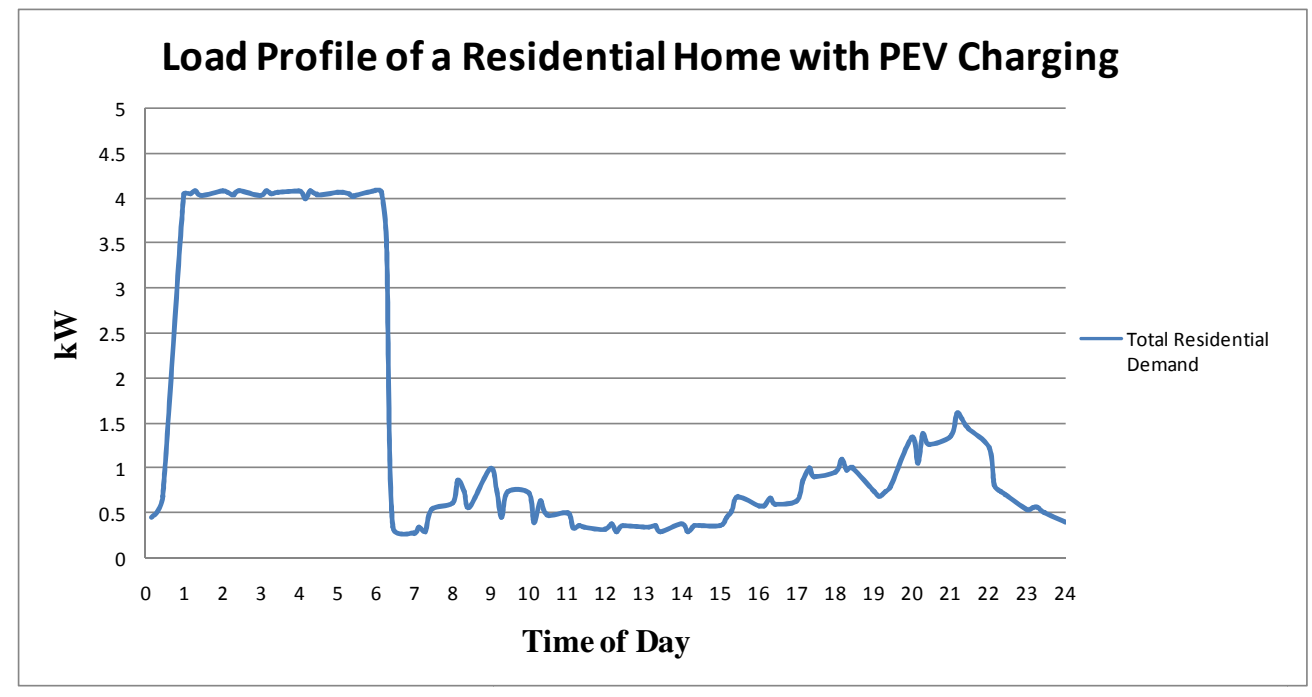

Figure 2: Load Profile of a Residential Home with PEV Charging between 1:00am and 6:30am 


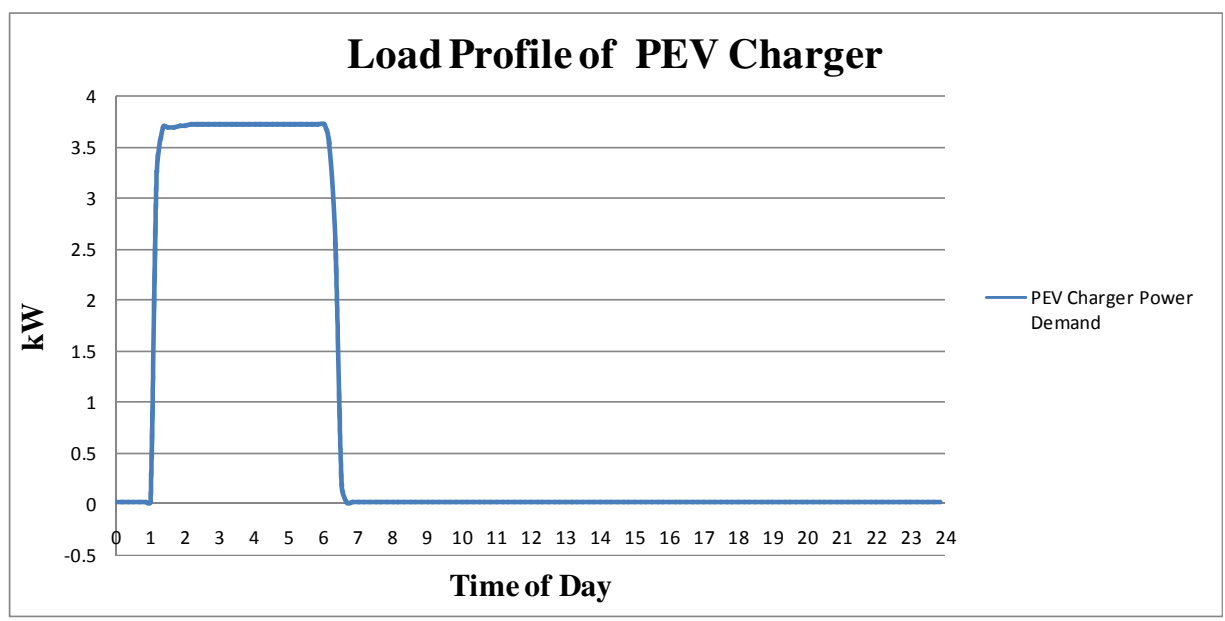

Figure 3: Load Profile of PEV Charging between 1am and 6:30am

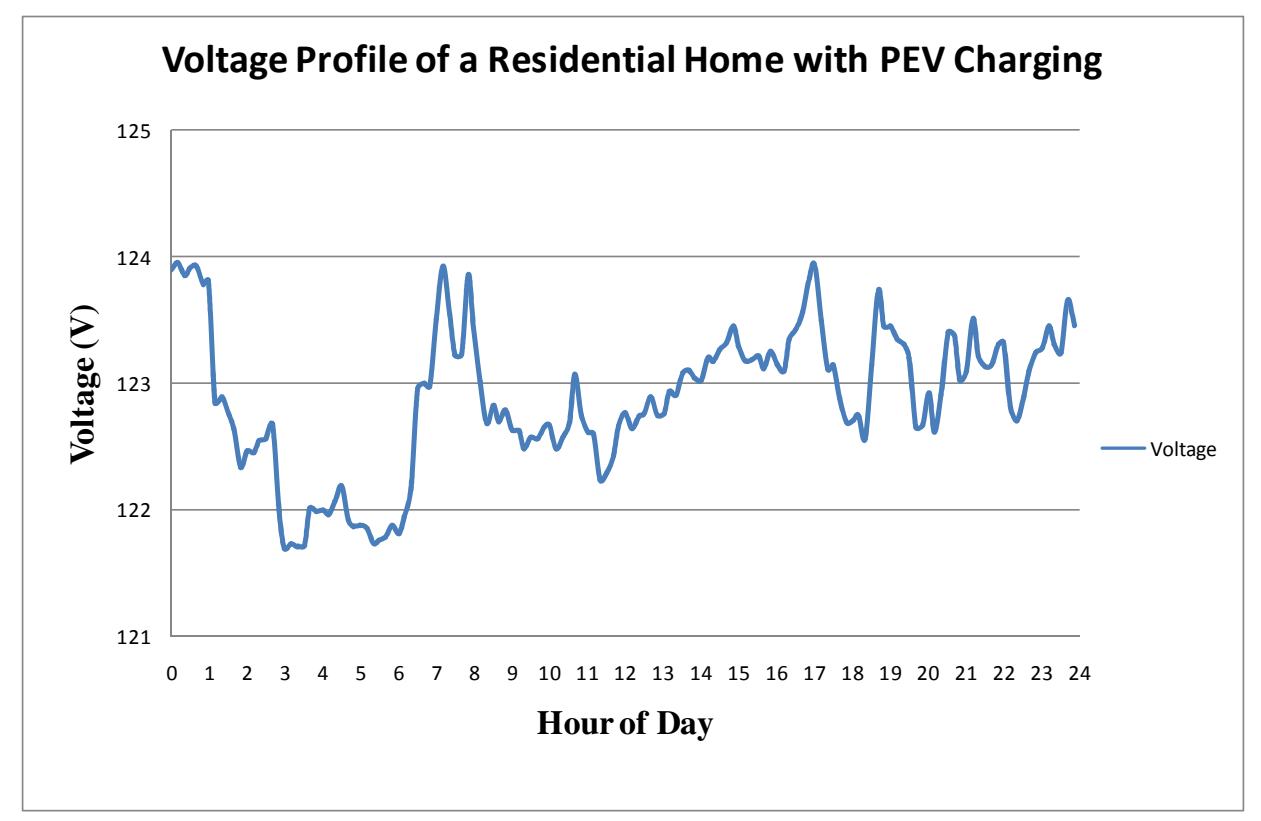

Figure 4: Voltage Profile of Residential Home with PEV charging from 1am to 6:30am

Figures 4 shows the voltage profile measured from the residential meter of the household. Though figure 6 illustrates that the residential home which the data was collected from is located next to the service transformer, the customer still experiences voltage drop from line losses due to the PEV load. However, in this case, the customer 
voltage is well within the optimal service voltage limit $(114 \mathrm{~V}-126 \mathrm{~V})$ set by the American National Standard ANSI C84.1 - 1989. This study investigates various system wide impacts of PEV charging on residential homes of an actual electric distribution circuit at 2\%,5\%,10\%, 20\%, and 50\% PEV penetration levels.

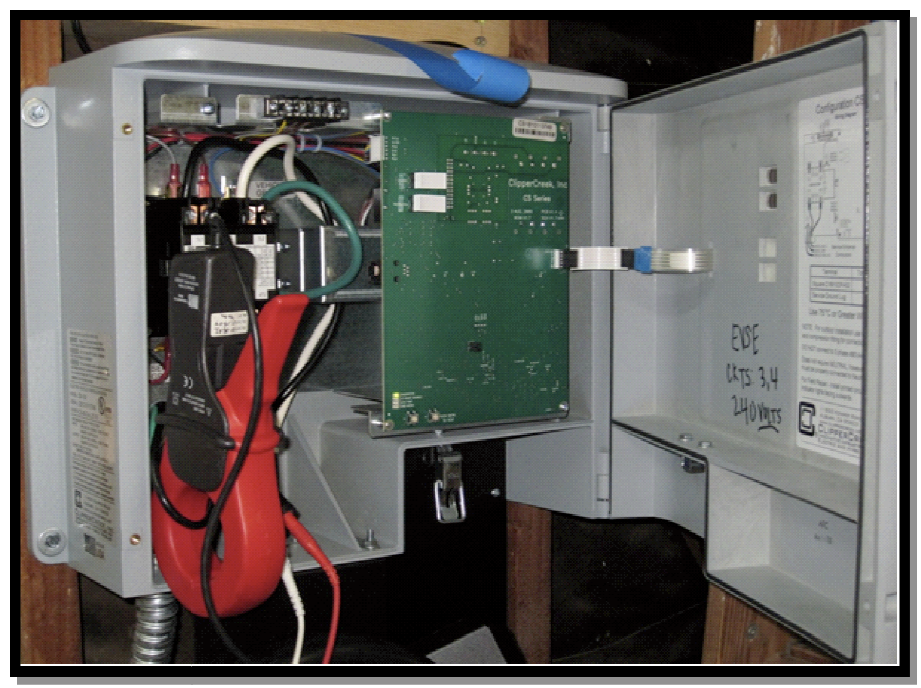

Figure 5: PQ Monitor Measuring EV Load

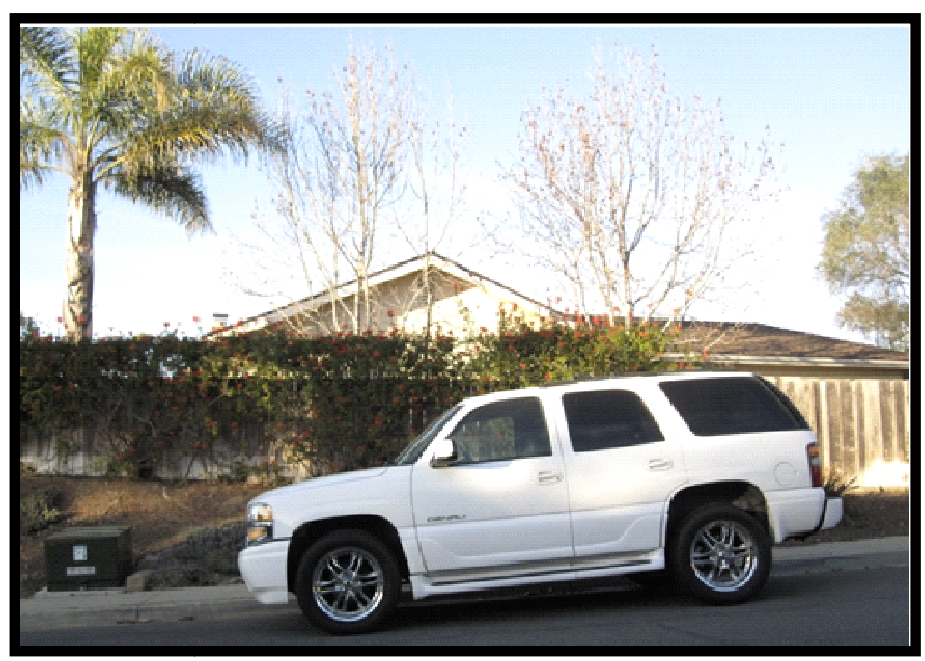

Figure 6: Household with PEV next to the Service Transformer 


\section{$1.2 \quad$ Thesis Scope}

The scope of this study includes both sensitivity and stochastic analysis of the impacts of PEV on an existing electric distribution system. The distribution system consists of primarily residential metered customers and is modeled using EPRI OpenDSS simulation software and MATLAB. About 7 months (June 2010 - December 2010) of metered load data for each household are collected at hourly intervals and used to perform hourly "dynamic" power flow analysis for various simulated PEV charging conditions. The study examines the potential impacts of PEV such as voltage drop, service transformers overload, energy loss, and service transformer thermal loss-of-life analysis.

\subsection{Thesis Organization}

The first chapter of this thesis covers the background of electric vehicles as well as the scope and organization of this study. Chapter 2 reviews literatures of previous studies on electric vehicles including PEV characteristics, PEV market forecast, and charging characteristics. Chapter 3 covers OpenDSS simulation software and how the software was used to model the residential electric distribution system. Chapter 4 looks into the methodologies used for the sensitivity and stochastic impact studies, as well as the assumptions made for both approaches. Chapter 5 presents results from both the sensitivity and stochastic impact studies. Summary of study findings and proposed recommendations to mitigate the potential impact of $\mathrm{PEV}$ on the electric distribution system are presented in chapter 6 . Chapter 7 covers the conclusion, while the bibliography, appendix, and nomenclature are covered in the later sections. 


\section{LITERATURE REVIEW}

\subsection{PEV Characteristics}

A range of vehicles make up the PEV fleet. Their characteristics differ in terms of vehicle ranges, battery capabilities, and vehicle drive trains. While these features affect the size and duration of charging PEV loads, they are also important for electric utilities for determining load demand. The three types of vehicles that make up the PEV fleet include:

- $\quad$ Plug-in Hybrid Electric Vehicles (PHEVs) are vehicles that utilize both internal combustion (IC) engine and large battery packs of about $5 \mathrm{kWh}$ to $22 \mathrm{kWh}$. Because the battery size is larger than traditional hybrid vehicles, it allows for longer all electric range. The combination of both IC engine and batteries allows unlimited driving range for PHEVs. A modified Toyota Prius with plug-in capability is an example of PHEV.

- $\quad$ Extended Range Electric Vehicles (EREVs) are vehicles with internal combustion engine and larger battery packs of about $16-27 \mathrm{kWh}$. The large battery capacity allows for all electric driving range of about 40-60 miles. The IC engine coupled with the battery provides an unlimited driving range by recharging the battery as needed. Chevy Volt is an example of EREV.

- Battery Electric Vehicles (BEVs) are vehicles with no IC engine and operate on battery stored energy only. The large battery size of about $25-35$ $\mathrm{kWh}$ allows for all-electric driving range of about 60-300 miles. They require 
recharging after using the energy stored in the battery packs [3]. Examples of BEV include Nissan Leaf and Tesla Roadster.

\subsection{PEV projection}

The Obama administration has set a goal of achieving one million PEVs on the road by 2015. Recent government incentives and stimulus investments to accelerate market acceptance, including grants and loans to manufacturer and tax credits to consumers, indicate movement towards this goal [2]. Projected market penetration of conventional vehicles (CVs), hybrid electric vehicles (HEVs), and plug-in electric vehicles (PHEVs) from 2010 to 2030 is illustrated in figure 1. HEVs represent about 15\% of the market new vehicle sales when PEVs are expected to enter the market in 2010. PEVs could reach a maximum of 10\% new vehicle market share by 2015 timeframe [3].

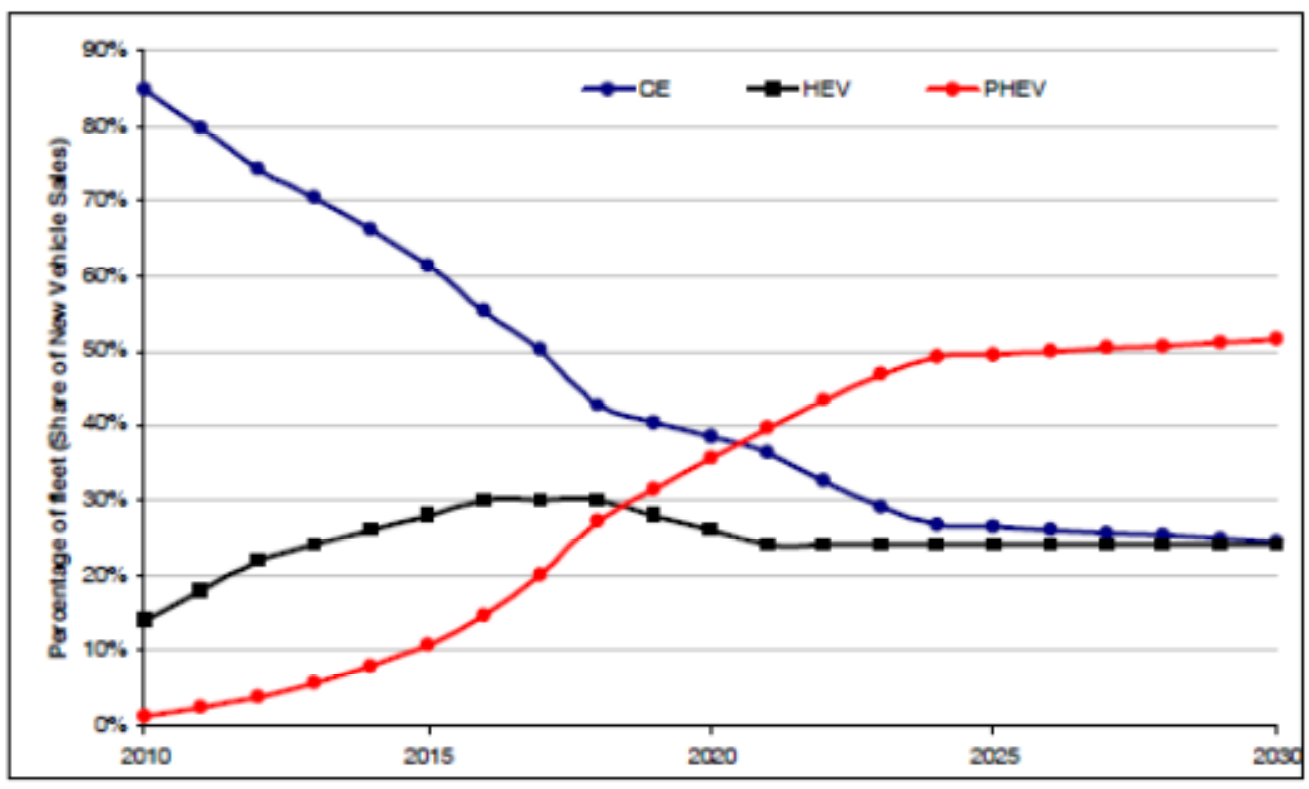

Figure 7: Projected New Vehicles Market Share Categories 


\subsection{Charging Characteristics}

\subsubsection{Levels of PEV Charger}

The various charging levels are characterized based on current and voltage ratings.

- $\quad$ Level 1 Charger uses a standard household grounded electrical outlet at $120 \mathrm{~V}$ and $15 \mathrm{~A}$. It requires up to $8-14 \mathrm{hrs}$ to fully charge a battery depending on the initial SOC (State of Charge) and capacity of the battery. These chargers are ideal for overnight residential charging purposes, but are not recommended for quick commercial or public charging purposes. However, they utilize portable EVSE (Electric Vehicle Supply Equipment) that can be transported with the vehicle.

- $\quad$ Level 2 Charger operates at $240 \mathrm{~V}$ and a current level not greater than 70A. They require about 3-6hrs to fully charge a battery, depending on the capacity and state of charge of the battery. It is the most common charging level found in homes and commercial areas and must be permanently hard-wired to the premise for EV charging purposes only.

- $\quad$ Level 3 Charger uses 3-phase 480V and current level up to 400A. They are capable of charging an EV to more than half its capacity in about 10-15 minutes. Though still under development and not yet UL (Underwriters Laboratories) approved, the level 3 charger provides very fast or rapid charging and is preferable for commercial and public charging purposes. 
Table 1: Characteristics of PEV Chargers

\begin{tabular}{|c|c|c|c|c|c|}
\hline Level & Voltage (V) & Max Current (A) & Power (kW) & Number of Phases & Standard Outlet \\
\hline 1 & 120 & 15 & 1.8 & Single & NEMA 5-15R \\
\hline 2 & $208 / 240$ & 60 & $12.48 / 14.4$ & Single & SAE J1772/3 \\
\hline 3 & 480 & 400 & 192 & Three & N/A \\
\hline
\end{tabular}

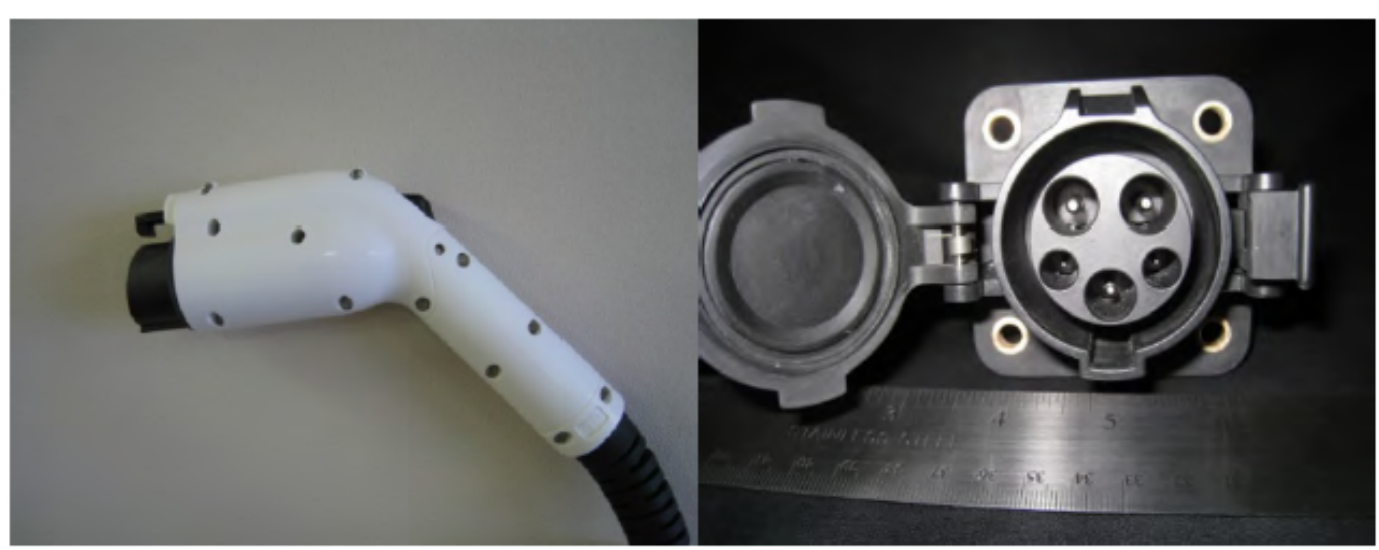

Figure 8: Example of J1772 Plug (Left) and PEV Receptacle (right) [13] 


\section{OVERVIEW OF MODELED RESIDENTIAL ELECTRIC DISTRIBUTION SYSTEM USING EPRI OPENDSS SOFTWARE}

\subsection{OpenDSS Simulation Software}

OpenDSS (Distribution System Simulator) is a comprehensive electrical power system simulation tool for electric utility distribution systems. The program has been under development for more than 10 years and was originally developed at Electrotek Concepts in 1997 and then purchased by EPRI in 2004. Among other functionalities, the simulator could be used for distribution planning and analysis, annual load and generation simulations, and distributed generation (wind and solar) interconnection studies. It performs all analysis including power flow, harmonics, fault study, and dynamic analysis in the frequency domain. The OpenDSS program offers various flexible built-in solution modes, including duty cycle, peak day, daily, and yearly power flow simulations [5].

\subsection{Modeled Residential Electric Distribution System}

The modeled electric distribution system consists of $373(98 \%)$ residential meters and $6(2 \%)$ primary metering stations. Though not modeled in this study, the primary metering stations consist of customers who purchase bulk energy at a higher voltage (12KV or higher). All 373 residential metered customers are modeled in the simulation. Like most distribution circuits, the modeled circuit is a radial system and originates from a substation with a 69/12 kV bank rated at 28 MVA. The circuit's main feeder consists of 
6554 feet of underground (UG) cable, which originates from the substation, and 8444 feet of overhead $(\mathrm{OH})$ conductor that distributes power to the metered customers. The circuit is comprised of 35 single phase, pole mount ( $12 \mathrm{kV}$ to $120 / 240 \mathrm{~V}$ ) distribution service transformers of 10,15, 25,50, and $75 \mathrm{kVA}$. The circuit is modeled up to the customer meter location, thereby accounting for both the secondary/service voltage drop. Figure 9 illustrates the modeled residential electric distribution system with the locations of the substation, UG cables, $\mathrm{OH}$ conductors, service transformers and metered customers. Figure 10 shows the $12 \mathrm{kV}$ three-phase feeders and the 120/240 single-phase secondary/service lines. 


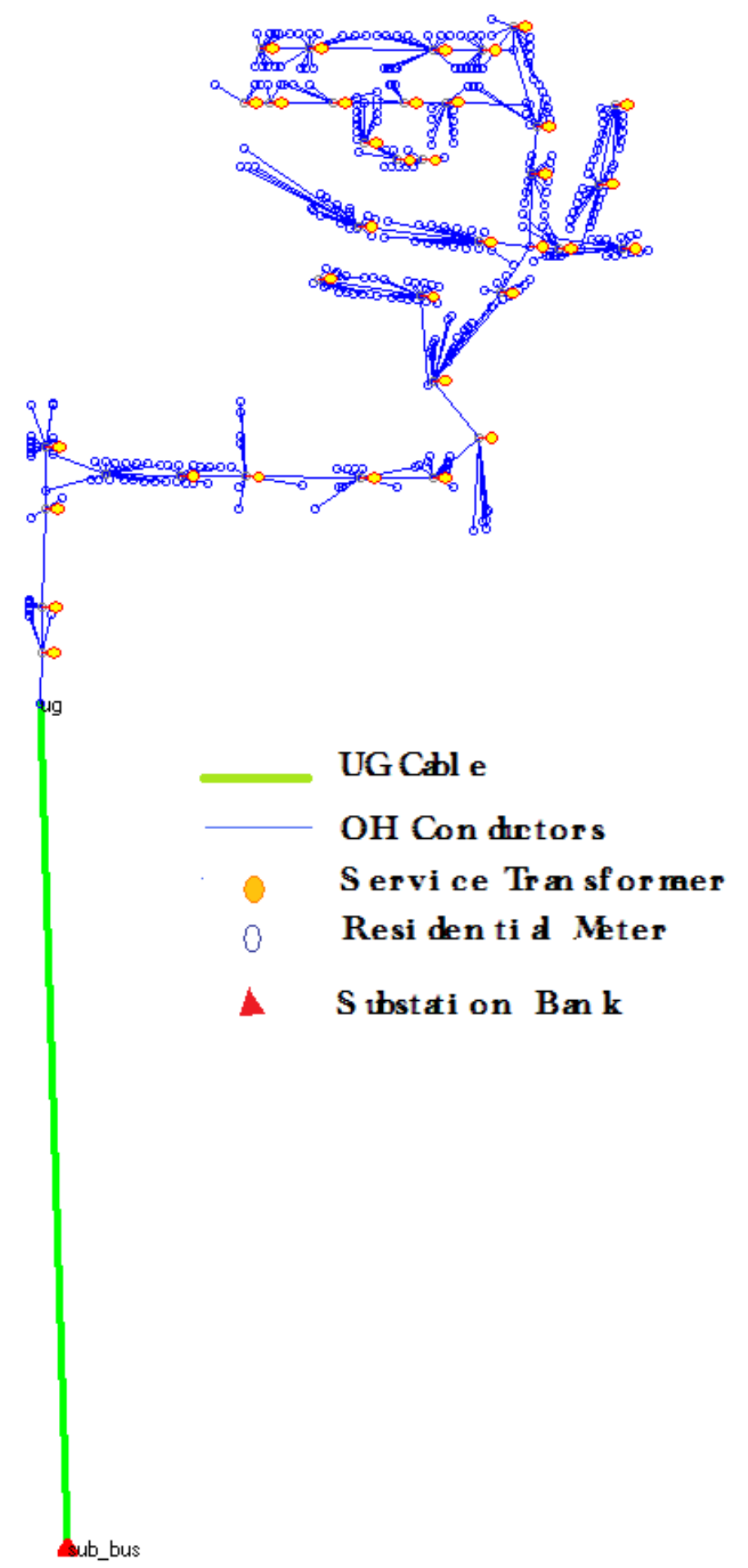

Figure 9: Modeled Residential Electric Distribution Circuit 


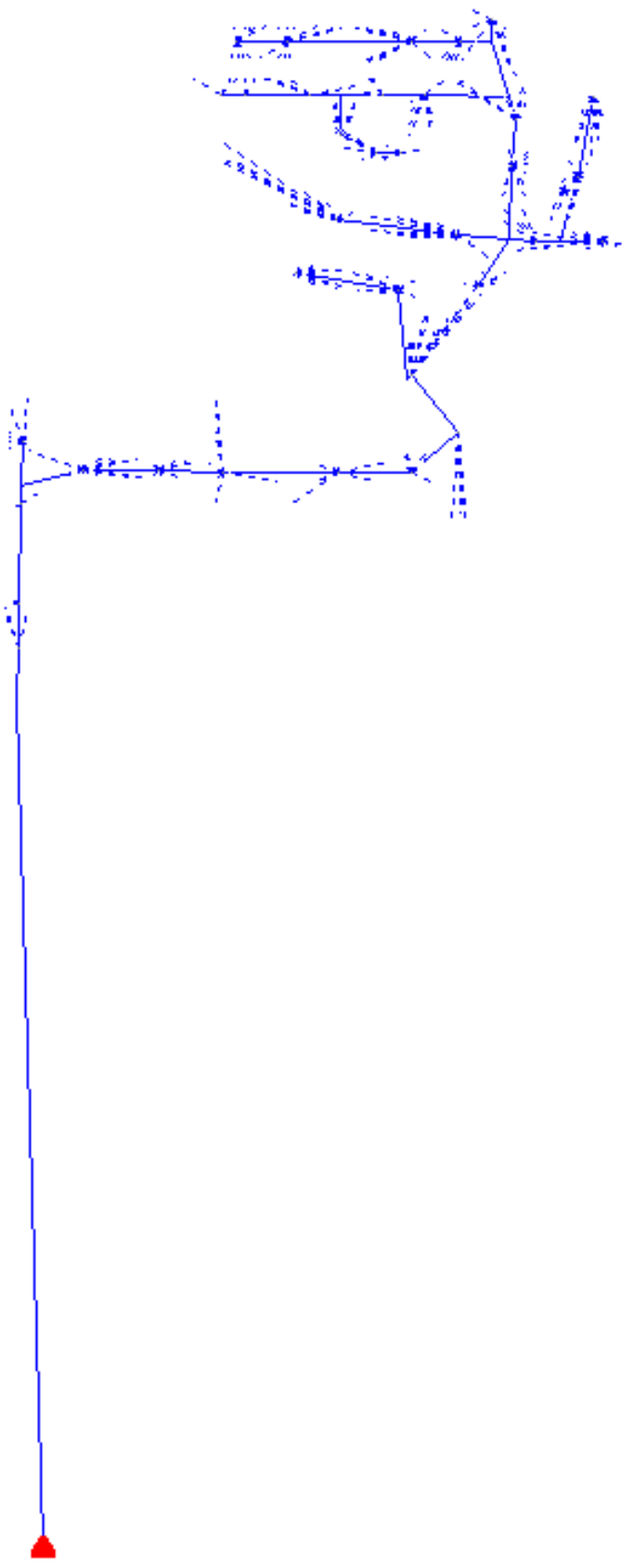

Figure 10: 12kV 3-Phase Feeder and 120/240V Single Phase Service/Secondary Lines 


\subsubsection{Transformers}

\subsubsection{Substation Bank}

The circuit, along with other neighboring distribution circuits, is served by a 28MVA substation bank. The bank is configured using a Delta-Wye (4 wire) system and the circuit is served by lines A and C only.

\subsubsection{Single Phase Service Transformer}

The service transformers are modeled as 3-winding center tapped transformers as shown below. The primary side is connected to lines A and C with $12 \mathrm{kV}$ L-L voltage, while the secondary side consists of the neutral and 120/240 V connections as shown in Figure 11 below.

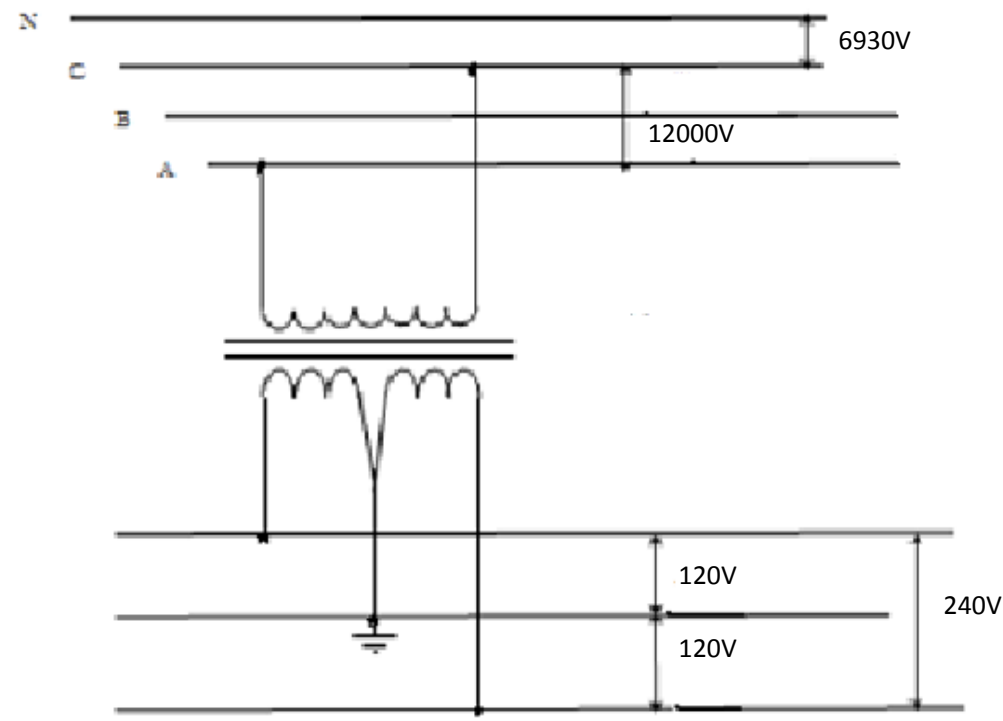

Figure 11: Service Transformers Connection

A sample script used to model a service transformer with OpenDSS is shown below. 


\section{Transformer Object}

New Transformer.name phases $=1$ Windings $=3$

$\sim X h l=2.04 X h t=2.04 X l t=1.36 \%$ noloadloss $=0.2$

$\sim W d g=1$ bus=1.1.3 $k v=12 \mathrm{kva}=25 \% \mathrm{r}=0.6$

$\sim W d g=2$ bus $=2.1 .0 \mathrm{kv}=0.12 \mathrm{kva}=25 \% \mathrm{r}=1.2$

$\sim W d g=3$ bus $=2.0 .2 \mathrm{kv}=0.12 \mathrm{kva}=25 \% \mathrm{r}=1.2$

Table 2: OpenDSS Single Phase Mid-Tap Service Transformer parameters

\begin{tabular}{|c|c|c|}
\hline Notation & Definition & Value \\
\hline Xhl & Percent reactance between winding s 1 and 2 & 2.04 \\
\hline Xht & Percent reactance between windings 1 and 3 & 2.04 \\
\hline Xlt & Percent reactance between winding 2 and 3 & 1.36 \\
\hline \% no load loss & Percent no load loss & 0.2 \\
\hline Wdg & Winding & $1 / 2 / 3$. \\
\hline kv & Voltage of winding & $12 \mathrm{kV}$ or 120V \\
\hline kva & KVA of winding & 25 \\
\hline Windings & Number of winding & 3 \\
\hline Bus & Connected Bus & \\
\hline$\% \mathrm{r}$ & $\%$ resistance of winding on the rated KVA base & $0.6 / 1.2$ \\
\hline
\end{tabular}

The table above shows the impedance values and other notations used to model service transformers and figure 12 illustrates a center tapped single phase transformer model. 


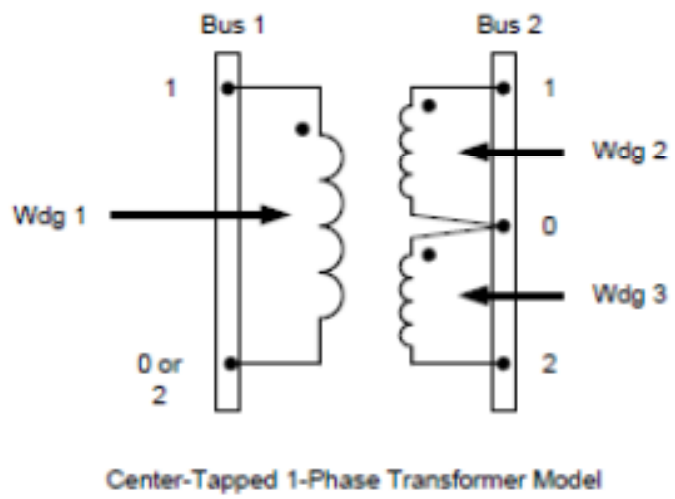

Figure 12: Center Tapped Single Phase Transformer Model

As shown in figure 12, Bus 1 represents the primary side of the transformer and points 1 and 2 are connected to phases $\mathrm{A}$ and $\mathrm{C}$ respectively. Bus 2 represents the secondary side of the transformer. $120 \mathrm{~V}$ loads can either be connected from points 1 to 0 or points 2 to 0 . $240 \mathrm{~V}$ loads are connected from point 1 to point 2 .

Tables 3 and 4 below show the breakdown by KVA, connected customers, and current ratings of the service transformers present in the residential electric distribution system. Emergency current rating is assumed to be $150 \%$ of the normal current rating.

Service Transformers Primary Side Current Rating:

\author{
Normal Current Rating $=\frac{\text { Nameplate } k V A}{12 k V}$ \\ Emergency Current Rating $=1.5 \times$ Normal Current Rating
}


Table 3: Current Ratings of Service Transformers (Primary Side)

\begin{tabular}{|c|c|c|c|}
\hline \multicolumn{4}{|c|}{ Service Transformers } \\
\hline KVA & Count & Normal Current Rating & Emergency Current Rating \\
\hline 10 & 3 & 0.83 & 0.913 \\
\hline 15 & 3 & 1.3 & 1.43 \\
\hline 25 & 15 & 2.1 & 2.31 \\
\hline 50 & 13 & 4.2 & 4.62 \\
\hline 75 & 1 & 6.3 & 6.93 \\
\hline Total & $\mathbf{3 5}$ & & \\
\hline
\end{tabular}

Table 4: Number of Connected Households to Each Service Transformers

\begin{tabular}{|c|c|c|c|}
\hline Transformer \# & KVA & $\begin{array}{l}\text { Connected } \\
\text { Customers }\end{array}$ & KVA/Customer \\
\hline 1 & 50 & 16 & 3.13 \\
\hline 2 & 75 & 34 & 2.21 \\
\hline 3 & 15 & 15 & 1.00 \\
\hline 4 & 10 & 2 & 5.00 \\
\hline 5 & 25 & 11 & 2.27 \\
\hline 6 & 25 & 8 & 3.13 \\
\hline 7 & 50 & 10 & 5.00 \\
\hline 8 & 50 & 15 & 3.33 \\
\hline 9 & 25 & 14 & 1.79 \\
\hline 10 & 25 & 8 & 3.13 \\
\hline 11 & 50 & 15 & 3.33 \\
\hline 12 & 50 & 18 & 2.78 \\
\hline 13 & 50 & 17 & 2.94 \\
\hline 14 & 25 & 17 & 1.47 \\
\hline 15 & 25 & 13 & 1.92 \\
\hline 16 & 25 & 6 & 4.17 \\
\hline 17 & 10 & 3 & 3.33 \\
\hline 18 & 25 & 5 & 5.00 \\
\hline 19 & 50 & 8 & 6.25 \\
\hline 20 & 10 & 7 & 1.43 \\
\hline 21 & 50 & 9 & 5.56 \\
\hline 22 & 15 & 4 & 3.75 \\
\hline 23 & 25 & 5 & 5.00 \\
\hline 24 & 15 & 8 & 1.88 \\
\hline 25 & 25 & 7 & 3.57 \\
\hline 26 & 50 & 11 & 4.55 \\
\hline 27 & 50 & 13 & 3.85 \\
\hline 28 & 25 & 11 & 2.27 \\
\hline 29 & 50 & 12 & 4.17 \\
\hline 30 & 50 & 9 & 5.56 \\
\hline 31 & 25 & 16 & 1.56 \\
\hline 32 & 25 & 10 & 2.50 \\
\hline 33 & 50 & 7 & 7.14 \\
\hline 34 & 25 & 2 & 12.50 \\
\hline \multirow[t]{2}{*}{35} & 25 & 7 & 3.57 \\
\hline & 1175 & 373 & \\
\hline
\end{tabular}




\subsubsection{Overhead Conductors and Underground Cable}

The modeled distribution circuit is comprised of both $\mathrm{UG}$ cable and $\mathrm{OH}$ conductors of sizes ranging from $1000 \mathrm{KCMIL}$ aluminum primary feeder to \#2 copper conductor at the secondary neutral. Positive sequence impedance and zero sequence impedance of the lines, in ohms per unit length, are shown in tables 5 and 6 . The normal and emergency current ratings are illustrated in table 7 below. OH conductors and UG cables can carry current above their normal rating for a limited amount of time without becoming permanently damaged. Emergency current rating is assumed to be 150 percent of normal current rating of the wires.

Table 5: Impedance of $\mathrm{OH}$ Conductor

\begin{tabular}{|c|c|c|c|c|}
\hline \multicolumn{5}{|c|}{ OH Conductor Impedance } \\
\hline & \multicolumn{2}{|c|}{ Positive Sequence } & \multicolumn{2}{c|}{ Zero Sequence } \\
\hline Size & $\mathbf{R}$ & $\mathbf{X}$ & $\mathbf{R}$ & $\mathbf{X}$ \\
\hline $636 \mathrm{MCM}$ ACSR & 0.356 & 1.29 & 1.06 & 7.48 \\
\hline $4 / 0$ & 0.677 & 1.38 & 1.37 & 7.7 \\
\hline $1 / 0$ & 1.35 & 1.61 & 2.05 & 7.8 \\
\hline$\# 2$ & 2.15 & 1.68 & 2.85 & 7.87 \\
\hline$\# 4$ & 3.38 & 1.74 & 4.08 & 7.93 \\
\hline$\# 6$ & 5.38 & 1.81 & 6.08 & 8 \\
\hline
\end{tabular}

Table 6: Impedance of UG Cable

\begin{tabular}{|c|c|c|c|c|}
\hline \multicolumn{4}{|c|}{ UG Cable Impedance } \\
\hline & \multicolumn{2}{|c|}{ Positive Sequence } & \multicolumn{2}{c|}{ Zero Sequence } \\
\hline Size & $\mathbf{R}$ & $\mathbf{X}$ & $\mathbf{R}$ & $\mathbf{X}$ \\
\hline 1000 KCMIL Aluminum & 0.367 & 0.415 & 1.064 & 0.303 \\
\hline
\end{tabular}


Table 7: Normal and Emergency Current Ratings of UG Cable and OH Conductors

\begin{tabular}{|c|c|c|c|c|}
\hline Size & Material & UG/OH & Normal Ampacity & Emergency Ampacity \\
\hline 1000 KCMIL Aluminum & Aluminum & UG & 580 & 870 \\
\hline 636 MCM ACSR & Aluminum & OH & 780 & 1170 \\
\hline $4 / \mathrm{O}$ & Copper & OH & 230 & 345 \\
\hline $1 / \mathrm{O}$ & Copper & OH & 150 & 225 \\
\hline$\# 2$ & Copper & OH & 115 & 172.5 \\
\hline$\# 4$ & Copper & OH & 85 & 127.5 \\
\hline$\# 6$ & Copper & OH & 65 & 97.5 \\
\hline
\end{tabular}

A sample script used to model lines in OpenDSS is shown below.

\section{Line Object for 3-Phase Feeder}

New Linecode.1000KCMIL nphases $=3 \mathrm{rl}=0.367 \times \mathrm{l}=0.415 \mathrm{rO}=1.06 \times 0=303$

Units $=k f t$ Normamps $=580$

\section{Properties of Line Object for 3-Phase Feeder}

New Line.7 $\quad$ BUS1=9.1.2.3.0 $\quad$ BUS2=12.1.2.3.0 Linecode=1000KCMIL

Length=140 Units $=F t$

\section{Line Object for Single Phase Service Conductor}

New Linecode. $\# 2$ nphases $=1 \mathrm{rl}=3.38 \times 1=1.74 \mathrm{r} 0=4.08 \times 0=7.93$ Units $=k f t$

Normamps $=115$

\section{Properties of Line Object for Singe Phase Service Conductor}

New Line.1948681_L1 Phases=1 BUS1=25.1 BUS2=1948681.1 Linecode=\#2

Length=212.059 Units $=F t$

New Line.1948681_N Phases=1 BUS1=25.0 BUS2=1948681.0 Linecode $=\# 2$

Length=212.059 Units $=F t$

New Line.1948681_L2 Phases=1 BUS1=25.2 BUS2=1948681.2 Linecode=\#2

Length=212.059 Units $=F t$ 
The table below shows the descriptions of the notations used in the sample

OpenDSS script.

Table 8: OpenDSS Line Parameters and Definitions

\begin{tabular}{|c|c|}
\hline Notation & Definition \\
\hline R1 & Positive-sequence resistance, ohms per unit length \\
\hline X1 & Positive-sequence reactance, ohms per unit length \\
\hline R0 & Zero-sequence resistance, ohm per unit length \\
\hline X0 & Zero-sequence reactance, ohms per unit length \\
\hline C1 & Positive-sequence capacitance, nanofarads per unit length \\
\hline C0 & Zero-sequence capacitance, nanofarads per unit length \\
\hline Bus1 & Name of bus for terminal 1 \\
\hline Bus2 & Name of Bus for terminal 2 \\
\hline Linecode & Name of an existing LineCode onject containing impedance definitions \\
\hline Length & Length multiplier to be applied to the impedane data \\
\hline Normamps & Normal ampacity, amps \\
\hline Phases & Number of Phases \\
\hline
\end{tabular}

\subsubsection{Load}

Fifteen minute interval load data for the circuit is collected via SCADA

(Supervisory Control and Data Acquisition) at the substation site. The load data measured at the substation include all residential metered customers and primary metered customers served by the circuit. Primary metered customers are major customers who purchase bulk energy at $12 \mathrm{kV}$ voltage level and above. Figures 13 and 14 below show the annual $\mathrm{kW}$ and $\mathrm{kVAR}$ load profiles of the circuit respectively. 


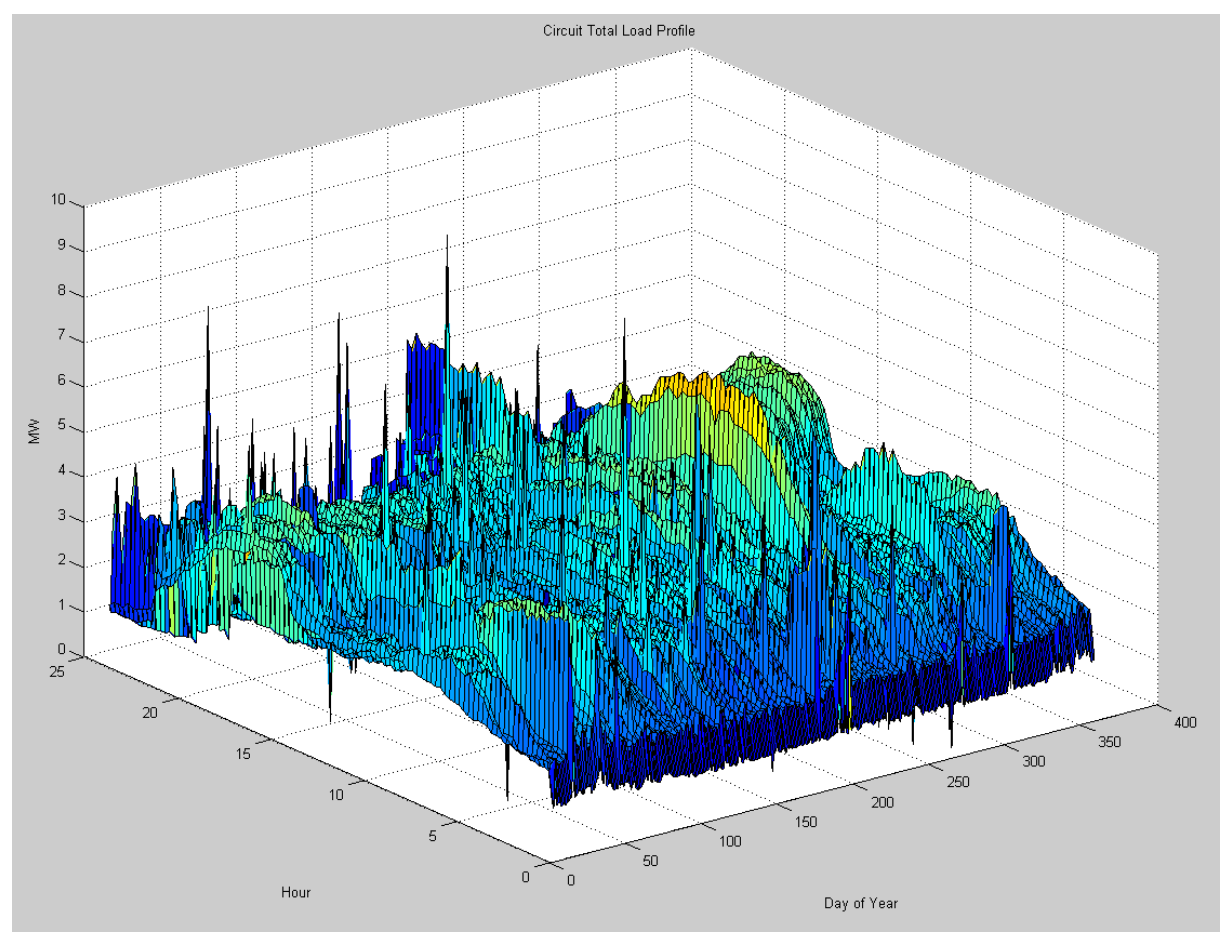

Figure 13: Total Circuit Real Power Profile (MW)

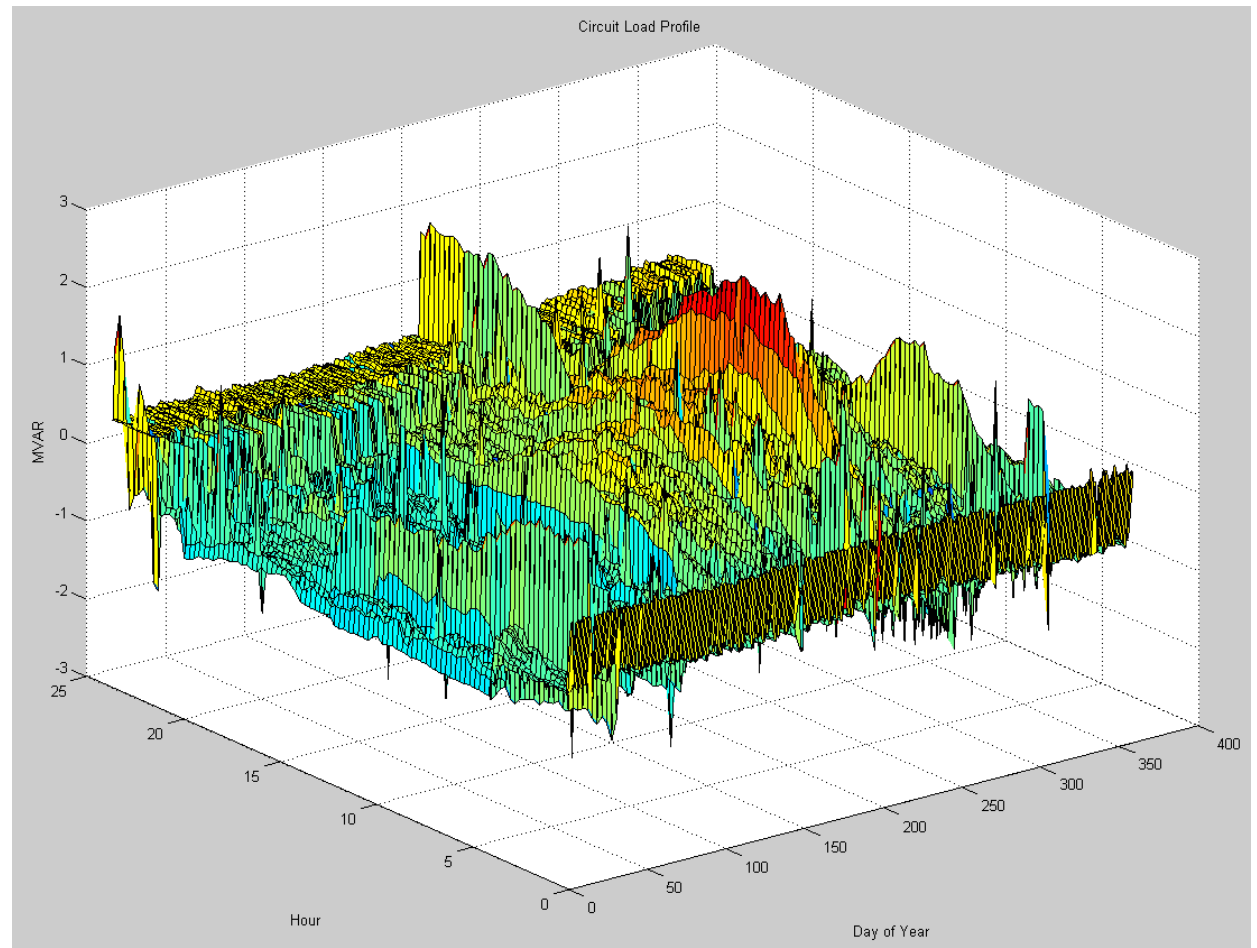

Figure 14: Total Circuit Reactive Power Profile (MVAR) 
Because this study is focused on the impacts on PEV on residential metered customers only, primary metered customers are not included in the circuit modeling or analysis. Seven months (June $1^{\text {st }}-$ Dec. $31^{\text {st }}$ ) of residential AMI data, collected at hourly intervals is illustrated in figure 15 below. Load data for each household is used for the respective residential bus during the "dynamic' power flow simulation at hourly interval for 7 months.

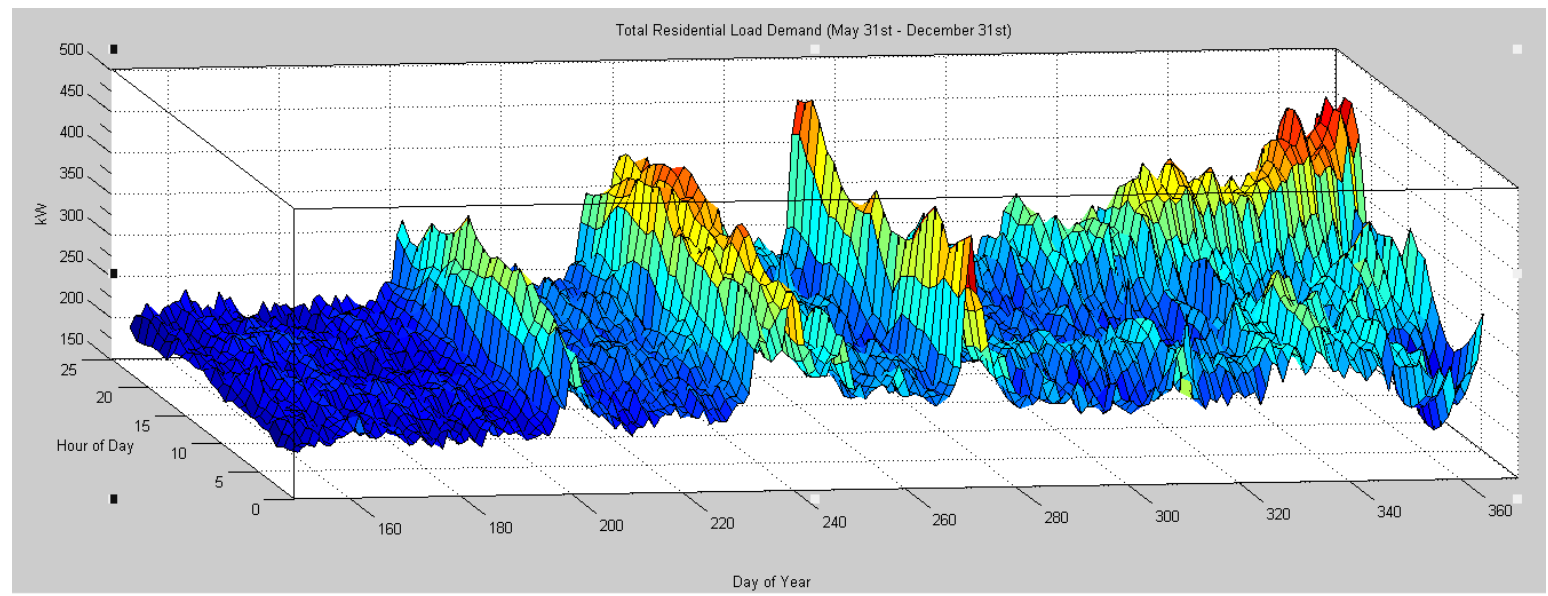

Figure 15: Total Residential Power Demand (kW)

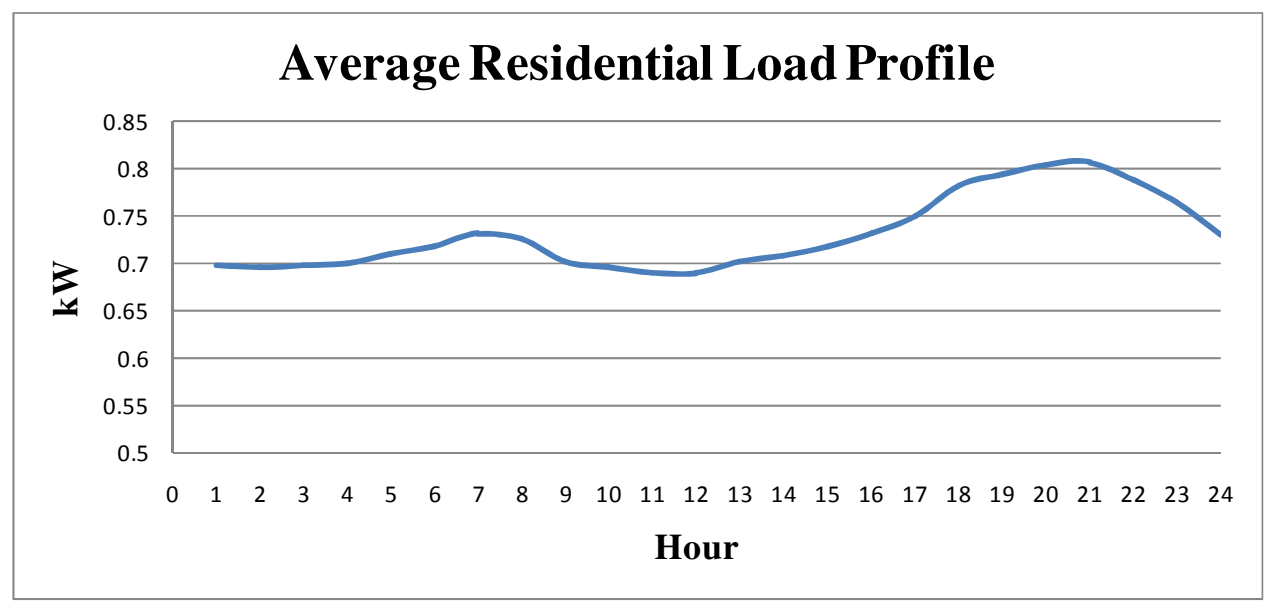

Figure 16: Daily Average Residential Load Profile 
As shown above, typical residential load profile experiences peak loading at the later part of the day when most residential loads are turned on. All residential loads are modeled as single phase $120 \mathrm{~V}$ loads distributed evenly from each $120 \mathrm{~V}$ terminals to the neutral of the service transformer. OpenDSS script used to model residential load is shown below.

\section{Load Object}

New Load.5032261_ab phases $=2$ bus1=5032261.1.2 yearly=5032261 pf=0.97

$k w=4.78$ status $=$ variable model $=1$

New Loadshape. 5032261 npts $=8760$ interval $=1$ mult $=($ File $=5032261)$

action=normalize 


\section{STUDY METHODOLOGY}

This study encompasses both sensitivity and stochastic analysis of the impact of PEV on residential electric distribution system. It takes into account temporal variation of PEV charging. The parameters used to determine the impacts of PEV include level of penetration, type of PEV, plug-in-time, and type of charger.

\subsection{Overview of PEV Parameters}

\subsubsection{Level of PEV Penetration}

For this study, the level of PEV penetration is defined as the ratio of the number of PEVs to the total number of vehicles present in the residential neighborhood. In other words, it represents the ratio of the number PEVs to number of total vehicles owned by the residents on the circuit (both PEVs and non-PEVs).

\section{PEV Level of Penetration}

$$
=\frac{\text { Number ofPEVs owned by residents connected to the circuit }}{\text { Total Number of Vehicles owned by residents (PEVs and non - PEVS) }}
$$

According to the 2001 NHTS (National Household Travel Survey) data shown in table 10, there are about 1.89 vehicles per household in the United States. Using 1.89 vehicles per household, this study assumes that there are about 705 vehicles owned by the 373 residential customers in the modeled distribution circuit. 
Table 9: 2001 National Household Travel Survey Data

\begin{tabular}{|c|c|}
\hline \multicolumn{2}{|c|}{ 2001 NHTS Data } \\
\hline Households with -- & Percent \\
\hline 0 Vehicle & 8.1 \\
\hline 1 Vehicle & 31.4 \\
\hline 2 Vehicle & 37.2 \\
\hline 3 or more Vehicle & 23.2 \\
\hline Average Vehicles Per Household & 1.89 \\
\hline
\end{tabular}

\section{Number of PEV per household}

As the penetration of PEV increases over time, one would expect that the percentage of households owning more than one PEV would increase as well. This assumption is reflected in this study by determining the probability of the number of PEV per household using binomial distribution method:

$$
b(x ; q, m)=\left\{\begin{array}{cc}
n \\
(x)^{m^{x}(1-m)^{q-x}} & x=0,1, \ldots, q \\
0 & \text { otherwise }
\end{array}\right.
$$

Where $\mathrm{m}$ is the probability that a vehicle is PEV based on PEV market penetration level, $\mathrm{q}$ and $\mathrm{n}$ are the total number of vehicles, and $\mathrm{x}$ is a random variable from 0 to $\mathrm{q}$.

Translating PEV market penetration level into number of PEV per household is based on the probability distribution $\mathrm{p}(y)$ where $Y$ is the discrete random variable for the number of vehicles per household. Therefore, distribution for the random variable for the number of plug-in electric vehicles per residential customer, $Z$, can be found using the equation below where the variable $k$ is the maximum number of vehicles considered for a single residence [13]. Table 10 shows the probability of the number of PEVs per household, while table 11 shows the total PEVs and number of PEVs per households for each penetration level. 


$$
p(z)=\sum_{j=z}^{k} P(Y=j) * b(z ; j, m)
$$

Table 10: Probability of Number of PEVs per Households

\begin{tabular}{|c|c|c|c|c|}
\hline \multicolumn{5}{|c|}{ Probability of Number of PEV Per Households } \\
\hline \% Penetration & 0 & 1 & 2 & 3 \\
\hline 2 & 0.9644 & 0.0343 & 0.0004 & 0.0000 \\
\hline 5 & 0.9139 & 0.0825 & 0.0026 & 0.0000 \\
\hline 10 & 0.8341 & 0.1547 & 0.0100 & 0.0002 \\
\hline 20 & 0.6891 & 0.2709 & 0.0372 & 0.0019 \\
\hline 50 & 0.3600 & 0.4300 & 0.1800 & 0.0290 \\
\hline
\end{tabular}

Table 11: Number of PEVs per Household

\begin{tabular}{|c|c|c|c|c|c|c|}
\hline \multirow[b]{2}{*}{ \% PEV Penetration } & \multicolumn{4}{|c|}{ Households with -- } & \multirow[b]{2}{*}{ Households with PEV } & \multirow[b]{2}{*}{ Total PEVs } \\
\hline & 0 & 1 & 2 & 3 & & \\
\hline 2 & 360 & 13 & 0 & 0 & 13 & 13 \\
\hline 5 & 341 & 31 & 1 & 0 & 32 & 33 \\
\hline 10 & 311 & 58 & 4 & 0 & 62 & 66 \\
\hline 20 & 257 & 101 & 14 & 1 & 116 & 132 \\
\hline 50 & 134 & 161 & 67 & 11 & 239 & 328 \\
\hline
\end{tabular}

PEV owners are randomly selected with no preference. However, new PEV owners are added to existing PEV owners at increasing PEV penetration level. Households with PEVs at lower PEV penetration are considered likely to own more than one PEV at increasing PEV penetration level.

\subsubsection{PEV Type}

Plug-in hybrid-electric vehicles are typically characterized by "PHEVx" notation, where "x" generally denotes the vehicle's All Electric Range (AER) - defined as the distance in miles that a fully charged PHEV can drive on stored electricity [6]. For instance PEV-40 indicates that the all electric range of the vehicle is 40 miles only. For this study, PEV type is based on commuter's daily mileage because regardless of a PEV 
battery size, only expended energy from daily commute is recharged. Figure 17 below shows the percent daily mileage of commuters according to NHTS survey data, and the cumulative distribution function $(\mathrm{CDF})$ of their mileage.

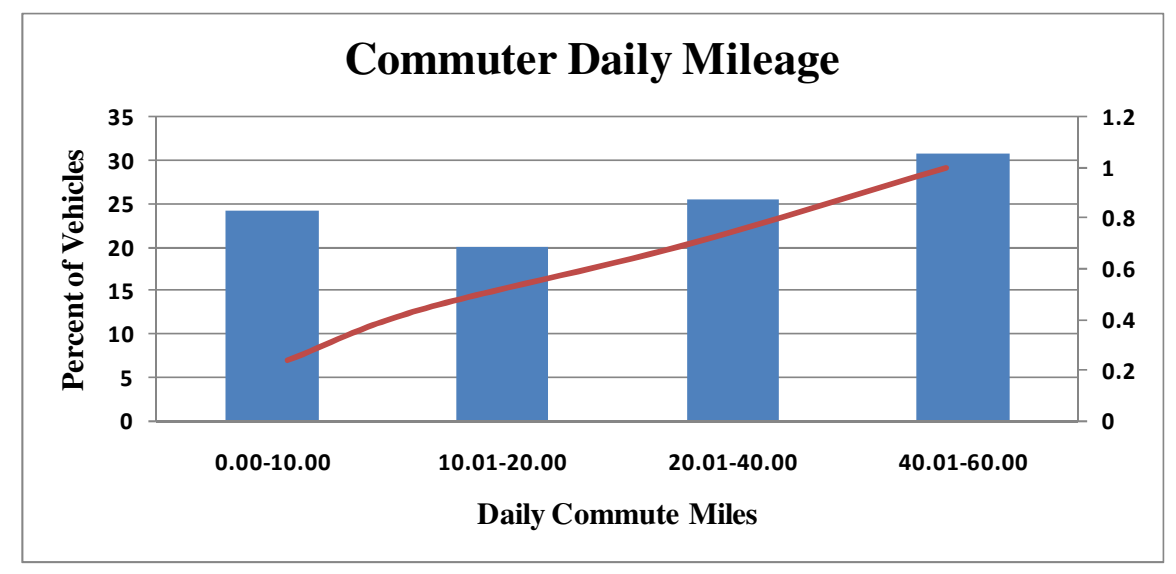

Figure 17: CDF of Daily Commuter's Miles Based on NHTS Data

Of the commuters who travel between 0 to 60 miles daily in the United States, the CDF above shows that about $24.1 \%$ travel 10 miles or less daily, $19.8 \%$ travel $10-20$ miles, $25.4 \%$ travel 20-40 miles, while 30.7 percent travel 40 - 60 miles on a daily basis. The near-term and long-term optimum PEV Type specification by the National Renewable Energy Laboratory (NREL) is shown in Table 12[7]. It is important to note that the near-term scenario is based on Nickel Metal Hydride (NiMH) battery chemistry, while the long-term scenario is based on Lithium-ion battery chemistry. 
Table 12: Optimum PHEV Design by NREL

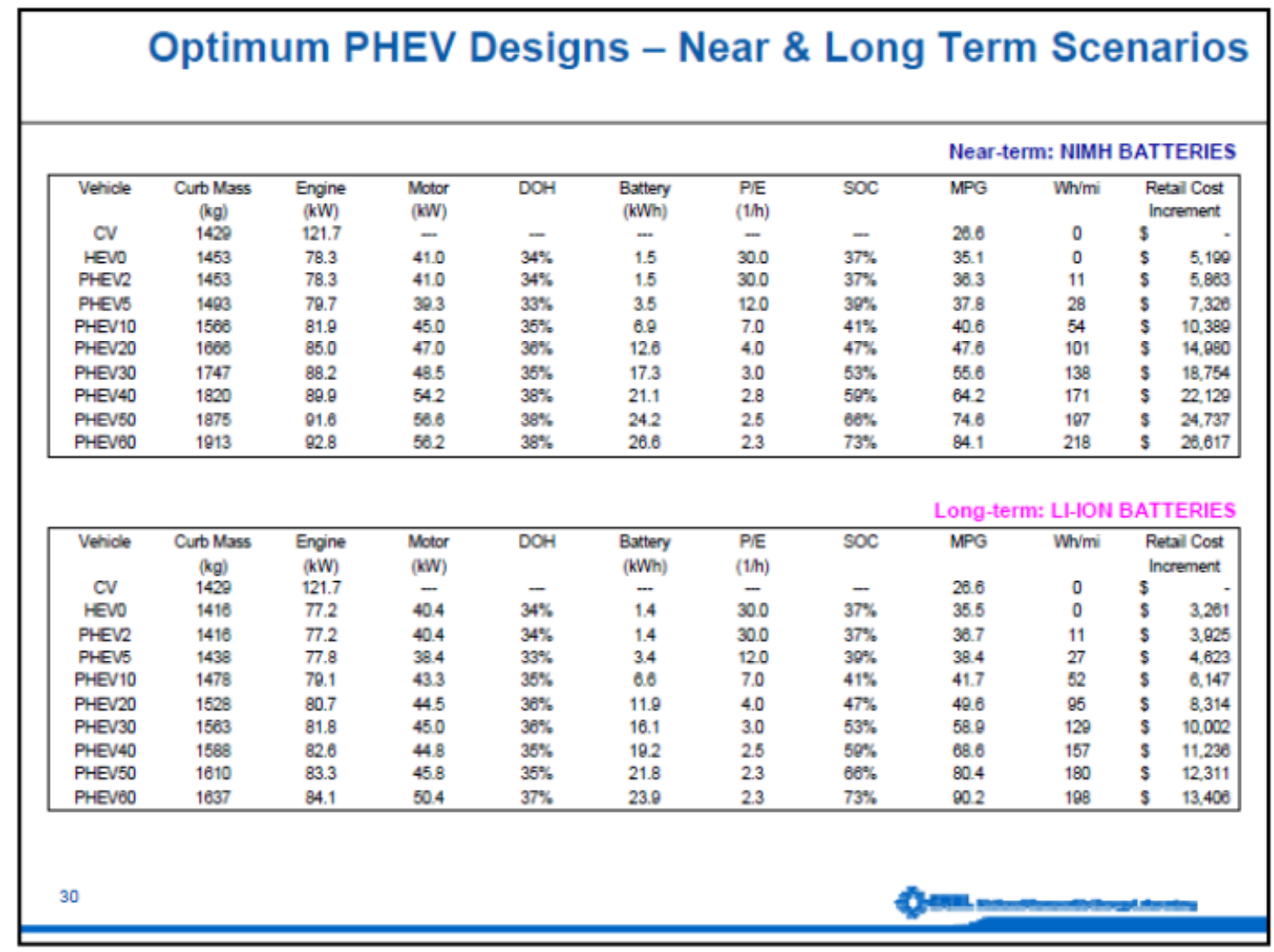

Only PEV60 is modeled for the sensitivity portion of this study, while PEV10,

PEV20, PEV40, and PEV60 are simulated for the stochastic approach. The characteristics and probabilities of the PEV types are shown in table 13 below. The probability is obtained from the CDF in figure 17.

Table 13: Probabilities of PEV Type

\begin{tabular}{|c|c|c|}
\hline \multicolumn{3}{|c|}{ PEV Type } \\
\hline PEV Type & Energy (kWH) & Probability \\
\hline PHEV10 & 6.6 & 0.241 \\
\hline PHEV20 & 11.5 & 0.198 \\
\hline PHEV40 & 19.2 & 0.254 \\
\hline PHEV60 & 23.9 & 0.307 \\
\hline
\end{tabular}




\subsubsection{Charger Type}

Levels 1 and 2 chargers are modeled for this study. The level 1 charger is rated at $1.8 \mathrm{~kW} 120 \mathrm{~V} 15 \mathrm{~A}$, while the level 2 chargers are rated at $3.6 \mathrm{~kW} 240 \mathrm{~V} 15 \mathrm{~A}$, and $7.2 \mathrm{~kW}$ 240V 30A. The sensitivity portion of the study assumes different charger types for different scenarios while the stochastic section assumes that of all the PEV owners, 20 percent own chargers rated at $1.8 \mathrm{~kW}, 60$ percent own chargers rated at $3.6 \mathrm{~kW}$, and 20 percent own chargers rated at $7.2 \mathrm{~kW}$. The charge times shown in table 15 are round up to account for the losses of the charger.

Table 14: Probabilities of PEV Charger Type (Stochastic Approach)

\begin{tabular}{|c|c|c|c|}
\hline \multicolumn{4}{|c|}{ Charger Type } \\
\hline Charger Type & Power(kW) & Assumed Probability & Level \\
\hline 120V, 15A & 1.8 & 0.2 & 1 \\
\hline $240 \mathrm{~V}, 15 \mathrm{~A}$ & 3.6 & 0.6 & 2 \\
\hline $240 \mathrm{~V}, 30 \mathrm{~A}$ & 7.2 & 0.2 & 2 \\
\hline
\end{tabular}

Table 15: Charge Time for PEV Chargers and PEV Type

\begin{tabular}{|c|c|c|c|}
\hline \multicolumn{3}{|c|}{ Charge Time (Hrs) for PEV Type and Charger Type } \\
\hline \multirow{3}{*}{ PEV Type } & \multicolumn{3}{|c|}{ Charger Type } \\
\cline { 2 - 4 } & $\mathbf{1 2 0 V}, \mathbf{1 5 A}$ & $\mathbf{2 4 0 V}, \mathbf{1 5 A}$ & $\mathbf{2 4 0 V , 3 0 A}$ \\
\hline PHEV10 & 4 & 2 & 1 \\
\hline PHEV20 & 7 & 4 & 2 \\
\hline PHEV40 & 11 & 6 & 3 \\
\hline PHEV60 & 14 & 7 & 4 \\
\hline
\end{tabular}




\subsubsection{Plug-in Time}

Two separate categories of PEV plug-in time are used for this study, one for the stochastic approach and the other for the sensitivity approach.

\subsubsection{Plug-in Times for Sensitivity Analysis}

- On-peak time indicates period of high load demand (around $9 \mathrm{pm}$ ). The time also correlates to periods when most residents are at home and the majority of electrical appliances are in use.

- Off-peak time corresponds to duration of low load demand (around 10am). It typically represents the time frame when most residents are away from home and nearly all electrical appliances are turned off.

\subsubsection{Plug-in time for Stochastic Study}

The stochastic analysis assumes that PEVs are plugged in upon arrival from their last trip of the day. Figures 18 below shows a histogram and CDF of the last trip arrival time of commuters based on the NHTS survey. 


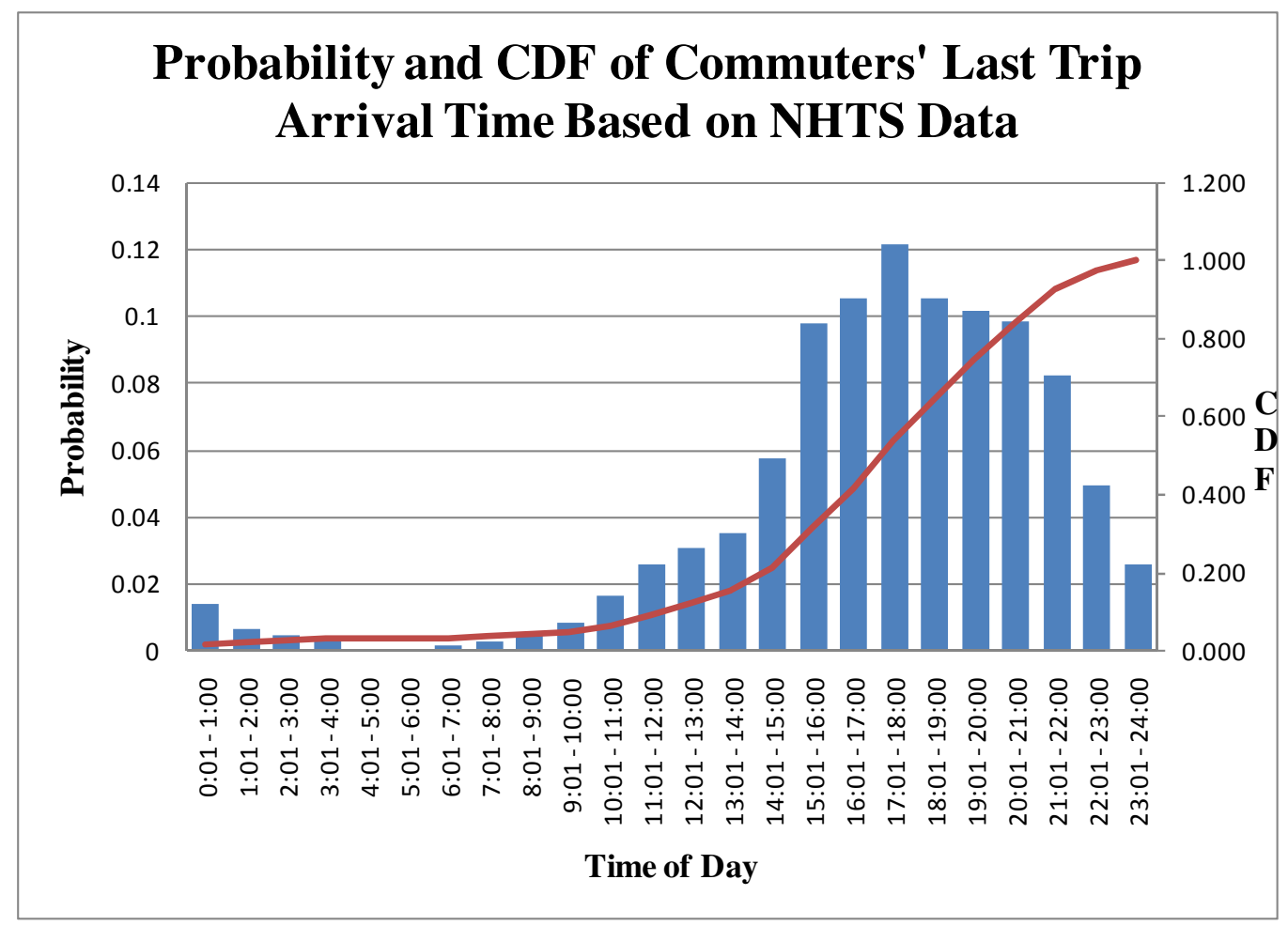

Figure 18: CDF of Commuters' Last Trip Arrival Time Based on the NHTS Data

The histogram illustrated above indicates that majority of the residential owners arrive between $6 \mathrm{pm}$ and 10pm, which overlaps with the peak load demand period.

\subsection{Overview of Analyzed Parameters}

\subsubsection{Voltage Drop}

PEVs could well introduce significant voltage drop on the secondary and service lines. The large current consumption of PEVs increases the losses on the secondary and service lines. Line loss under high load conditions causes considerable voltage drop that could cause electrical equipments to malfunction [8]. The distribution system for this study is modeled up to the each residential customer's service point (customer meter location or point of delivery), and the voltage measurement taken between each line and 
neutral. The study assumes that the utilization point (point of connection of the electrical equipment) of the PEV is at the meter location, in other words, the service point as shown in figure 19 below. The voltage drop caused by PEV load is measured against the American National Standard ANSI C84.1 - 1989. Tables 16 and 17 below show the optimal and tolerable voltage ranges for both the service and utilization points of an electrical system.

Table 16: Optimal and Tolerable Voltage Ranges for Service Point

\begin{tabular}{|c|c|c|c|c|}
\hline \hline $\begin{array}{c}\text { Nominal Service } \\
\text { Voltage }\end{array}$ & $\begin{array}{c}\text { Range B } \\
\text { Minimum }\end{array}$ & $\begin{array}{c}\text { Range A } \\
\text { Minimum }\end{array}$ & $\begin{array}{c}\text { Range A } \\
\text { Maximum }\end{array}$ & $\begin{array}{c}\text { Range B } \\
\text { Maximum }\end{array}$ \\
\hline$\%$ of Nominal & $91.7 \%$ & $\mathbf{9 5} \%$ & $\mathbf{1 0 5} \%$ & $105.8 \%$ \\
\hline \multicolumn{5}{|c|}{ Single-Phase } \\
\hline $120 / 240,3$ wire & $110 / 220$ & $\mathbf{1 1 4} / \mathbf{2 2 8}$ & $\mathbf{1 2 6 / 2 5 2}$ & $127 / 254$ \\
\hline \multicolumn{5}{|c|}{ Three-Phase } \\
\hline $240 / 120,4$ wire & $220 / 110$ & $\mathbf{2 2 8} / \mathbf{1 1 4}$ & $\mathbf{2 5 2} / \mathbf{1 2 6}$ & $254 / 127$ \\
\hline $208 Y / 120,4$ wire & $191 / 110$ & $\mathbf{1 9 7 / 1 1 4}$ & $\mathbf{2 1 8} / \mathbf{1 2 6}$ & $220 / 127$ \\
\hline $480 Y / 277,4$ wire & $440 / 254$ & $\mathbf{4 5 6 / 2 6 3}$ & $\mathbf{5 0 4 / 2 9 1}$ & $508 / 293$ \\
\hline 2.4 to $34.5 \mathrm{kV}$ & $95 \%$ & $\mathbf{9 7 . 5} \%$ & $\mathbf{1 0 5} \%$ & $105.8 \%$ \\
$\%$ of Nominal & & & & \\
\hline
\end{tabular}

Table 17: Optimal and Tolerable Voltage Ranges for Utilization Point

\begin{tabular}{|c|c|c|c|c|}
\hline $\begin{array}{c}\text { Nominal Service } \\
\text { Voltage }\end{array}$ & $\begin{array}{c}\text { Range B } \\
\text { Minimum }\end{array}$ & $\begin{array}{c}\text { Range A } \\
\text { Minimum }\end{array}$ & $\begin{array}{c}\text { Range A } \\
\text { Maximum }\end{array}$ & $\begin{array}{c}\text { Range B } \\
\text { Maximum }\end{array}$ \\
\hline$\%$ of Nominal & $88 \%$ & $91.7 \%$ & $105 \%$ & $105.8 \%$ \\
\hline \multicolumn{5}{|c|}{ Single-Phase } \\
\hline $120 / 240,3$ wire & $106 / 212$ & $110 / 220$ & $126 / 252$ & $127 / 254$ \\
\hline \multicolumn{5}{|c|}{ Three-Phase } \\
\hline $240 / 120,4$ wire & $212 / 106$ & $\mathbf{2 2 0 / 1 1 0}$ & $\mathbf{2 5 2} / 126$ & $254 / 127$ \\
\hline $208 \mathrm{Y} / 120,4$ wire & $184 / 106$ & $191 / 110$ & $218 / 126$ & $220 / 127$ \\
\hline $480 \mathrm{Y} / 277,4$ wire & $424 / 245$ & $\mathbf{4 4 0 / 2 5 4}$ & $\mathbf{5 0 4 / 2 9 1}$ & $508 / 293$ \\
\hline $\begin{array}{c}2.4 \text { to } 34.5 \mathrm{kV} \\
\% \text { of Nominal }\end{array}$ & $86.7 \%$ & $90 \%$ & $\mathbf{1 0 5} \%$ & $105.8 \%$ \\
\hline
\end{tabular}


Voltage range A is considered favorable zone, where voltage is near optimal.

Voltage range B is the tolerable zone where voltage level is acceptable but not optimal. Voltages within range B should be limited in extent, frequency, and duration. The goal of utility industries is to have customer within the optimal voltage range [9].

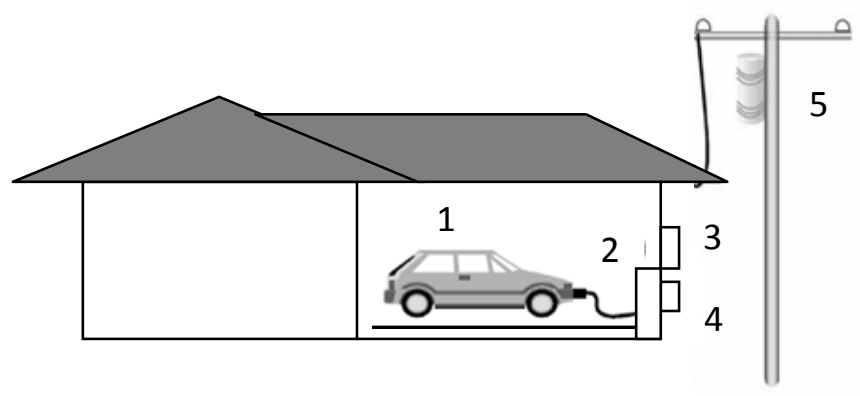

Figure 19: PEV Charging at Service and Utilization Point. (1) PEV (2) EVSE (3) Residential Meter (4) PEV Meter (5) Service Transformer

Voltage drop of single phase service lines is dependent on the length of the line, current flow on the line, and the resistance of the line.

Single Phase voltage drop is calculated as:

$$
\begin{gathered}
V D=\frac{2 \times L \times R \times I}{1000} \\
V D \%=\frac{V D}{\text { SOURCE VOLTAGE }} \times 100
\end{gathered}
$$

Where VD = Voltage Drop (in Volts, Conductor Temp of $75^{\circ} \mathrm{C}$ )

VD $\%=$ Percent Voltage Drop

$\mathrm{L}=$ One way Length of the Circuit Feeder (in Feet)

$\mathrm{I}=$ Load Current (in Amps) 
$\mathrm{R}=$ Resistance Factor (in Ohms/Feet)

\subsubsection{Service Transformer Overload}

Service transformers are susceptible to overload conditions during high load demand. Some of these equipments are able to withstand current levels above their nameplate rating for a period of time without failing, however prolonged operation at current levels well above their normal rating make them susceptible to failure. Introduction of PEV loads to the distribution system allows overload of distribution assets to become more of a concern. The load demand by these chargers could overload distribution assets above their emergency rating. This study examines service transformers overloads at different PEV penetration levels. Emergency rating is considered to be 150 percent of the nameplate rating, while normal rating is considered to be the nameplate rating.

A transformer is considered overloaded once it exceeds $150 \%$ of its nameplate rating anytime during 7 months. Also, a transformer is considered at risk of overload when loaded above $100 \%$ but not over $150 \%$ of nameplate rating anytime within 7 months. Overloaded transformers are not accounted for when counting transformers at risk of overload even though at some point within 7 months, the transformer is loaded below emergency rating.

\subsubsection{Energy Loss}

Energy loss on electric distribution system refers to the losses in both power delivery and power conversion elements. There are two main sources of losses in power distribution systems which are transformers and distribution lines. Additionally, there are 
two major types of losses that occur in these components. These losses are often referred to as core losses and copper losses $\left(\mathrm{I}^{2} \mathrm{R}\right)$. Core losses in transformers account for the majority of the losses at low power levels. The core losses are made up of eddy current and hysteresis losses. Eddy current losses are due to magnetically induced currents in the core, and hysteresis losses occur because of the less than perfect permeability. The copper losses in transformers are essentially the same as those in the power distribution lines. As load increases in the transformer, the copper losses become more significant. Copper loss is calculated using:

$$
\text { CopperLoss }=P=I^{2} \times R
$$

With the addition of PEV loads in the electric grid, it is essential to investigate the amount of energy losses contributed by PEVs on the electric distribution system [10].

\subsubsection{Service Transformer Loss-of-Life}

Most transformer failures are related to the deterioration of the insulation material. Emergency and/or planned overloading of oil-filled power transformers beyond their nameplate ratings depends on several factors including design, operation, daily loading, and load cycle. For the most common applications, transformer overloading capabilities and the life expectancy are determined by the winding "hottest-spot" temperatures. Overtime, oil-impregnated paper insulation used in liquid-filled transformer winding losses mechanical and electrical strength and becomes brittles when exposed to elevated operating temperatures [14].

A load serving transformer not only experiences an electrical process but also goes through a thermal process that is driven by heat. The heat generated by the no-load 
and load losses is the main source of temperature rise in the transformer. However, the $I^{2} R$ losses of the windings and stray losses seen from the structural parts are the main factors of heat generation within the transformer. The thermal energy produced by the windings is transferred to the windings' insulation and consequently to the oil and transformer walls [15].

As PEV penetration level rises, the loading on distribution transformer is affected significantly. The load level coupled with ambient temperatures of some regions makes service transformers' life expectancy a concern for utilities. Methodology used to determine transformer loss-of-life expectancy is explained in the Appendix.

\subsection{Sensitivity Analysis Methodology}

\subsubsection{Overview}

Sensitivity approach involves simulations where quantitative assumptions are changed systematically to assess their effect on the final outcome. In other words, it demonstrates how changes in certain parameter or parameters affect the model's conclusion. Sensitivity analysis can help determine which parameters are the key drivers of a model's result. By reporting extensive outputs from sensitivity analysis, modelers are able to consider a wide range of scenarios and, as such, can increase the level of confidence that a reviewer will have in the model. While these sensitivity scenarios do not necessarily create an exact replica of the real world, they can be useful in demonstrating the relationships and interactions between various different factors [11]. 


\subsubsection{Proposed Methodology for Sensitivity Approach}

This study examines 8 sensitivity scenarios. Each scenario represents variation of one or more PEV parameters including level of PEV penetration, charger type, and plugin-time. The PEV Type is kept constant for all scenarios. Table 18 shows the simulated scenarios and the algorithm used for the sensitivity simulation is illustrated in figure 20 below.

\section{Table 18: Scenarios for Sensitivity Analysis}

\begin{tabular}{|c|c|c|c|c|}
\hline \multicolumn{5}{|c|}{ Sensitivity Scenarios } \\
\hline Scenario \# & \% PEV Penetration & Charger Type & Plug-in-Time & PEV Type \\
\hline Scenario 1 & $2,5,10,20,50$ & $120 \mathrm{~V}, 15 \mathrm{~A}$ & Off-Peak & PEV-60 \\
\hline Scenario 2 & $2,5,10,20,50$ & $120 \mathrm{~V}, 15 \mathrm{~A}$ & Peak & PEV-60 \\
\hline Scenario 3 & $2,5,10,20,50$ & $240 \mathrm{~V}, 15 \mathrm{~A}$ & Off-Peak & PEV-60 \\
\hline Scenario 4 & $2,5,10,20,50$ & $240 \mathrm{~V}, 15 \mathrm{~A}$ & Peak & PEV-60 \\
\hline Scenario 5 & $2,5,10,20,50$ & $240 \mathrm{~V}, 30 \mathrm{~A}$ & Off-Peak & PEV-60 \\
\hline Scenario 6 & $2,5,10,20,50$ & $240 \mathrm{~V}, 30 \mathrm{~A}$ & Peak & PEV-60 \\
\hline Scenario 7 & $2,5,10,20,50$ & $33.3 \%$ 240V, 30A; 33.3\% 240V, 15A, 33.3\% 120V, 15A & Off-Peak & PEV-60 \\
\hline Scenario 8 & $2,5,10,20,50$ & $33.3 \%$ 240V, 30A; 33.3\% 240V, 15A, 33.3\% 120V, 15A & Peak & PEV-60 \\
\hline
\end{tabular}




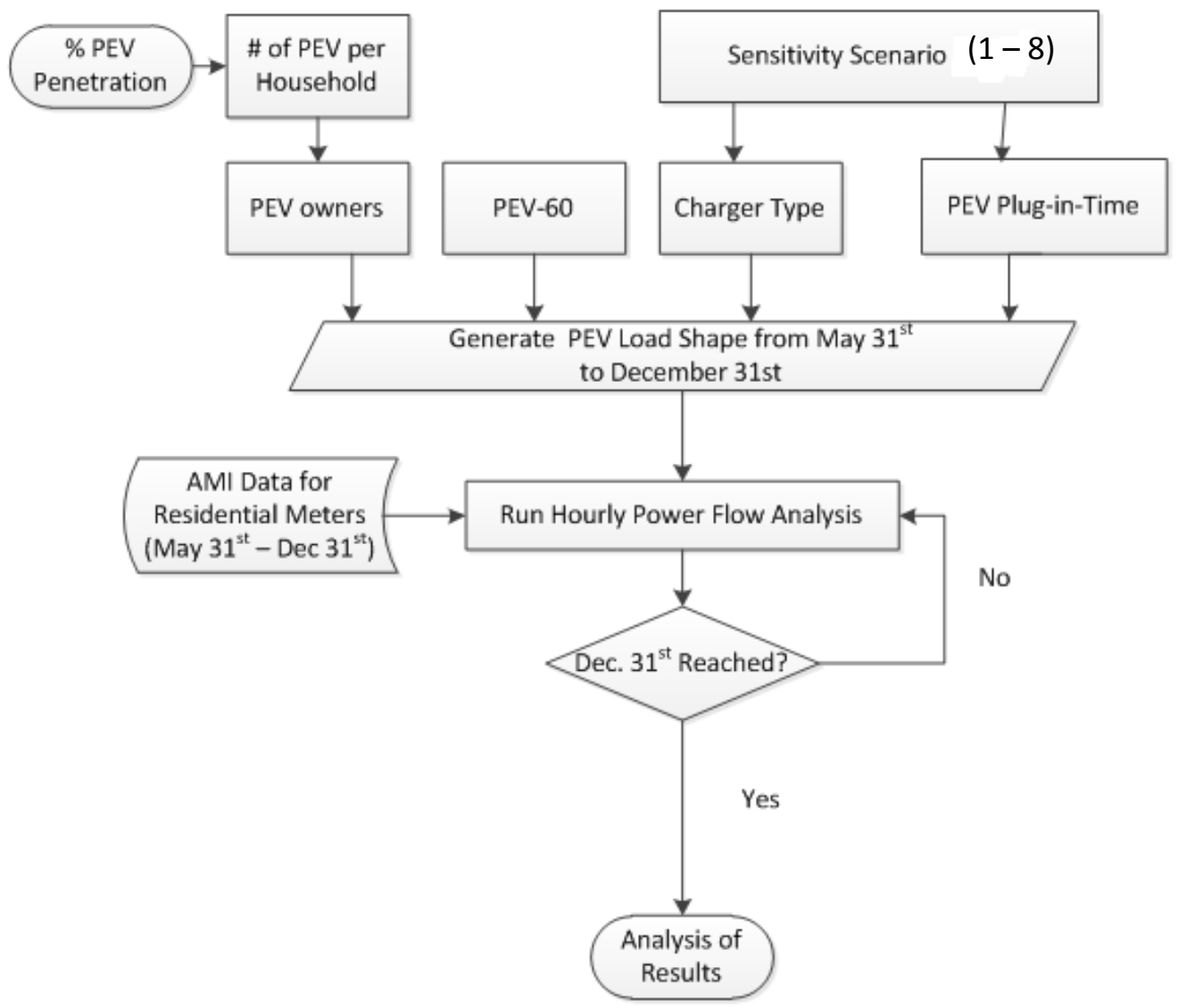

Figure 20: Simulation Algorithm for Sensitivity Analysis

\subsection{Stochastic Analysis Methodology}

\subsubsection{Overview}

Stochastic approach helps predict future impacts of PEV by using both predictable and unknown characteristics of potential PEV owners. Stochastic impact analysis helps predict more real life impacts of PEV on the electric distribution grid compared to the sensitivity scenario. The approach used in this study takes into account the time of charging, percent penetration of PEV, type of charger, and mileage travelled 
by PEV owners. This study employs Monte Carlo simulation method. Monte Carlo Simulation (MCS) is a modeling technique that involves repetition of a set of probability distributions defining the random variables of interest. In a MCS, the random variables are sampled at each repetition from a probability density function and used as inputs to the load flow program.

\subsubsection{Proposed Methodology for Stochastic Approach}

Inputs used for the stochastic analysis are data derived from section 4.1 above. About 20 simulations are run for each PEV penetration level and results are averaged. Figure 21 illustrates the algorithm used for the stochastic analysis and table 19 shows the input values respectively. 
Monte Carlo Simulation Algorithm for Stochastic Analysis

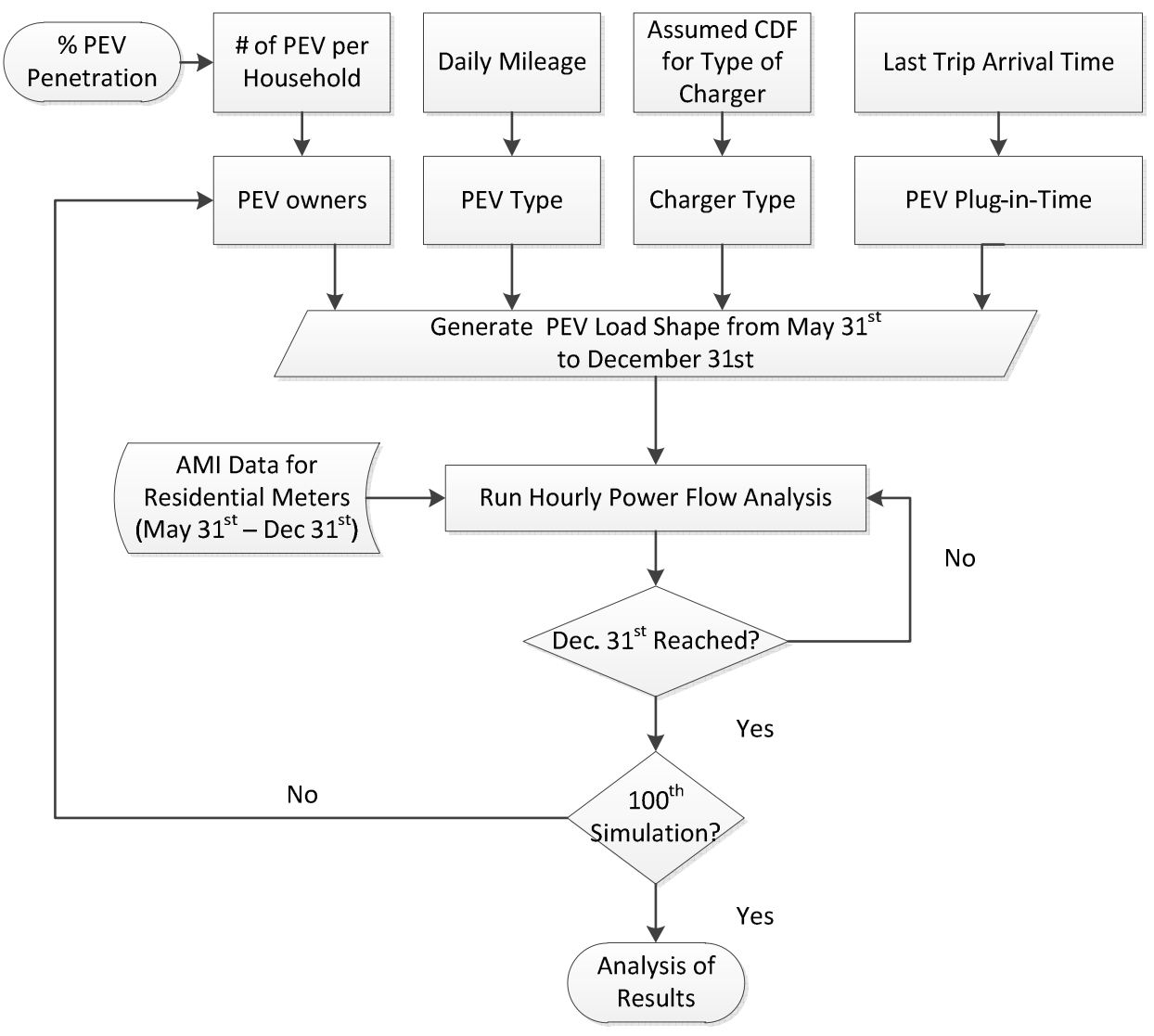

Figure 21: Monte Carlo Simulation Algorithm for Stochastic Analysis

Table 19: Inputs for Stochastic Analysis

\begin{tabular}{|c|c|}
\hline \multicolumn{2}{|c|}{ Inputs for Stochastic Analysis } \\
\hline Parameters & Values \\
\hline$\%$ PEV Penetration & $2 \%, 5 \%, 10 \%, 20 \%, 50 \%$ \\
\hline PEV Type & CDF of Commuter Daily Mileage \\
\hline Plug-in-Time & CDF of Commuters Last Trip Arrival Time \\
\hline Charger Typer & 120V 15A (20\%), 240V 15A (60\%), 240V 30A (20\%) \\
\hline
\end{tabular}




\section{PEV IMPACT ANALYSIS}

\subsection{Assumptions}

Assumptions made for the simulations and the results include:

- $\quad$ Power Factor of 0.97 for all loads

- $\quad$ Optimal voltage range falls between 0.917p.u - 1.05p.u (per unit)

- $\quad$ Tolerable voltage range falls between 0.917 p.u and 0.88 p.u

- $\quad$ Below tolerable voltage range falls below 0.88p.u

- Households that experience below tolerable voltage range are not replicated when counting households within tolerable voltage range, even though at some point within 7 months they experienced tolerable voltage level.

- Households within tolerable voltage range did not experience below tolerable voltage levels at all times within 7 months

- $\quad$ Normal Rating of transformers equals nameplate rating

- $\quad$ Overloaded Transformers are loaded at $150 \%$ or higher of nameplate rating at any time within 7 months

- Transformers at risk of overload are loaded above $100 \%$ but below $150 \%$ of nameplate rating at any time within 7 months

- $\quad$ Overloaded Transformers are not replicated when counting number transformers at risk of overload 


\subsection{Sensitivity Impacts}

\subsubsection{Voltage Drop}

By ANSI C84.1 - 1989 standards in table 17, optimal voltage range at the utilization point falls between 0.917 p.u and 1.05p.u. The goal of utilities is to serve customers at optimal voltage levels and minimize durations of low voltage conditions. Table 21 shows the number of households that experience tolerable voltage level (0.917p.u - 0.88p.u), within 7 months duration, for all simulated scenarios. The parameters for all scenarios are outlined in table 20 below. As mentioned earlier, voltage levels within the tolerable zone are acceptable but not optimal and should be limited in extent, frequency, and duration. While the number of households within tolerable voltage level increases with PEV penetration level, it is important to note that it decreases under scenarios 5 and 6 conditions at higher penetration levels, as shown in table 21 below. These households are reflected in table 22 which shows the number of households that experience below tolerable voltage range. The households reflected in table 21 are not replicated in table 22, even though at some point within 7 months, the households in table 22 experienced tolerable voltage level as well. 
Table 20: Scenarios for Sensitivity Analysis

\begin{tabular}{|c|c|c|c|c|}
\hline \multicolumn{5}{|c|}{ Sensitivity Scenarios } \\
\hline Scenario \# & \% PEV Penetration & Charger Type & Plug-in-Time & PEV Type \\
\hline Scenario 1 & $2,5,10,20,50$ & $120 \mathrm{~V}, 15 \mathrm{~A}$ & Off-Peak & PEV-60 \\
\hline Scenario 2 & $2,5,10,20,50$ & $120 \mathrm{~V}, 15 \mathrm{~A}$ & Peak & PEV-60 \\
\hline Scenario 3 & $2,5,10,20,50$ & $240 \mathrm{~V}, 15 \mathrm{~A}$ & Off-Peak & PEV-60 \\
\hline Scenario 4 & $2,5,10,20,50$ & $240 \mathrm{~V}, 15 \mathrm{~A}$ & Peak & PEV-60 \\
\hline Scenario 5 & $2,5,10,20,50$ & $240 \mathrm{~V}, 30 \mathrm{~A}$ & Off-Peak & PEV-60 \\
\hline Scenario 6 & $2,5,10,20,50$ & $240 \mathrm{~V}, 30 \mathrm{~A}$ & Peak & PEV-60 \\
\hline Scenario 7 & $2,5,10,20,50$ & $33.3 \%$ 240V, 30A; 33.3\% 240V, 15A, 33.3\% 120V, 15A & Off-Peak & PEV-60 \\
\hline Scenario 8 & $2,5,10,20,50$ & $33.3 \%$ 240V, 30A; 33.3\% 240V, 15A, 33.3\% 120V, 15A & Peak & PEV-60 \\
\hline
\end{tabular}

By ANSI C84.1 - 1989 standards, distribution voltage levels below 0.88p.u

$(105.6 \mathrm{~V})$ at the utilization point is considered below tolerable voltage limit and could cause electrical equipments to malfunction. At higher PEV penetration level, more customer experience voltage levels below 0.88p.u. Note that from figure 22 below, under scenarios 5 and 6 conditions, the percent of households that experience voltage level below 0.88p.u increases rapidly at higher PEV penetration level. The high disparity between scenarios 5 and 6 from other scenarios is because the power consumption from the PEV charger $(7.2 \mathrm{~kW})$ causes low voltage conditions at the secondary side of the transformer. For non PEV owners connected to the same transformer, the low voltage at the secondary side of the transformer coupled with the voltage drop from their service line increases the likely hood for them to experience voltage drop issues as well.

Table 21: Number of Households with Voltage Levels within Tolerable Voltage Range

\begin{tabular}{|c|c|c|c|c|c|c|}
\hline \multicolumn{7}{|c|}{ \# of households within tolerable voltage range } \\
\hline \% PEV Penetration & 0 & 2 & 5 & 10 & 20 & 50 \\
\hline Scenario 1 & 13 & 15 & 15 & 18 & 31 & 72 \\
\hline Scenario 2 & 13 & 16 & 17 & 19 & 33 & 71 \\
\hline Scenario 3 & 13 & 15 & 16 & 22 & 35 & 104 \\
\hline Scenario 4 & 13 & 14 & 15 & 23 & 46 & 105 \\
\hline Scenario 5 & 13 & 16 & 27 & 37 & 48 & 56 \\
\hline Scenario 6 & 13 & 15 & 29 & 38 & 61 & 48 \\
\hline Scenario 7 & 13 & 15 & 17 & 27 & 35 & 103 \\
\hline Scenario 8 & 13 & 16 & 16 & 25 & 44 & 107 \\
\hline
\end{tabular}


Table 22: Number of Households with Voltage Levels below Tolerable Voltage Range

\begin{tabular}{|c|c|c|c|c|c|c|}
\hline \multicolumn{7}{|c|}{ \# of households below tolerable voltage range } \\
\hline \% PEV Penetration & 0 & 2 & 5 & 10 & 20 & 50 \\
\hline Scenario 1 & 15 & 16 & 17 & 20 & 26 & 67 \\
\hline Scenario 2 & 15 & 16 & 17 & 20 & 27 & 69 \\
\hline Scenario 3 & 15 & 16 & 17 & 22 & 36 & 114 \\
\hline Scenario 4 & 15 & 18 & 20 & 23 & 38 & 129 \\
\hline Scenario 5 & 15 & 18 & 22 & 32 & 86 & 302 \\
\hline Scenario 6 & 15 & 19 & 23 & 36 & 93 & 315 \\
\hline Scenario 7 & 15 & 17 & 19 & 23 & 43 & 129 \\
\hline Scenario 8 & 15 & 18 & 21 & 25 & 48 & 148 \\
\hline
\end{tabular}

$\%$ of households below tolerable voltage range

$=\frac{\text { numberof households that experience voltage level below } 0.88 p . u \text { (within } 7 \text { months) }}{\text { total number of household }}$ $\times 100$

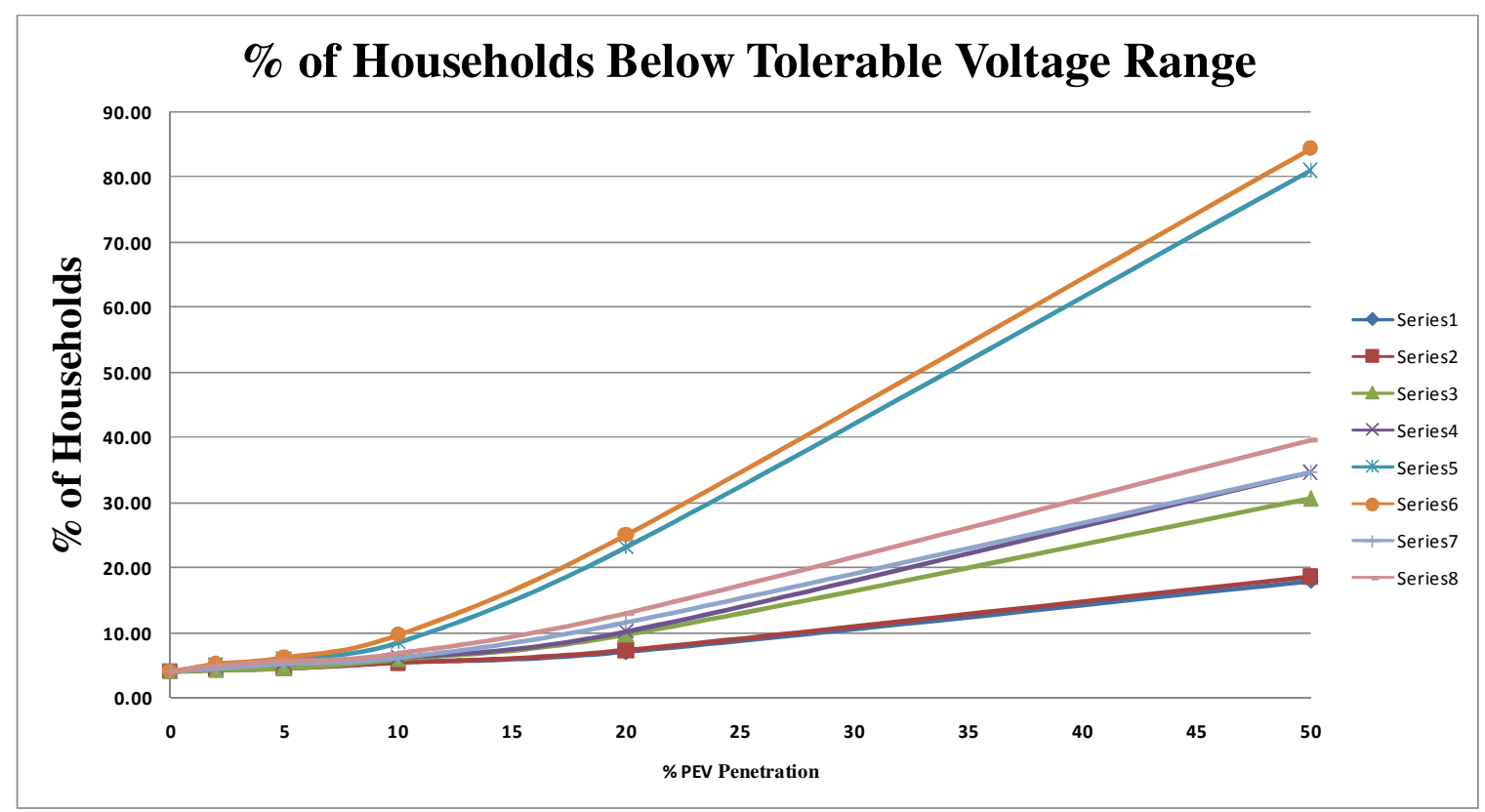

Figure 22: Percent of Households that Experienced Voltage Levels Below Tolerable Voltage Range 
Figure 22 above demonstrates that the type of PEV charger used is more likely to affect voltage drop than the time of plug in. Scenarios 3, 4, 7 and 8 are similar because the average size of the chargers for each scenario is comparable. Scenarios 7 and 8 comprise chargers with sizes $1.8 \mathrm{~kW}, 3.6 \mathrm{~kW}$ and $7.2 \mathrm{~kW}$ evenly distributed among the PEV owners. Scenarios 3 and 4 are made up of $3.6 \mathrm{~kW}$ chargers only. The voltage drop impact of scenarios 7 and 8 is slightly higher than scenarios 3 and 4 because the average size of charger for 7 and 8 is about $0.6 \mathrm{~kW}$ greater than the average size of charger for 3 and 4 .

Table 23 below focuses on PEV owners only, that experience below optimal voltage level $(<0.917)$ at some point within the seven months. The 3 households at $0 \%$ PEV penetration reflect the household with voltage issues before owning a PEV. PEV owners for scenario 6 condition experience more frequent voltage conditions below 0.917p.u. Figure 23 below illustrates that at all PEV penetration levels, the number of PEV owners that experience low voltage conditions is dependent on the type of charger. PEV owners with fast chargers (high power rating) are susceptible to low voltage conditions even at low PEV penetration level. At $2 \%$ penetration level, about $38 \%$ of PEV owners experience voltage drop issues under scenario 1 compared to $69 \%$ of PEV owners under in scenario 6. In addition, at 50\% Penetration level, $43.5 \%$ of PEV owners experience voltage drop issues under scenario 1 compared to $100 \%$ of PEV owners in scenario 6 . 
Table 23: Number of PEV Households with Voltage Drop Issues for all Sensitivity Scenarios

\begin{tabular}{|c|c|c|c|c|c|c|}
\hline \multicolumn{7}{|c|}{ \# of PEV Households with voltage drop Issues } \\
\hline \% PEV Penetration & 0 & 2 & 5 & 10 & 20 & 50 \\
\hline Scenario 1 & 3 & 5 & 5 & 14 & 32 & 104 \\
\hline Scenario 2 & 3 & 5 & 6 & 15 & 33 & 106 \\
\hline Scenario 3 & 3 & 5 & 7 & 17 & 43 & 167 \\
\hline Scenario 4 & 3 & 6 & 8 & 17 & 51 & 180 \\
\hline Scenario 5 & 3 & 7 & 21 & 38 & 83 & 239 \\
\hline Scenario 6 & 3 & 9 & 21 & 40 & 93 & 239 \\
\hline Scenario 7 & 3 & 6 & 8 & 22 & 51 & 176 \\
\hline Scenario 8 & 3 & 6 & 9 & 23 & 56 & 185 \\
\hline
\end{tabular}

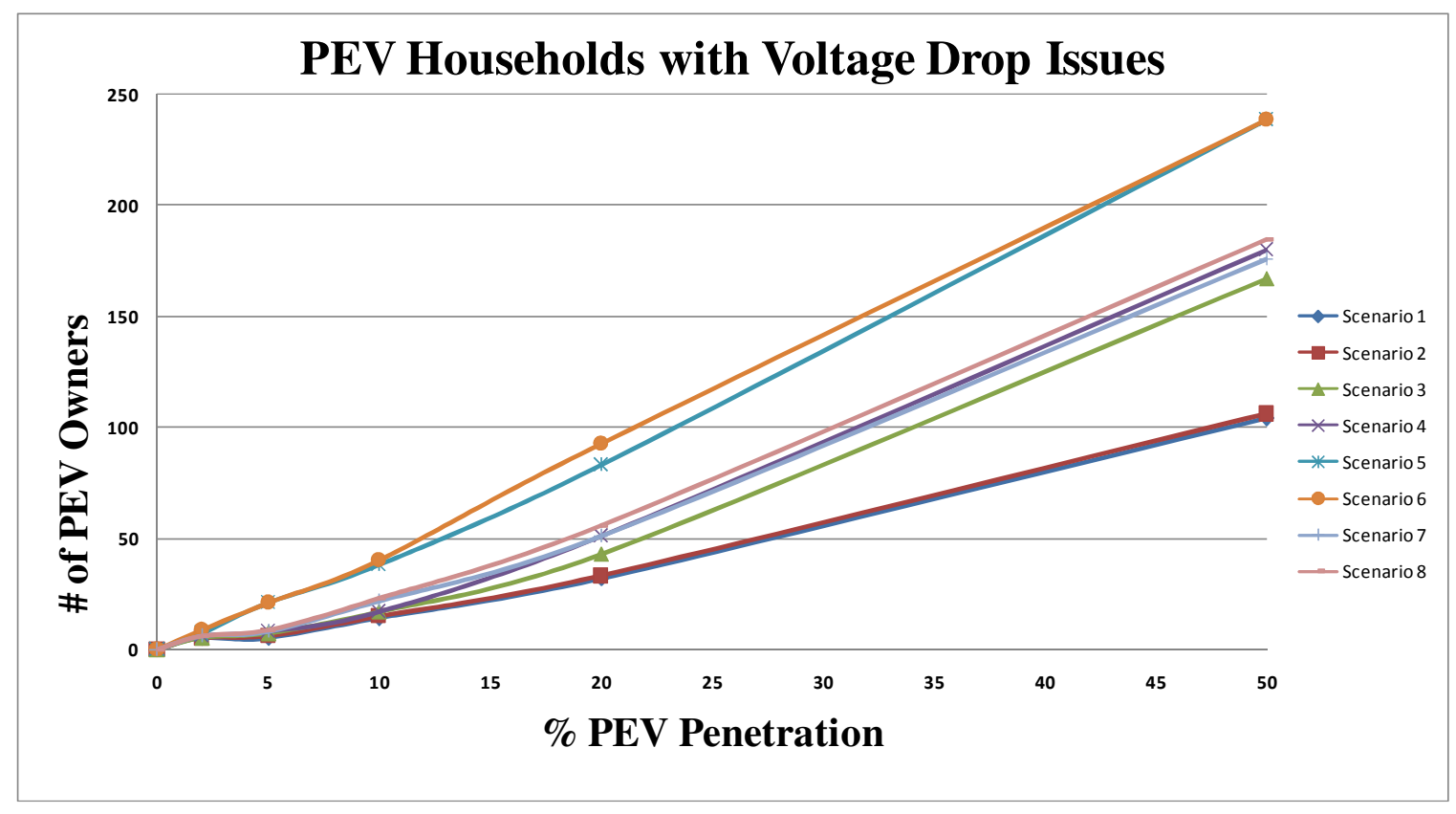

Figure 23: Number of PEV Owners with Voltage Drop Issues for all Sensitivity Scenarios 


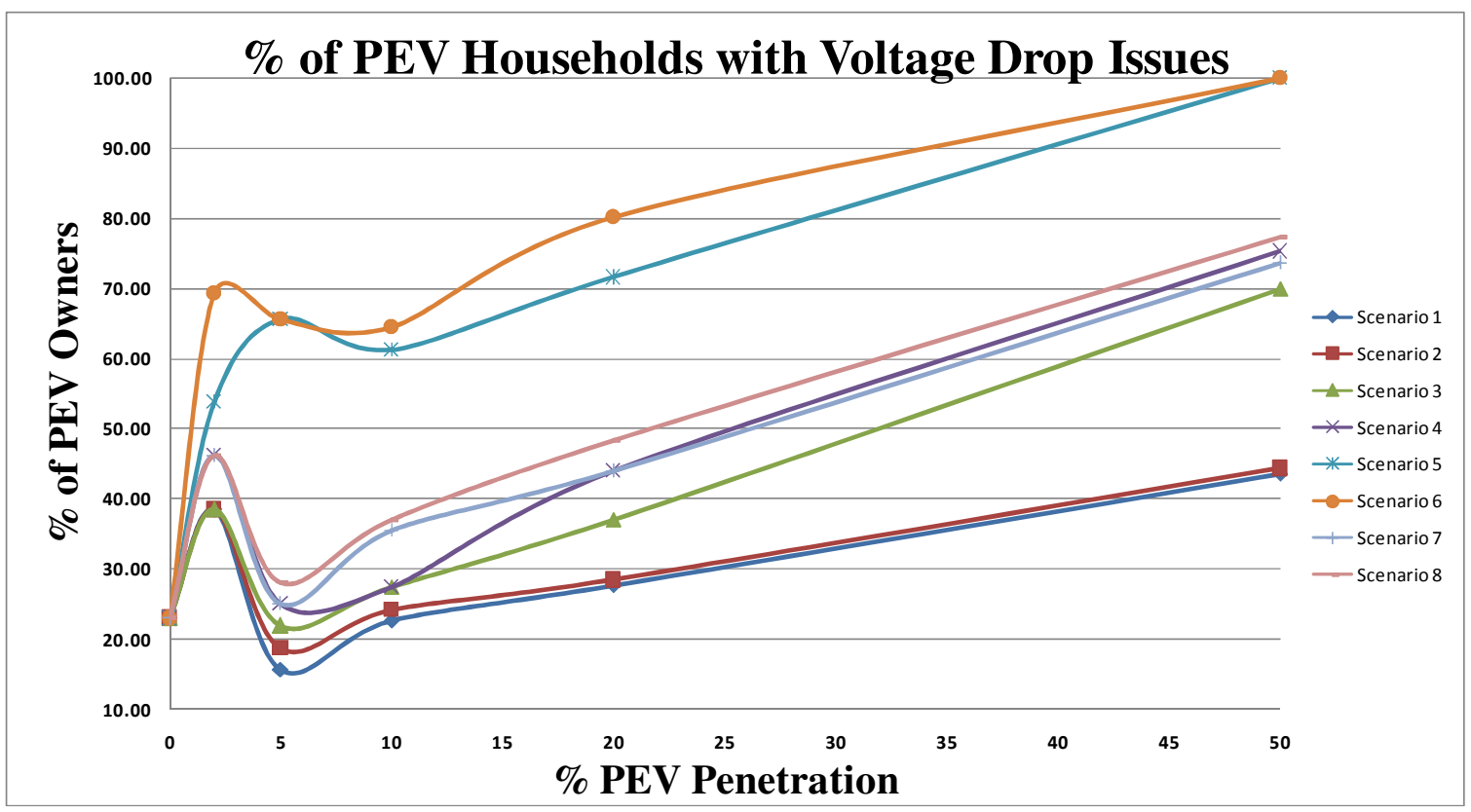

Figure 24: Percent of PEV Owners with Voltage Drop Issues for all Sensitivity Scenarios

Even though the number of PEV owners with voltage drop issues increases with level of penetration, note that in figure 24, the curve for the percent of PEV owners with voltage drop issues is not linear. This is because the percentage is obtained by finding the ratio of the number of households with PEV and voltage drop issues to the total number of households with PEV at each penetration level. For instance, for scenario 3, at 2\% PEV penetration, only 5 households experience voltage drop issues out of 13 households with PEV; while at 5\% PEV penetration, only 7 households experience voltage drop issues out of 32 households with PEV. Though the number of household with voltage drop issue increases from 5 to 7 as penetration level went from $2 \%$ to $5 \%$, the dip reflected in the graph occurs because the percent of household with PEV and voltage drop issue decreased from $38.4 \%$ to $21 \%$ (based on the number of households with PEV for each penetration level). 
$\%$ of PEV Households with voltage drop issues at $x \%$ PEV penetration level

$$
\begin{aligned}
& =\frac{\text { number of Households with PEV and voltage drop issues }}{\text { Total Households with PEV at } x \% \text { PEV penetration level }} \\
& \times 100
\end{aligned}
$$

Where $\mathrm{x}$ is $2,5,10,20$, or 50

\subsubsection{Service Transformer Overloads}

PEV load allows distribution service transformers to become more susceptible to overload conditions. Table 24 shows the number service transformers that are at risk of overload, and table 25 shows overloaded transformers for all sensitivity scenarios. Transformers loaded between $100 \%$ - $150 \%$ only at any point within 7 months are considered at risk of overload. As expected, the number of transformers within this category increases with PEV penetration level. However, as shown in figure 25, the number decreases from 20\%-50\% PEV penetration under scenarios 5 and 6 conditions because most transformers become overloaded. As mentioned earlier, any transformer loaded above $150 \%$ of its nameplate within 7 month period is considered overloaded. Overloaded transformers are not replicated in the number of transformers at risk of overload even though at some point within 7 months they are loaded below 150\%. Figure 26 illustrates the percent of overloaded service transformers for scenarios 1 to 6 as the PEV penetration level increases. Fast chargers with higher $\mathrm{kW}$ rating pose more threat to distribution service transformers. PEV clustering at any location in the distribution circuit is more likely to overload service transformers compared to disperse PEV owners. At higher penetration level, the time of plug-in does affect the number of number of 
overloaded transformers for scenarios 5-8. Table 41 in the appendix shows PEV distribution by transformer ID.

Table 24: Number of Service Transformers at risk of Overload for all Sensitivity Scenarios

\begin{tabular}{|c|c|c|c|c|c|c|}
\hline \multicolumn{7}{|c|}{ \# of Service Tx at risk of Overload (Above Nameplate Rating) } \\
\hline \% PEV Penetration & 0 & 2 & 5 & 10 & 20 & 50 \\
\hline Scenario 1 & 3 & 5 & 4 & 6 & 9 & 13 \\
\hline Scenario 2 & 3 & 5 & 4 & 5 & 8 & 12 \\
\hline Scenario 3 & 3 & 5 & 4 & 5 & 8 & 12 \\
\hline Scenario 4 & 3 & 6 & 5 & 6 & 9 & 13 \\
\hline Scenario 5 & 3 & 4 & 4 & 7 & 16 & 10 \\
\hline Scenario 6 & 3 & 6 & 5 & 8 & 14 & 7 \\
\hline Scenario 7 & 3 & 5 & 4 & 4 & 10 & 12 \\
\hline Scenario 8 & 3 & 6 & 5 & 6 & 10 & 9 \\
\hline
\end{tabular}

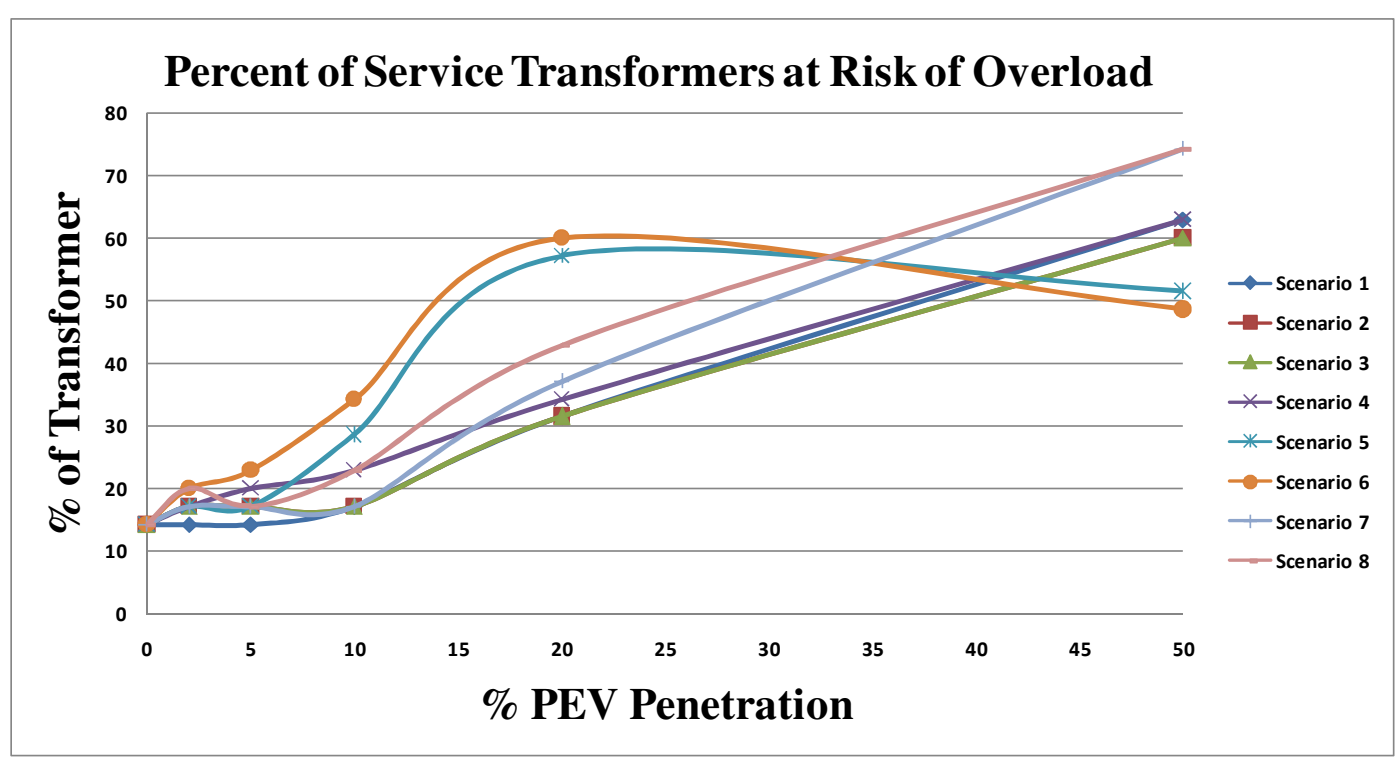

Figure 25: Percent of Service Transformers at Risk of Overload

$\%$ of service transformers at risk of overload

$$
=\frac{\text { number of transformer at risk of overload }}{\text { total number of transformers }} \times 100
$$


Table 25: Number of Overloaded Service Transformers for all Sensitivity Scenarios

\begin{tabular}{|c|c|c|c|c|c|c|}
\hline \multicolumn{7}{|c|}{ \# of Service Tx loaded above emergency rating } \\
\hline \% PEV Penetration & 0 & 2 & 5 & 10 & 20 & 50 \\
\hline Scenario 1 & 1 & 1 & 2 & 2 & 3 & 9 \\
\hline Scenario 2 & 1 & 1 & 2 & 3 & 4 & 10 \\
\hline Scenario 3 & 1 & 1 & 2 & 3 & 4 & 12 \\
\hline Scenario 4 & 1 & 1 & 2 & 3 & 4 & 12 \\
\hline Scenario 5 & 1 & 2 & 2 & 3 & 5 & 21 \\
\hline Scenario 6 & 1 & 2 & 4 & 5 & 8 & 24 \\
\hline Scenario 7 & 1 & 1 & 2 & 3 & 4 & 14 \\
\hline Scenario 8 & 1 & 1 & 2 & 3 & 6 & 17 \\
\hline
\end{tabular}

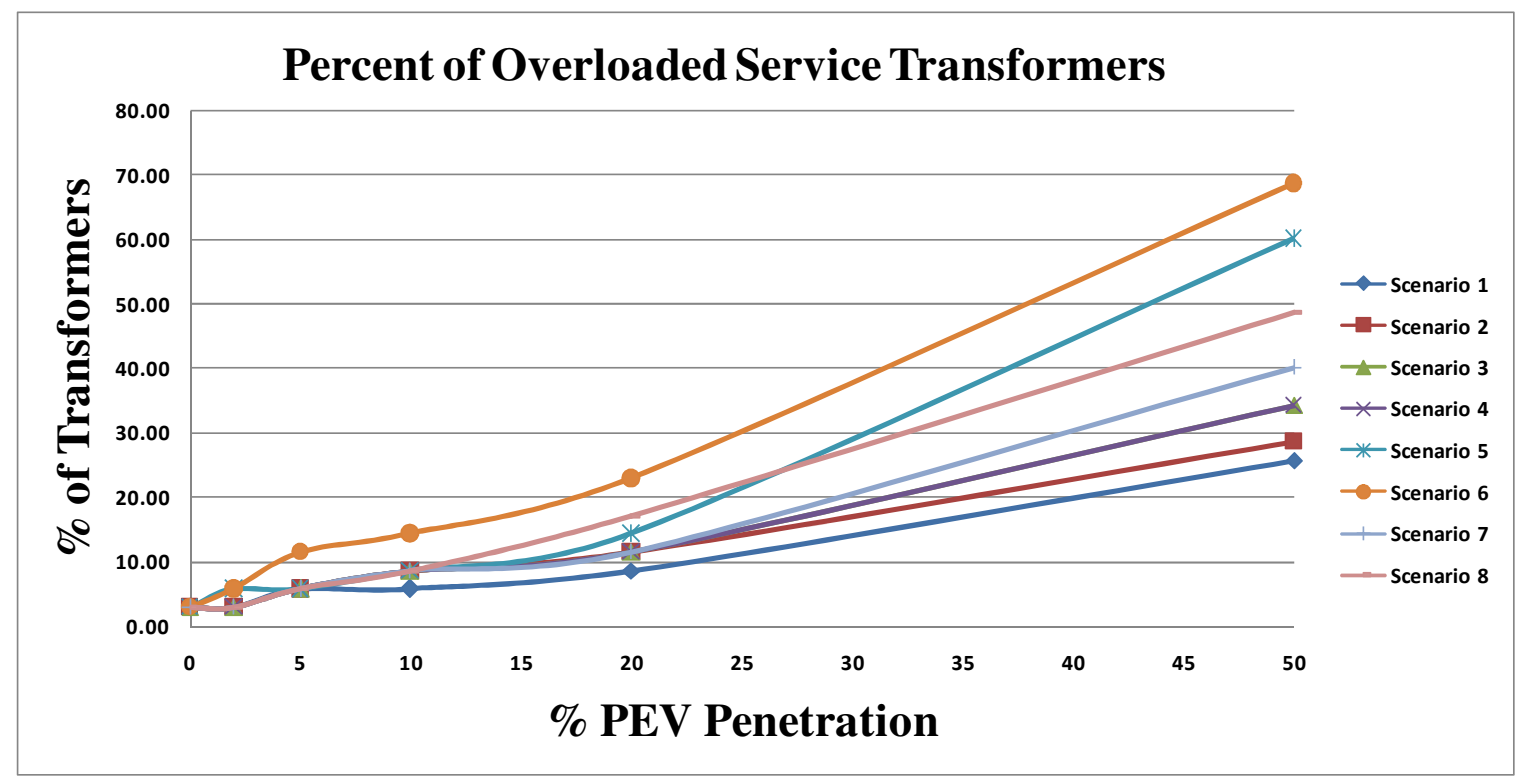

Figure 26: Percent of Overloaded Service Transformers for all Sensitivity Scenarios

$\%$ of overloaded service transformers

$$
=\frac{\text { number of transformer loaded above emergency }}{\text { total number of transformers }} \times 100
$$

Tables 26, 27, 28, and 29 below show the percent of overloaded transformers by size (kVA). While the chances of transformer overloads depend on the number of connected customers and number of connected PEV owners, smaller size transformers 
are more vulnerable to overloads even at low PEV penetration level, especially with fast chargers. The table below shows that about two-third of 10kVA transformers are overloaded even at low PEV penetration level and smaller kW PEV chargers, keeping in mind that the PEV owners were randomly distributed along the circuit with no preference. Table 30 shows the number of PEVs connected to each transformer at increasing penetration levels from the random PEV assignment. Utilities should be aware of PEV owners that are connected to small size transformers.

Table 26: Percent of Overloaded Transformers by kVA for Scenarios 1 and 2

\begin{tabular}{|c|c|c|c|c|c|c|c|c|c|c|c|c|}
\hline \multirow[b]{2}{*}{ Tx kVA } & \multirow[b]{2}{*}{ Count } & \multirow{2}{*}{$\begin{array}{l}\text { Base } \\
\text { Case }\end{array}$} & \multicolumn{5}{|c|}{ Scenario 1} & \multicolumn{5}{|c|}{ Scenario 2} \\
\hline & & & 2 & 5 & 10 & 20 & 50 & 2 & 5 & 10 & 20 & 50 \\
\hline 10 & 3 & 33.33 & 33.33 & 66.67 & 66.67 & 66.67 & 66.67 & 33.33 & 66.67 & 66.67 & 66.67 & 66.67 \\
\hline 15 & 3 & 0.00 & 0.00 & 0.00 & 0.00 & 0.00 & 66.67 & 0.00 & 0.00 & 0.00 & 0.00 & 66.67 \\
\hline 25 & 15 & 0.00 & 0.00 & 0.00 & 0.00 & 6.67 & 26.67 & 0.00 & 0.00 & 6.67 & 13.33 & 33.33 \\
\hline 50 & 13 & 0.00 & 0.00 & 0.00 & 0.00 & 0.00 & 0.00 & 0.00 & 0.00 & 0.00 & 0.00 & 0.00 \\
\hline 75 & 1 & 0.00 & 0.00 & 0.00 & 0.00 & 0.00 & 100.00 & 0.00 & 0.00 & 0.00 & 0.00 & 100.00 \\
\hline
\end{tabular}

Table 27: Percent of Overloaded Transformers by kVA for Scenarios 3 and 4

\begin{tabular}{|c|c|c|c|c|c|c|c|c|c|c|c|c|}
\hline \multirow[b]{2}{*}{ Tx kVA } & \multirow[b]{2}{*}{ Count } & \multirow[b]{2}{*}{$\begin{array}{l}\text { Base } \\
\text { Case }\end{array}$} & \multicolumn{5}{|c|}{ Scenario 3} & \multicolumn{5}{|c|}{ Scenario 4} \\
\hline & & & 2 & 5 & 10 & 20 & 50 & 2 & 5 & 10 & 20 & 50 \\
\hline 10 & 3 & 33.33 & 33.33 & 66.67 & 66.67 & \begin{tabular}{|l|}
66.67 \\
\end{tabular} & 66.67 & 33.33 & 66.67 & 66.67 & 66.67 & 66.67 \\
\hline 15 & 3 & 0.00 & 0.00 & 0.00 & 0.00 & \begin{tabular}{|l|}
0.00 \\
\end{tabular} & 66.67 & 0.00 & 0.00 & 0.00 & 0.00 & 66.67 \\
\hline 25 & 15 & 0.00 & 0.00 & 0.00 & 6.67 & \begin{tabular}{|l|}
13.33 \\
\end{tabular} & 46.67 & 0.00 & 0.00 & 6.67 & 13.33 & 46.67 \\
\hline 50 & 13 & 0.00 & 0.00 & 0.00 & 0.00 & 0.00 & 0.00 & 0.00 & 0.00 & 0.00 & 0.00 & 0.00 \\
\hline 75 & 1 & 0.00 & 0.00 & 0.00 & 0.00 & 0.00 & 100.00 & 0.00 & 0.00 & 0.00 & 0.00 & 100.00 \\
\hline
\end{tabular}


Table 28: Percent of Overloaded Transformers by kVA for Scenarios 5 and 6

\begin{tabular}{|c|c|c|c|c|c|c|c|c|c|c|c|c|}
\hline \multirow[b]{2}{*}{ Tx kVA } & \multirow[b]{2}{*}{ Count } & \multirow{2}{*}{$\begin{array}{l}\text { Base } \\
\text { Case }\end{array}$} & \multicolumn{5}{|c|}{ Scenario 5} & \multicolumn{5}{|c|}{ Scenario 6} \\
\hline & & & 2 & 5 & 10 & 20 & 50 & 2 & 5 & 10 & 20 & 50 \\
\hline 10 & 3 & 33.33 & 66.67 & 66.67 & 66.67 & 66.67 & 100.00 & 66.67 & 66.67 & 66.67 & 66.67 & 100.00 \\
\hline 15 & 3 & 0.00 & 0.00 & 0.00 & 0.00 & 0.00 & 100.00 & 0.00 & 33.33 & 33.33 & 66.67 & 100.00 \\
\hline 25 & 15 & 0.00 & 0.00 & 0.00 & 6.67 & 13.33 & 66.67 & 0.00 & 6.67 & 13.33 & 20.00 & \begin{tabular}{|l|}
86.67 \\
\end{tabular} \\
\hline 50 & 13 & 0.00 & 0.00 & 0.00 & 0.00 & 0.00 & 30.77 & 0.00 & 0.00 & 0.00 & 0.00 & 30.77 \\
\hline 75 & 1 & 0.00 & 0.00 & 0.00 & 0.00 & 100.00 & 100.00 & 0.00 & 0.00 & 0.00 & 100.00 & 100.00 \\
\hline
\end{tabular}

Table 29: Percent of Overloaded Transformers by kVA for Scenarios 7 and 8

\begin{tabular}{|c|c|c|c|c|c|c|c|c|c|c|c|c|}
\hline \multirow[b]{2}{*}{ Tx kVA } & \multirow[b]{2}{*}{ Count } & \multirow[b]{2}{*}{$\begin{array}{l}\text { Base } \\
\text { Case }\end{array}$} & \multicolumn{5}{|c|}{ Scenario 7} & \multicolumn{5}{|c|}{ Scenario 8} \\
\hline & & & 2 & 5 & 10 & 20 & 50 & 2 & 5 & 10 & 20 & 50 \\
\hline 10 & 3 & 33.33 & 33.33 & \begin{tabular}{|c|}
66.67 \\
\end{tabular} & 66.67 & 66.67 & 66.67 & 33.33 & \begin{tabular}{|c|}
66.67 \\
\end{tabular} & 66.67 & 66.67 & 66.67 \\
\hline 15 & 3 & 0.00 & 0.00 & \begin{tabular}{|l|}
0.00 \\
\end{tabular} & 0.00 & 0.00 & 66.67 & 0.00 & \begin{tabular}{|l|}
0.00 \\
\end{tabular} & \begin{tabular}{|l}
0.00 \\
\end{tabular} & 33.33 & 100.00 \\
\hline 25 & 15 & 0.00 & 0.00 & 0.00 & 6.67 & 13.33 & 53.33 & 0.00 & 0.00 & 6.67 & 13.33 & 60.00 \\
\hline 50 & 13 & 0.00 & 0.00 & 0.00 & 0.00 & 0.00 & 7.69 & 0.00 & 0.00 & 0.00 & 0.00 & 15.38 \\
\hline 75 & 1 & 0.00 & 0.00 & 0.00 & 0.00 & 0.00 & 100.00 & 0.00 & 0.00 & 0.00 & 100.00 & 100.00 \\
\hline
\end{tabular}

Table 30: Table showing Number of Transformers Sizes and Connected PEV

\begin{tabular}{|c|c|c|c|c|c|c|}
\hline \multirow[b]{2}{*}{ Tx\# } & \multirow[b]{2}{*}{ Size (kVA) } & \multicolumn{5}{|c|}{ Number of Connected PEV } \\
\hline & & $2 \%$ & $5 \%$ & $10 \%$ & $20 \%$ & $50 \%$ \\
\hline 1 & 50 & 0 & 1 & 1 & 9 & 16 \\
\hline 2 & 75 & 1 & 2 & 7 & 13 & 36 \\
\hline 3 & 15 & 0 & 1 & 2 & 4 & 10 \\
\hline 4 & 10 & 0 & 0 & 2 & 2 & 4 \\
\hline 5 & 25 & 1 & 1 & 2 & 3 & 7 \\
\hline 6 & 25 & 1 & 1 & 3 & 6 & 13 \\
\hline 7 & 50 & 0 & 0 & 1 & 2 & 6 \\
\hline 8 & 50 & 0 & 1 & 1 & 3 & 8 \\
\hline 9 & 25 & 0 & 1 & 2 & 3 & 12 \\
\hline 10 & 25 & 1 & 1 & 1 & 3 & 8 \\
\hline 11 & 50 & 1 & 3 & 5 & 9 & 20 \\
\hline 12 & 50 & 1 & 2 & 2 & 6 & 14 \\
\hline 13 & 50 & 2 & 3 & 6 & 9 & 19 \\
\hline 14 & 25 & 0 & 0 & 0 & 2 & 9 \\
\hline 15 & 25 & 0 & 1 & 1 & 1 & 10 \\
\hline 16 & 25 & 0 & 0 & 1 & 3 & 5 \\
\hline 17 & 10 & 1 & 2 & 2 & 3 & 3 \\
\hline 18 & 25 & 1 & 1 & 1 & 2 & 3 \\
\hline 19 & 50 & 0 & 0 & 1 & 4 & 7 \\
\hline 20 & 10 & 0 & 0 & 2 & 4 & 9 \\
\hline 21 & 50 & 0 & 1 & 3 & 6 & 11 \\
\hline 22 & 15 & 0 & 0 & 1 & 1 & 4 \\
\hline 23 & 25 & 0 & 1 & 1 & 1 & 5 \\
\hline 24 & 15 & 0 & 0 & 1 & 1 & 5 \\
\hline 25 & 25 & 0 & 0 & 1 & 1 & 5 \\
\hline 26 & 50 & 0 & 0 & 0 & 1 & 6 \\
\hline 27 & 50 & 1 & 1 & 1 & 5 & 9 \\
\hline 28 & 25 & 0 & 1 & 1 & 2 & 8 \\
\hline 29 & 50 & 0 & 0 & 2 & 3 & 10 \\
\hline 30 & 50 & 1 & 1 & 1 & 3 & 7 \\
\hline 31 & 25 & 1 & 2 & 6 & 9 & 19 \\
\hline 32 & 25 & 0 & 2 & 2 & 2 & 7 \\
\hline 33 & 50 & 0 & 2 & 2 & 4 & 8 \\
\hline 34 & 25 & 0 & 1 & 1 & 1 & 2 \\
\hline 35 & 25 & 0 & 0 & 0 & 1 & 3 \\
\hline & al PEV & 13 & 33 & 66 & 132 & 328 \\
\hline
\end{tabular}




\subsubsection{Energy Losses}

Figures 27, 28, and 29 below show the percent increase in energy loss (kWh) for the circuit, service Lines, and service transformers respectively as a multiple of the base case. All scenarios use PEV60 and charge at different time of day or different type of charger. As expected the losses increase with increasing PEV penetration. However, smaller size PEV chargers $(1.8 \mathrm{~kW})$ for scenario 1 and scenario 2 contribute more energy loss than $3.6 \mathrm{~kW}$ chargers for scenarios 3 and 4 because of the extended period of time it takes to charge the same PEV. The fast chargers in scenarios 5 and 6 produce the most losses largely due to the high amount of current $\left(\mathrm{I}^{2} \mathrm{R}\right)$ that offsets the time factor. Overall, PEV charging during peak hours increases losses in the electric distribution due to the high power flow.

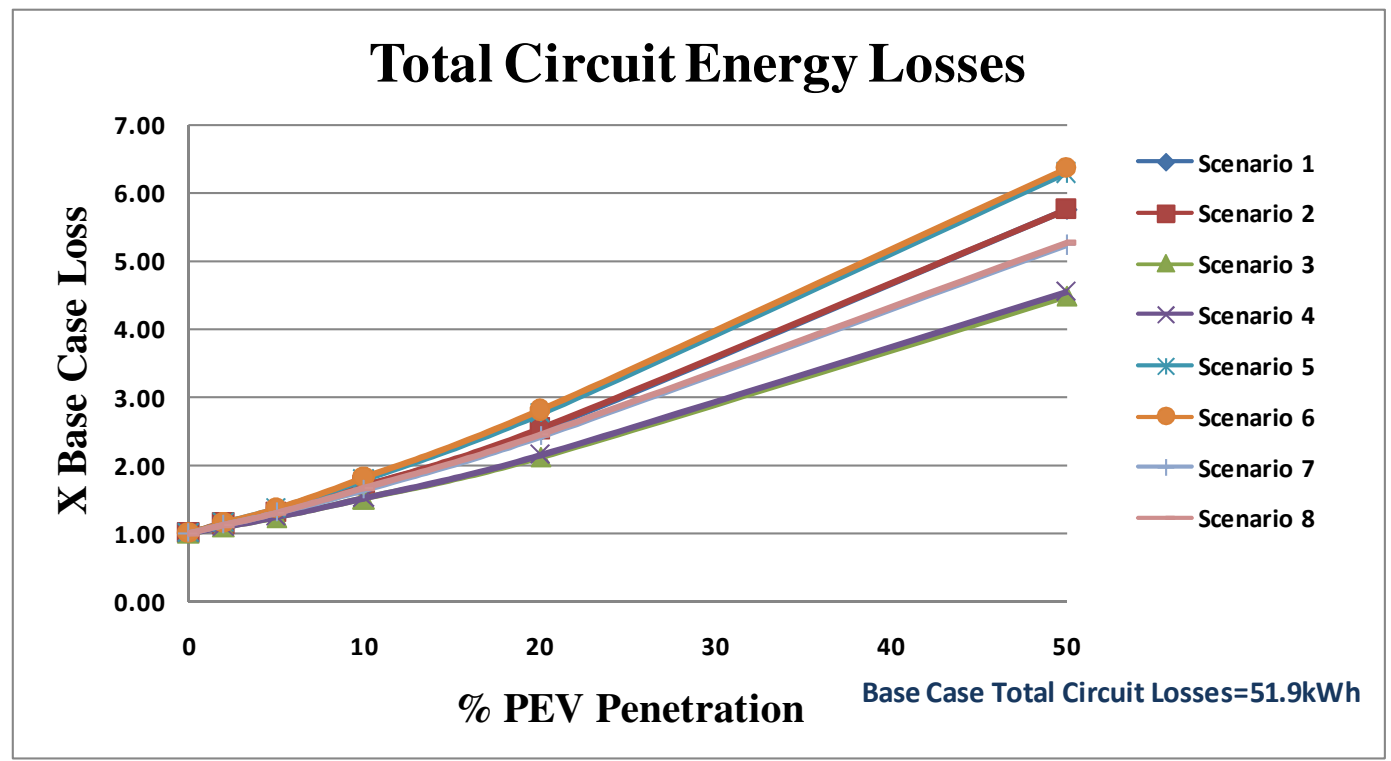

Figure 27: Percent increase in total Circuit Losses (As multiple of Base Case) 


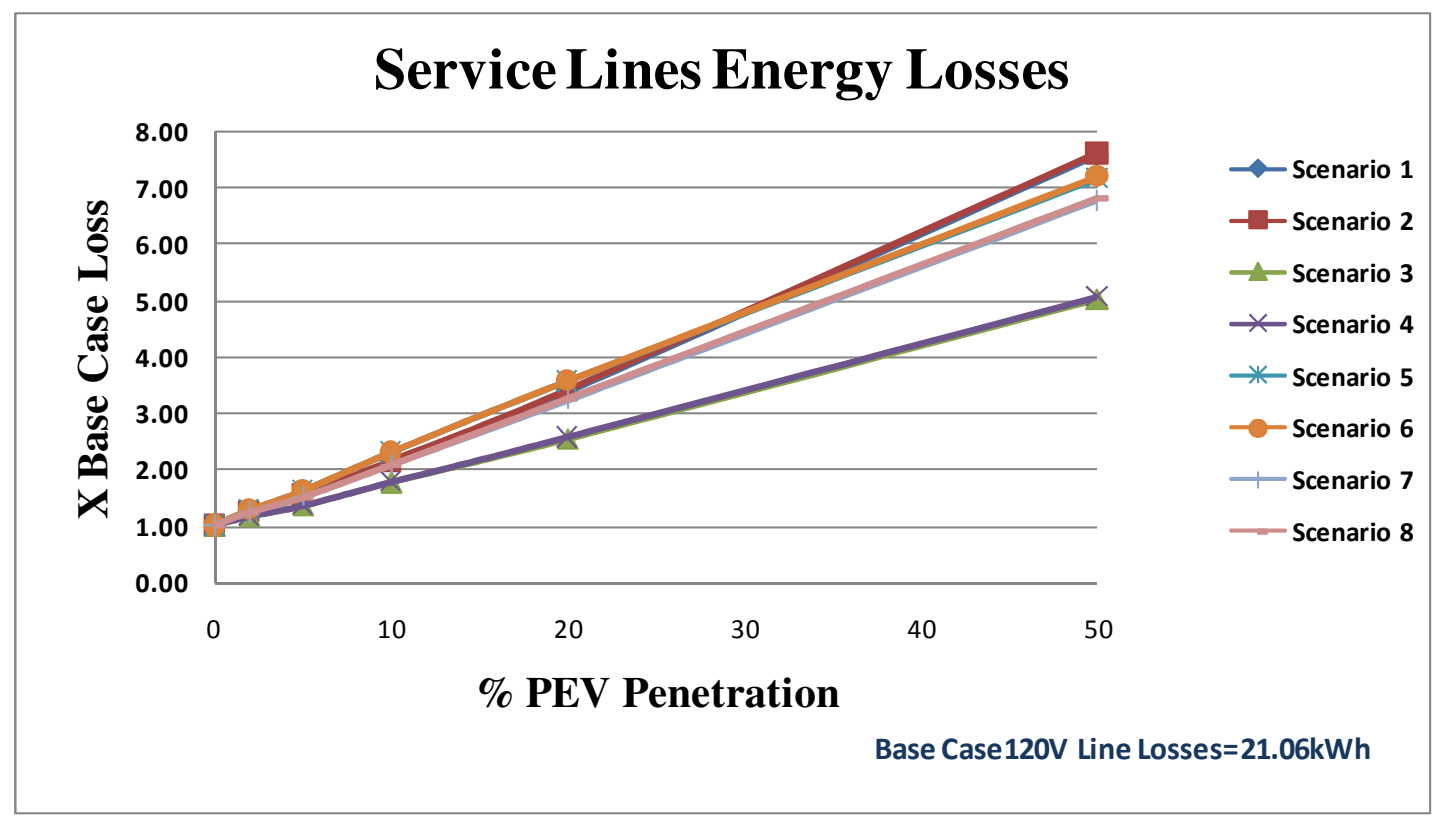

Figure 28: Percent Increase in Service Lines Losses (As multiple of Base Case)

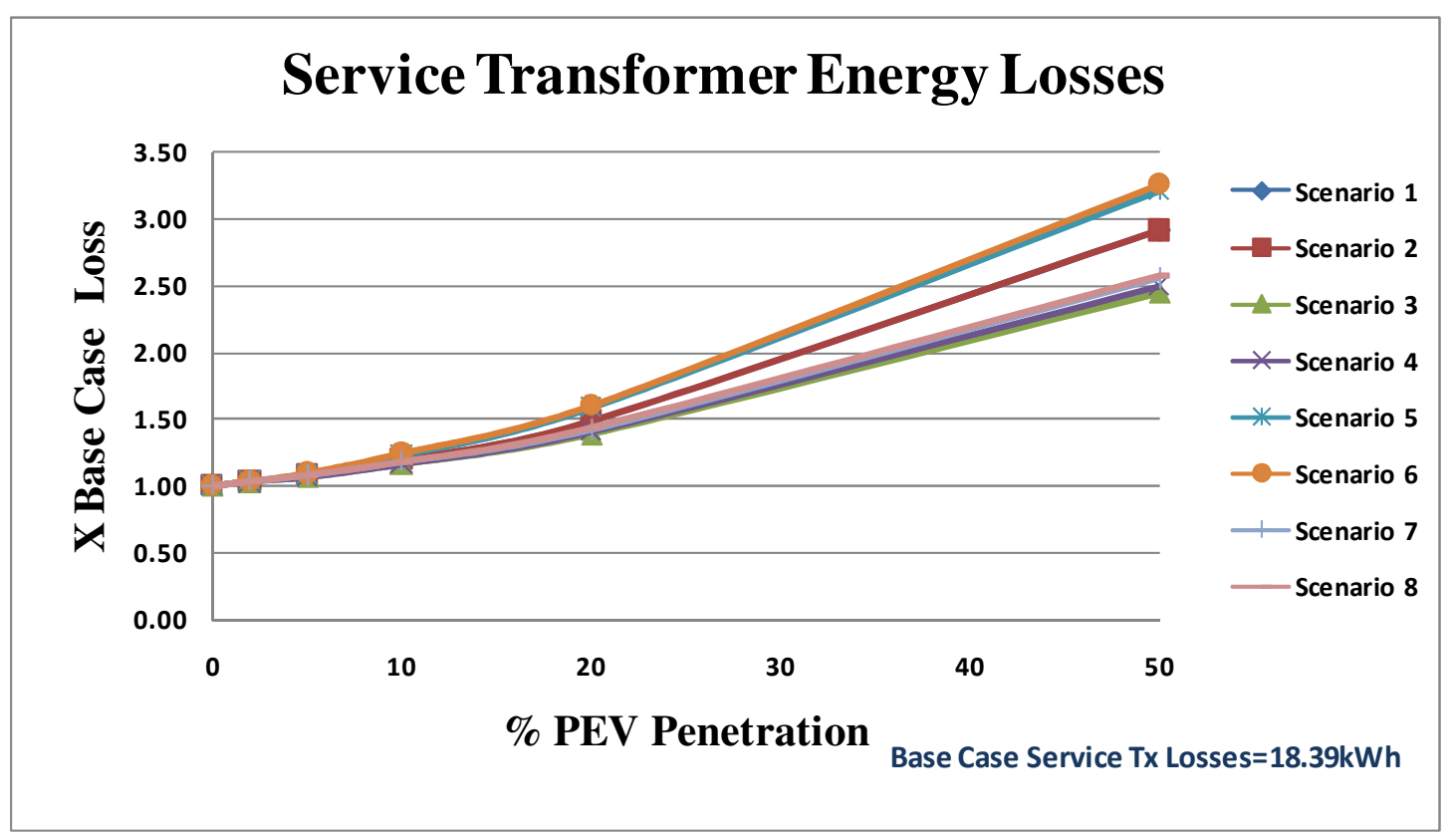

Figure 29: Percent Increase in Service Transformer Losses (As multiple of Base Case) 


\subsubsection{Service Transformer loss-of-life expectancy}

PEV increases the thermal loading of service transformers. As a result, the life expectancy of service transformers decreases overtime due to deterioration of the insulation material. Transformers loaded above nameplate and emergency rating for an extended period of time experience severe loss of life expectancy. The number of PEV connected to a transformer and the durations of overload contributes to transformer's life expectancy. Table 31 and Figure 30 illustrates the average hours of all transformers at risk of overload as a percent of the base case.

Average hours of service transformers at risk of overload

$$
=\frac{\sum_{i=1}^{M} \text { hours within risk of overload }}{\text { Total hours within } 7 \text { monthsof simulation }} \times 100
$$

Where $\mathrm{M}$ is the number of service transformers

Average hours as percent of basecase

$$
=\frac{\text { Average hours at PEV penetration level }}{\text { Average hours at basecase }} \times 100
$$

Table 31: Average Hours of Service Transformers at Risk of Overload as a Percent of Base Case

\begin{tabular}{|c|c|c|c|c|c|c|}
\hline \multicolumn{6}{|c|}{ Average Hours of Service Tx's at Risk of Overload As a Percent of Base Case } \\
\hline \% PEV Penetration & 0 & 2 & 5 & 10 & 20 & 50 \\
\hline Scenario 1 & 100.00 & 105.26 & 122.93 & 474.44 & 1672.18 & 5373.68 \\
\hline Scenario 2 & 100.00 & 107.14 & 119.92 & 486.84 & 1846.99 & 5562.78 \\
\hline Scenario 3 & 100.00 & 104.51 & 134.96 & 802.26 & 1377.07 & 6198.50 \\
\hline Scenario 4 & 100.00 & 108.65 & 136.09 & 860.53 & 1644.74 & 6287.59 \\
\hline Scenario 5 & 100.00 & 121.80 & 444.74 & 1070.30 & 1656.77 & 2522.18 \\
\hline Scenario 6 & 100.00 & 126.69 & 519.17 & 1177.07 & 1841.35 & 2488.35 \\
\hline Scenario 7 & 100.00 & 121.43 & 425.94 & 1025.56 & 897.74 & 5592.86 \\
\hline Scenario 8 & 100.00 & 126.69 & 451.88 & 1019.92 & 846.24 & 5597.74 \\
\hline
\end{tabular}




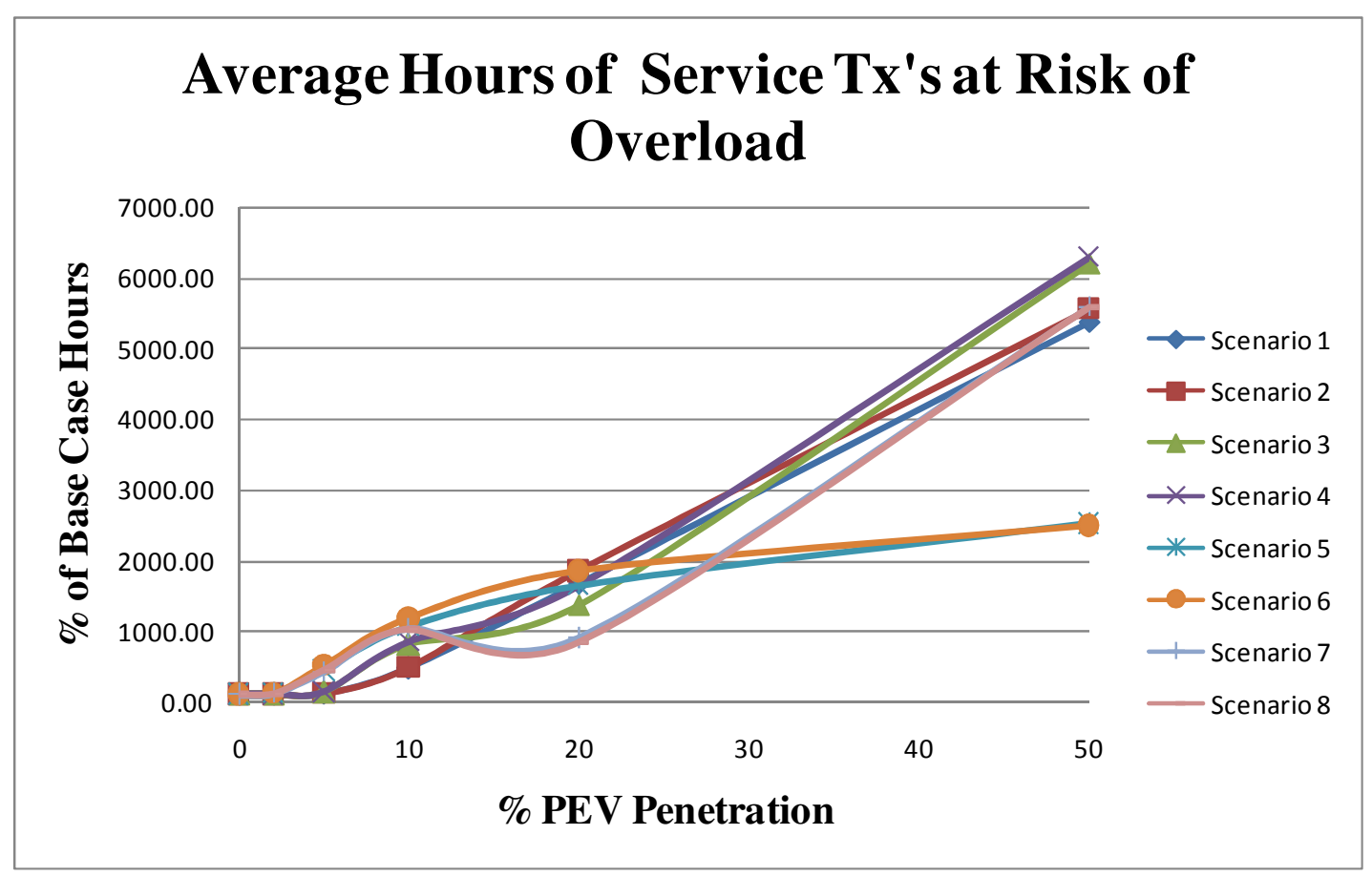

Figure 30: Average Hours of All Service Transformers within Risk of Overload (As a percent of Base Case)

At lower PEV penetration level, more transformers are within risk of overload for scenario 6 conditions. However, as PEV penetration level increases, figure 30 shows that the average hours for scenarios 5 and 6 decreases because most transformers become overloaded. Note that the hours which transformers are at risk of overload increases continuously for scenarios 1 and 2 because the longer time duration it takes to charge the PEV battery. The dip in scenarios 7 and 8 is because transformers become overloaded for a longer duration of time as reflected in figure 31 . Figure 31 and table 32 show that the average time frame for which transformers are overloaded increases as PEV penetration increases, especially under scenarios 5 and 6 conditions. The average hours of transformer overload are highly dependent on type of PEV charger. Load levels above 
transformer's nameplate rating deteriorates it life expectancy, especially load levels above the emergency ratings.

Table 32: Average Hours of Overloaded Service Transformers as a Percent of Base Case

\begin{tabular}{|c|c|c|c|c|c|c|}
\hline \multicolumn{6}{|c|}{ Average Hours of Overloaded Service Tx's As a Percent of Base Case } \\
\hline \% PEV Penetration & 0 & 2 & 5 & 10 & 20 & 50 \\
\hline Scenario 1 & 100.00 & 100.00 & 102.17 & 276.09 & 1056.52 & 13658.70 \\
\hline Scenario 2 & 100.00 & 100.00 & 110.87 & 382.61 & 1289.13 & 13854.35 \\
\hline Scenario 3 & 100.00 & 100.00 & 102.17 & 306.52 & 2741.30 & 16623.91 \\
\hline Scenario 4 & 100.00 & 100.00 & 102.17 & 589.13 & 3582.61 & 17426.09 \\
\hline Scenario 5 & 100.00 & 102.17 & 136.96 & 2880.43 & 9069.57 & 33519.57 \\
\hline Scenario 6 & 100.00 & 102.17 & 173.91 & 3223.91 & 9126.09 & 34017.39 \\
\hline Scenario 7 & 100.00 & 100.00 & 134.78 & 384.78 & 5067.39 & 14393.48 \\
\hline Scenario 8 & 100.00 & 104.35 & 178.26 & 676.09 & 5767.39 & 14410.87 \\
\hline
\end{tabular}

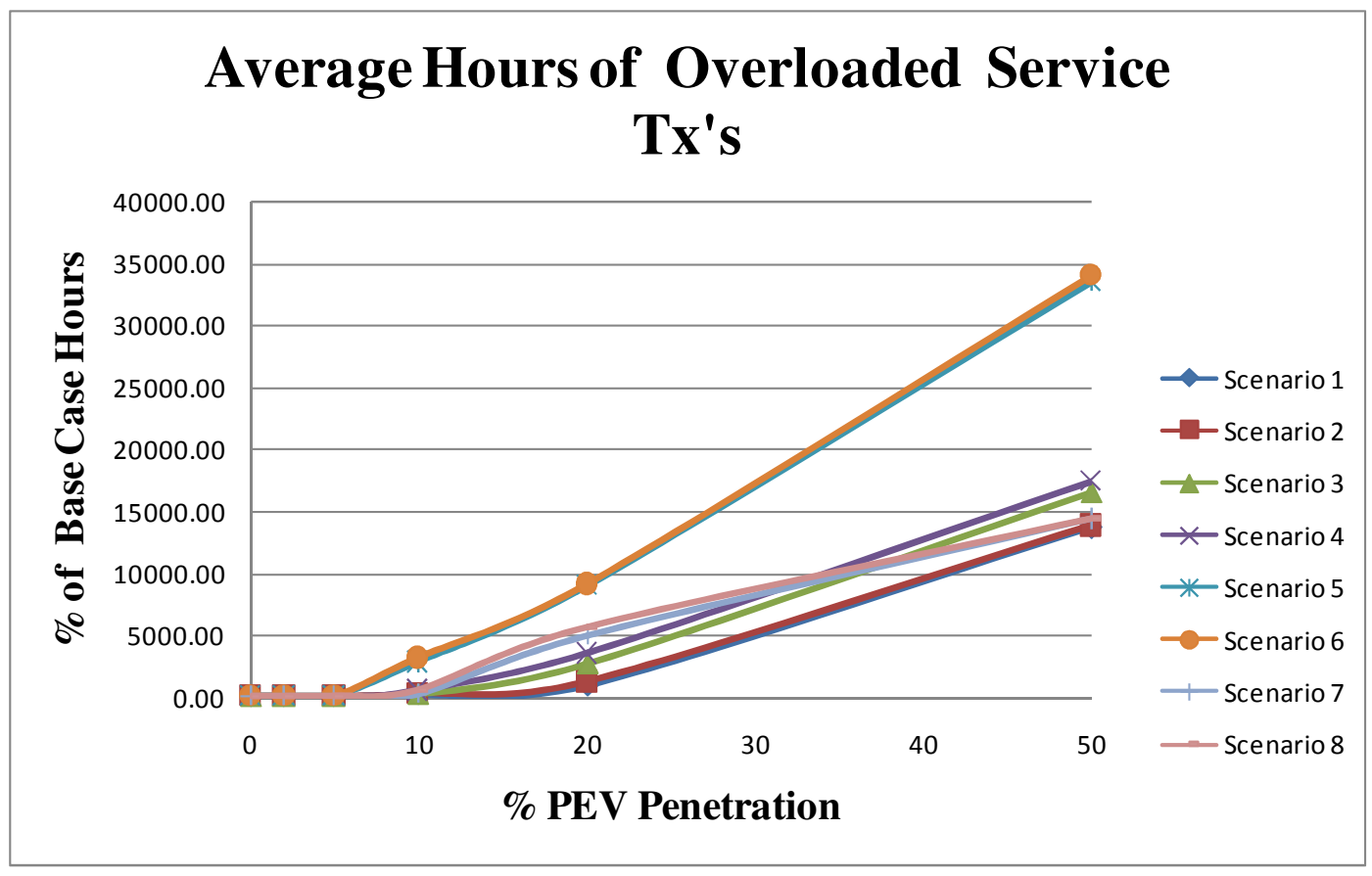

Figure 31: Average Hours of Overloaded Service Transformers (As a percent of the Base Case) 
Results from figures 29 and 30 above are reflected in results from the loss-of-life calculation presented in tables 33 to 37 . Fast chargers are more likely to severely impact transformer's life expectancy because the high load significantly increases the temperature of the core and drastically deteriorates transformer's insulation medium. As mentioned earlier, while the number of PEV connected to a transformer influence the life expectancy, the size of the transformer compared to the total additional PEV load is crucial as well. Table 42 in the appendix section contains the number of PEV added to each transformer at the various penetration levels. The life expectancy of transformers with no additional PEV stays constant even with increasing PEV penetration level. Additional PEV loads significantly accelerate service transformer's life expectancy, especially fast chargers for scenarios 5 and 6.

$$
\begin{aligned}
& \% \text { transformer loss of life as percent of base } \\
& \qquad=\frac{\text { transformer loss of live at PEV penetration level }}{\text { transformer loss of life at base case }} \times 100
\end{aligned}
$$


Table 33: Loss-of-life Expectancy for each transformer for scenarios 1 and 2 as a percent of Base

Case (x100)

\begin{tabular}{|c|c|c|c|c|c|c|}
\hline \multicolumn{7}{|c|}{ Scenario 1 Tx Percent Loss-Of-Life (X100) } \\
\hline \multirow{2}{*}{ Tx I.D } & \multicolumn{7}{|c|}{ \% PEV Penetration } \\
\cline { 2 - 7 } & 2 & 5 & 10 & 20 & 50 \\
\hline 1 & 1.00 & 1.00 & 1.09 & 1.09 & 5.82 & 53.99 \\
\hline 2 & 1.00 & 1.05 & 1.11 & 1.88 & 6.31 & 5885.64 \\
\hline 3 & 1.00 & 1.00 & 2.04 & 7.02 & 180.60 & 3583505.67 \\
\hline 4 & 1.00 & 1.00 & 1.00 & 8.09 & 8.09 & 1071.24 \\
\hline 5 & 1.00 & 2.00 & 2.00 & 4.65 & 12.36 & 307.57 \\
\hline 6 & 1.00 & 1.81 & 1.81 & 8.12 & 162.61 & 61460.98 \\
\hline 7 & 1.00 & 1.00 & 1.00 & 1.08 & 1.21 & 2.86 \\
\hline 8 & 1.00 & 1.00 & 1.14 & 1.14 & 1.66 & 8.99 \\
\hline 9 & 1.00 & 1.00 & 1.85 & 4.09 & 9.92 & 35077.70 \\
\hline 10 & 1.00 & 1.31 & 1.31 & 1.32 & 3.74 & 303.69 \\
\hline 11 & 1.00 & 1.13 & 1.63 & 2.84 & 12.51 & 1837.52 \\
\hline 12 & 1.00 & 1.11 & 1.28 & 1.28 & 3.59 & 110.80 \\
\hline 13 & 1.00 & 1.39 & 1.73 & 4.06 & 14.09 & 1379.26 \\
\hline 14 & 1.00 & 1.00 & 1.00 & 1.00 & 2.00 & 963.23 \\
\hline 15 & 1.00 & 1.00 & 1.49 & 1.50 & 1.52 & 4657.29 \\
\hline 16 & 1.00 & 1.00 & 1.01 & 1.70 & 9.08 & 51.71 \\
\hline 17 & 1.00 & 1.22 & 2.39 & 2.39 & 8.33 & 8.33 \\
\hline 18 & 1.00 & 1.41 & 1.41 & 1.41 & 2.42 & 4.73 \\
\hline 19 & 1.00 & 1.00 & 1.00 & 1.07 & 1.55 & 2.96 \\
\hline 20 & 1.00 & 1.00 & 0.99 & 6.28 & 83.70 & 7529.42 \\
\hline 21 & 1.00 & 1.00 & 1.10 & 1.46 & 3.15 & 18.81 \\
\hline 22 & 1.00 & 1.00 & 1.00 & 1.45 & 1.45 & 44.82 \\
\hline 23 & 1.00 & 1.00 & 1.98 & 1.98 & 1.97 & 52.46 \\
\hline 24 & 1.00 & 1.00 & 1.00 & 2.24 & 2.30 & 625.44 \\
\hline 25 & 1.00 & 1.00 & 1.00 & 1.64 & 1.65 & 37.25 \\
\hline 26 & 1.00 & 1.00 & 1.00 & 1.00 & 1.17 & 4.88 \\
\hline 27 & 1.00 & 1.13 & 1.13 & 1.13 & 2.77 & 10.92 \\
\hline 28 & 1.00 & 1.00 & 1.52 & 1.53 & 2.94 & 849.99 \\
\hline 29 & 1.00 & 0.12 & 0.21 & 0.59 & 0.85 & 0.52 \\
\hline 30 & 1.00 & 1.09 & 1.09 & 1.09 & 1.35 & 3.12 \\
\hline 31 & 1.00 & 1.82 & 4.04 & 137.10 & 2128.29 & 3057827.13 \\
\hline 32 & 1.00 & 1.00 & 2.70 & 2.72 & 2.74 & 320.48 \\
\hline 33 & 1.00 & 1.00 & 1.21 & 1.21 & 1.68 & 4.85 \\
\hline 34 & 1.00 & 1.00 & 1.40 & 1.40 & 1.40 & 2.27 \\
\hline 35 & 1.00 & 1.00 & 1.00 & 1.00 & 1.47 & 5.56 \\
\hline
\end{tabular}

\begin{tabular}{|c|c|c|c|c|c|c|}
\hline \multicolumn{7}{|c|}{ Scenario 2 Tx Percent Loss-Of-Life (X100) } \\
\hline \multirow{2}{*}{ Tx I.D } & \multicolumn{7}{|c|}{ \% PEV Penetration } \\
\cline { 2 - 7 } & 1 & 2 & 5 & 10 & 20 & 50 \\
\hline 1 & 1.00 & 1.00 & 1.18 & 1.19 & 10.30 & 99.58 \\
\hline 2 & 1.00 & 1.10 & 1.23 & 2.73 & 11.08 & 9115.26 \\
\hline 3 & 1.00 & 1.00 & 2.90 & 11.64 & 289.51 & 4903632.89 \\
\hline 4 & 1.00 & 1.00 & 1.00 & 15.61 & 15.61 & 1903.87 \\
\hline 5 & 1.00 & 2.00 & 2.01 & 4.69 & 12.76 & 614.01 \\
\hline 6 & 1.00 & 2.25 & 2.26 & 12.00 & 230.31 & 76129.56 \\
\hline 7 & 1.00 & 1.00 & 1.00 & 1.19 & 1.50 & 5.32 \\
\hline 8 & 1.00 & 1.00 & 1.18 & 1.18 & 1.86 & 10.36 \\
\hline 9 & 1.00 & 1.00 & 1.91 & 4.27 & 10.27 & 35819.36 \\
\hline 10 & 1.00 & 2.35 & 2.36 & 2.38 & 13.33 & 1211.23 \\
\hline 11 & 1.00 & 1.21 & 2.05 & 3.97 & 18.42 & 2352.64 \\
\hline 12 & 1.00 & 1.34 & 1.83 & 1.84 & 9.12 & 338.95 \\
\hline 13 & 1.00 & 1.60 & 2.11 & 5.49 & 19.12 & 1662.48 \\
\hline 14 & 1.00 & 1.01 & 1.01 & 1.03 & 7.00 & 4639.48 \\
\hline 15 & 1.00 & 1.00 & 2.33 & 2.36 & 2.41 & 9839.41 \\
\hline 16 & 1.00 & 1.00 & 1.01 & 2.28 & 15.50 & 89.15 \\
\hline 17 & 1.00 & 9.36 & 53.61 & 53.61 & 209.22 & 209.22 \\
\hline 18 & 1.00 & 1.91 & 1.92 & 1.92 & 4.12 & 9.13 \\
\hline 19 & 1.00 & 1.00 & 1.00 & 1.12 & 1.95 & 4.30 \\
\hline 20 & 1.00 & 1.00 & 1.01 & 23.68 & 414.85 & 33633.18 \\
\hline 21 & 1.00 & 1.00 & 1.21 & 1.96 & 5.38 & 35.51 \\
\hline 22 & 1.00 & 1.00 & 1.00 & 2.07 & 2.08 & 102.72 \\
\hline 23 & 1.00 & 1.00 & 2.06 & 2.03 & 1.97 & 52.61 \\
\hline 24 & 1.00 & 1.01 & 1.02 & 4.62 & 4.75 & 1357.42 \\
\hline 25 & 1.00 & 1.00 & 1.01 & 2.48 & 2.51 & 97.16 \\
\hline 26 & 1.00 & 1.00 & 1.00 & 1.00 & 1.29 & 7.37 \\
\hline 27 & 1.00 & 1.22 & 1.23 & 1.23 & 3.98 & 16.87 \\
\hline 28 & 1.00 & 1.00 & 2.04 & 2.05 & 4.88 & 1422.97 \\
\hline 29 & 1.00 & 0.21 & 0.54 & 1.37 & 1.48 & 3.40 \\
\hline 30 & 1.00 & 1.19 & 1.19 & 1.19 & 1.77 & 5.57 \\
\hline 31 & 1.00 & 2.57 & 6.96 & 245.71 & 3520.74 & 4063688.52 \\
\hline 32 & 1.00 & 1.00 & 3.53 & 3.55 & 3.59 & 406.13 \\
\hline 33 & 1.00 & 1.00 & 1.42 & 1.42 & 2.33 & 8.40 \\
\hline 34 & 1.00 & 1.00 & 1.49 & 1.49 & 1.49 & 2.57 \\
\hline 35 & 1.00 & 1.00 & 1.00 & 1.01 & 1.94 & 9.92 \\
\hline
\end{tabular}


Table 34: Loss-of-life Expectancy for each transformer for scenarios 3 and 4 as a percent of Base

\section{Case (x100)}

\begin{tabular}{|c|c|c|c|c|c|c|}
\hline \multicolumn{7}{|c|}{ Scenario 3 Tx Percent Loss-Of-Life (X 100) } \\
\hline \multirow{2}{*}{ Tx I.D } & \multicolumn{7}{|c|}{$\%$ PEV Penetration } \\
\cline { 2 - 7 } & 0 & 2 & 5 & 10 & 20 & 50 \\
\hline 1 & 1 & 1.00 & 1.11 & 1.11 & 21.65 & $7.42 \mathrm{E}+02$ \\
\hline 2 & 1 & 1.05 & 1.13 & 2.67 & 26.26 & $9.56 \mathrm{E}+05$ \\
\hline 3 & 1 & 1.00 & 3.82 & 43.77 & 7908.47 & $1.28 \mathrm{E}+09$ \\
\hline 4 & 1 & 1.00 & 1.00 & 91.74 & 91.74 & $7.85 \mathrm{E}+04$ \\
\hline 5 & 1 & 1.53 & 1.53 & 3.69 & 12.03 & $2.98 \mathrm{E}+03$ \\
\hline 6 & 1 & 2.10 & 2.09 & 22.67 & 1854.85 & $3.91 \mathrm{E}+06$ \\
\hline 7 & 1 & 1.00 & 1.00 & 1.08 & 1.23 & $4.36 \mathrm{E}+00$ \\
\hline 8 & 1 & 1.00 & 1.12 & 1.12 & 1.77 & $2.34 \mathrm{E}+01$ \\
\hline 9 & 1 & 1.00 & 1.76 & 4.80 & 18.06 & $1.76 \mathrm{E}+06$ \\
\hline 10 & 1 & 1.56 & 1.56 & 1.55 & 12.59 & $9.50 \mathrm{E}+03$ \\
\hline 11 & 1 & 1.17 & 2.04 & 5.42 & 79.15 & $1.00 \mathrm{E}+05$ \\
\hline 12 & 1 & 1.15 & 1.44 & 1.44 & 9.68 & $2.35 \mathrm{E}+03$ \\
\hline 13 & 1 & 1.50 & 2.16 & 10.55 & 87.38 & $5.37 \mathrm{E}+04$ \\
\hline 14 & 1 & 1.00 & 1.00 & 1.01 & 3.90 & $3.51 \mathrm{E}+04$ \\
\hline 15 & 1 & 1.00 & 1.84 & 1.84 & 1.84 & $2.26 \mathrm{E}+05$ \\
\hline 16 & 1 & 1.00 & 1.01 & 2.17 & 31.74 & $3.58 \mathrm{E}+02$ \\
\hline 17 & 1 & 1.05 & 3.06 & 3.06 & 31.16 & $3.12 \mathrm{E}+01$ \\
\hline 18 & 1 & 1.76 & 1.76 & 1.75 & 4.69 & $1.36 \mathrm{E}+01$ \\
\hline 19 & 1 & 1.00 & 1.00 & 1.07 & 1.88 & $5.67 \mathrm{E}+00$ \\
\hline 20 & 1 & 1.00 & 0.99 & 21.36 & 835.50 & $3.03 \mathrm{E}+05$ \\
\hline 21 & 1 & 1.00 & 1.10 & 1.61 & 5.70 & $1.07 \mathrm{E}+02$ \\
\hline 22 & 1 & 1.00 & 1.00 & 1.79 & 1.76 & $6.00 \mathrm{E}+02$ \\
\hline 23 & 1 & 1.00 & 1.73 & 1.73 & 1.72 & $1.92 \mathrm{E}+02$ \\
\hline 24 & 1 & 1.00 & 1.00 & 1.68 & 1.68 & $3.80 \mathrm{E}+03$ \\
\hline 25 & 1 & 1.00 & 1.00 & 1.45 & 1.44 & $8.91 \mathrm{E}+01$ \\
\hline 26 & 1 & 1.00 & 1.00 & 1.00 & 1.22 & $1.15 \mathrm{E}+01$ \\
\hline 27 & 1 & 1.16 & 1.16 & 1.16 & 5.03 & $4.80 \mathrm{E}+01$ \\
\hline 28 & 1 & 1.00 & 1.89 & 1.89 & 5.65 & $1.87 \mathrm{E}+04$ \\
\hline 29 & 1 & 0.13 & 0.13 & 1.52 & 0.71 & $3.24 \mathrm{E}+00$ \\
\hline 30 & 1 & 1.09 & 1.09 & 1.09 & 1.45 & $6.10 \mathrm{E}+00$ \\
\hline 31 & 1 & 2.18 & 7.28 & 1417.54 & 54890.46 & $2.86 \mathrm{E}+08$ \\
\hline 32 & 1 & 1.00 & 5.28 & 5.19 & 5.03 & $5.52 \mathrm{E}+03$ \\
\hline 33 & 1 & 1.00 & 1.33 & 1.32 & 2.48 & $1.83 \mathrm{E}+01$ \\
\hline 34 & 1 & 1.00 & 1.37 & 1.37 & 1.36 & $2.30 \mathrm{E}+00$ \\
\hline 35 & 1 & 1.00 & 1.00 & 1.00 & 1.47 & $1.03 \mathrm{E}+01$ \\
\hline
\end{tabular}

\begin{tabular}{|c|c|c|c|c|c|c|}
\hline \multicolumn{7}{|c|}{ Scenario 4 Tx Percent Loss-Of-Life (X100) } \\
\hline \multirow{2}{*}{ Tx I.D } & \multicolumn{7}{|c|}{ \% PEV Penetration } \\
\cline { 2 - 7 } & & 2 & 5 & 10 & 20 & 50 \\
\hline 1 & 1.00 & 1.00 & 1.18 & 1.18 & 31.99 & $1.01 \mathrm{E}+03$ \\
\hline 2 & 1.00 & 1.10 & 1.25 & 4.13 & 44.85 & $1.27 \mathrm{E}+06$ \\
\hline 3 & 1.00 & 1.00 & 4.03 & 46.41 & 9495.64 & $1.47 \mathrm{E}+09$ \\
\hline 4 & 1.00 & 1.00 & 1.00 & 165.19 & 165.19 & $1.18 \mathrm{E}+05$ \\
\hline 5 & 1.00 & 2.73 & 2.73 & 11.37 & 48.65 & $1.24 \mathrm{E}+04$ \\
\hline 6 & 1.00 & 2.22 & 2.22 & 27.10 & 2224.60 & $5.20 \mathrm{E}+06$ \\
\hline 7 & 1.00 & 1.00 & 1.00 & 1.26 & 1.73 & $1.27 \mathrm{E}+01$ \\
\hline 8 & 1.00 & 1.00 & 1.23 & 1.23 & 2.45 & $3.96 \mathrm{E}+01$ \\
\hline 9 & 1.00 & 1.00 & 1.82 & 5.36 & 21.72 & $2.27 \mathrm{E}+06$ \\
\hline 10 & 1.00 & 2.59 & 2.59 & 2.59 & 33.04 & $1.65 \mathrm{E}+04$ \\
\hline 11 & 1.00 & 1.22 & 2.35 & 6.37 & 83.43 & $1.12 \mathrm{E}+05$ \\
\hline 12 & 1.00 & 1.38 & 2.14 & 2.13 & 23.93 & $4.90 \mathrm{E}+03$ \\
\hline 13 & 1.00 & 1.64 & 2.47 & 12.02 & 92.36 & $5.83 \mathrm{E}+04$ \\
\hline 14 & 1.00 & 1.00 & 1.01 & 1.02 & 7.17 & $4.48 \mathrm{E}+04$ \\
\hline 15 & 1.00 & 1.00 & 2.30 & 2.30 & 2.30 & $2.49 \mathrm{E}+05$ \\
\hline 16 & 1.00 & 1.00 & 1.01 & 2.34 & 33.37 & $3.62 \mathrm{E}+02$ \\
\hline 17 & 1.00 & 1.66 & 13.25 & 13.25 & 154.55 & $1.55 \mathrm{E}+02$ \\
\hline 18 & 1.00 & 1.93 & 1.92 & 1.92 & 5.09 & $1.49 \mathrm{E}+01$ \\
\hline 19 & 1.00 & 1.00 & 1.00 & 1.12 & 2.51 & $8.63 \mathrm{E}+00$ \\
\hline 20 & 1.00 & 1.01 & 1.02 & 41.34 & 1845.50 & $3.97 \mathrm{E}+05$ \\
\hline 21 & 1.00 & 1.00 & 1.24 & 2.49 & 12.23 & $2.28 \mathrm{E}+02$ \\
\hline 22 & 1.00 & 1.00 & 1.00 & 2.72 & 2.65 & $1.16 \mathrm{E}+03$ \\
\hline 23 & 1.00 & 1.00 & 3.05 & 2.94 & 2.72 & $3.46 \mathrm{E}+02$ \\
\hline 24 & 1.00 & 1.00 & 1.01 & 3.56 & 3.58 & $9.49 \mathrm{E}+03$ \\
\hline 25 & 1.00 & 1.00 & 1.01 & 2.19 & 2.21 & $2.91 \mathrm{E}+02$ \\
\hline 26 & 1.00 & 1.00 & 1.00 & 1.00 & 1.25 & $1.17 \mathrm{E}+01$ \\
\hline 27 & 1.00 & 1.21 & 1.21 & 1.21 & 5.78 & $5.02 \mathrm{E}+01$ \\
\hline 28 & 1.00 & 1.00 & 2.11 & 2.10 & 6.23 & $2.26 \mathrm{E}+04$ \\
\hline 29 & 1.00 & 0.13 & 0.13 & 2.67 & 1.75 & $8.80 \mathrm{E}+00$ \\
\hline 30 & 1.00 & 1.20 & 1.20 & 1.20 & 1.99 & $1.19 \mathrm{E}+01$ \\
\hline 31 & 1.00 & 2.44 & 9.10 & 2396.07 & 97899.01 & $4.41 \mathrm{E}+08$ \\
\hline 32 & 1.00 & 1.00 & 5.52 & 5.43 & 5.27 & $7.54 \mathrm{E}+03$ \\
\hline 33 & 1.00 & 1.00 & 1.43 & 1.42 & 2.82 & $1.91 \mathrm{E}+01$ \\
\hline 34 & 1.00 & 1.00 & 1.59 & 1.59 & 1.58 & $3.16 \mathrm{E}+00$ \\
\hline 35 & 1.00 & 1.00 & 1.00 & 1.01 & 2.16 & $2.28 \mathrm{E}+01$ \\
\hline
\end{tabular}


Table 35: Loss-of-life Expectancy for each transformer for scenarios 5 and 6 as a percent of Base

Case (x100)

\begin{tabular}{|c|c|c|c|c|c|c|}
\hline \multicolumn{7}{|c|}{ Scenario 5 Tx Percent Loss-Of-Life (X100) } \\
\hline \multirow{2}{*}{ Tx I.D } & & \multicolumn{7}{|c|}{ \% PEV Penetration } \\
\hline & & 2 & 5 & 10 & 20 & 50 \\
\hline 1 & 1.00 & 1.00 & 1.18 & 1.17 & $1.46 \mathrm{E}+03$ & $1.89 \mathrm{E}+05$ \\
\hline 2 & 1.00 & 1.08 & 1.24 & 18.67 & $3.39 \mathrm{E}+03$ & $7.31 \mathrm{E}+09$ \\
\hline 3 & 1.00 & 1.00 & 11.44 & 1841.08 & $1.37 \mathrm{E}+07$ & $1.13 \mathrm{E}+13$ \\
\hline 4 & 1.00 & 1.00 & 1.00 & 75430.27 & $4.93 \mathrm{E}+04$ & $5.68 \mathrm{E}+08$ \\
\hline 5 & 1.00 & 2.14 & 2.11 & 21.97 & $2.64 \mathrm{E}+02$ & $1.82 \mathrm{E}+06$ \\
\hline 6 & 1.00 & 2.73 & 2.68 & 256.71 & $5.21 \mathrm{E}+05$ & $4.15 \mathrm{E}+09$ \\
\hline 7 & 1.00 & 1.00 & 1.00 & 1.14 & $1.55 \mathrm{E}+00$ & $5.37 \mathrm{E}+01$ \\
\hline 8 & 1.00 & 1.00 & 1.20 & 1.19 & $4.03 \mathrm{E}+00$ & $1.18 \mathrm{E}+03$ \\
\hline 9 & 1.00 & 1.00 & 2.86 & 28.71 & $4.13 \mathrm{E}+02$ & $3.32 \mathrm{E}+09$ \\
\hline 10 & 1.00 & 2.61 & 2.57 & 2.50 & $1.90 \mathrm{E}+02$ & $2.84 \mathrm{E}+06$ \\
\hline 11 & 1.00 & 1.27 & 4.76 & 51.24 & $8.70 \mathrm{E}+03$ & $1.80 \mathrm{E}+08$ \\
\hline 12 & 1.00 & 1.30 & 2.42 & 2.36 & $2.79 \mathrm{E}+02$ & $1.34 \mathrm{E}+06$ \\
\hline 13 & 1.00 & 2.20 & 5.90 & 206.36 & $1.08 \mathrm{E}+04$ & $7.41 \mathrm{E}+07$ \\
\hline 14 & 1.00 & 1.00 & 1.00 & 1.00 & $1.46 \mathrm{E}+01$ & $1.59 \mathrm{E}+07$ \\
\hline 15 & 1.00 & 1.00 & 2.87 & 2.82 & $2.71 \mathrm{E}+00$ & $1.94 \mathrm{E}+08$ \\
\hline 16 & 1.00 & 1.00 & 1.00 & 2.89 & $4.73 \mathrm{E}+02$ & $7.44 \mathrm{E}+03$ \\
\hline 17 & 1.00 & 1.51 & 293.87 & 223.72 & $1.44 \mathrm{E}+04$ & $2.27 \mathrm{E}+03$ \\
\hline 18 & 1.00 & 2.20 & 2.17 & 2.12 & $1.14 \mathrm{E}+01$ & $6.72 \mathrm{E}+01$ \\
\hline 19 & 1.00 & 1.00 & 1.00 & 1.11 & $6.02 \mathrm{E}+00$ & $7.50 \mathrm{E}+01$ \\
\hline 20 & 1.00 & 0.99 & 0.98 & 69.03 & $3.26 \mathrm{E}+04$ & $3.34 \mathrm{E}+07$ \\
\hline 21 & 1.00 & 1.00 & 1.18 & 3.84 & $1.24 \mathrm{E}+02$ & $1.53 \mathrm{E}+04$ \\
\hline 22 & 1.00 & 1.00 & 1.00 & 5.07 & $4.46 \mathrm{E}+00$ & $3.14 \mathrm{E}+05$ \\
\hline 23 & 1.00 & 1.00 & 2.23 & 2.19 & $2.10 \mathrm{E}+00$ & $6.53 \mathrm{E}+03$ \\
\hline 24 & 1.00 & 1.00 & 1.00 & 3.66 & $3.41 \mathrm{E}+00$ & $9.84 \mathrm{E}+05$ \\
\hline 25 & 1.00 & 1.00 & 1.00 & 1.59 & $1.54 \mathrm{E}+00$ & $3.44 \mathrm{E}+03$ \\
\hline 26 & 1.00 & 1.00 & 1.00 & 1.00 & $1.27 \mathrm{E}+00$ & $9.75 \mathrm{E}+01$ \\
\hline 27 & 1.00 & 1.23 & 1.23 & 1.22 & $3.32 \mathrm{E}+01$ & $1.34 \mathrm{E}+03$ \\
\hline 28 & 1.00 & 1.00 & 3.12 & 3.05 & $3.06 \mathrm{E}+01$ & $1.18 \mathrm{E}+07$ \\
\hline 29 & 1.00 & 0.13 & 0.36 & 0.18 & $2.21 \mathrm{E}-01$ & $2.66 \mathrm{E}+02$ \\
\hline 30 & 1.00 & 1.15 & 1.14 & 1.14 & $2.12 \mathrm{E}+00$ & $6.55 \mathrm{E}+01$ \\
\hline 31 & 1.00 & 2.17 & 20.19 & 248995.19 & $4.62 \mathrm{E}+07$ & $3.23 \mathrm{E}+11$ \\
\hline 32 & 1.00 & 1.00 & 41.11 & 37.83 & $3.21 \mathrm{E}+01$ & $6.08 \mathrm{E}+06$ \\
\hline 33 & 1.00 & 1.00 & 1.67 & 1.65 & $8.51 \mathrm{E}+00$ & $3.77 \mathrm{E}+02$ \\
\hline 34 & 1.00 & 1.00 & 1.76 & 1.73 & $1.67 \mathrm{E}+00$ & $4.53 \mathrm{E}+00$ \\
\hline 35 & 1.00 & 1.00 & 1.00 & 1.00 & $2.14 \mathrm{E}+00$ & $1.24 \mathrm{E}+02$ \\
\hline & & & & & \\
\hline
\end{tabular}

\begin{tabular}{|c|c|c|c|c|c|c|}
\hline \multicolumn{7}{|c|}{ Scenario 6 Tx Percent Loss-Of-Life (X100) } \\
\hline \multirow{2}{*}{ Tx I.D } & \multicolumn{7}{|c|}{ \% PEV Penetration } \\
\cline { 2 - 7 } & & 2 & 5 & 10 & 20 & 50 \\
\hline 1 & 1.00 & 1.00 & 1.19 & 1.19 & $1.53 \mathrm{E}+03$ & $1.89 \mathrm{E}+05$ \\
\hline 2 & 1.00 & 1.10 & 1.31 & 22.62 & $3.85 \mathrm{E}+03$ & $7.76 \mathrm{E}+09$ \\
\hline 3 & 1.00 & 1.00 & 30.83 & 5609.38 & $2.89 \mathrm{E}+07$ & $1.37 \mathrm{E}+13$ \\
\hline 4 & 1.00 & 1.00 & 1.00 & 89555.34 & $5.89 \mathrm{E}+04$ & $6.32 \mathrm{E}+08$ \\
\hline 5 & 1.00 & 7.67 & 7.59 & 143.89 & $1.67 \mathrm{E}+03$ & $5.06 \mathrm{E}+06$ \\
\hline 6 & 1.00 & 3.72 & 3.62 & 332.11 & $5.24 \mathrm{E}+05$ & $4.82 \mathrm{E}+09$ \\
\hline 7 & 1.00 & 1.00 & 1.00 & 1.36 & $2.49 \mathrm{E}+00$ & $1.52 \mathrm{E}+02$ \\
\hline 8 & 1.00 & 1.00 & 1.33 & 1.32 & $5.92 \mathrm{E}+00$ & $1.69 \mathrm{E}+03$ \\
\hline 9 & 1.00 & 1.00 & 3.76 & 44.82 & $6.69 \mathrm{E}+02$ & $3.71 \mathrm{E}+09$ \\
\hline 10 & 1.00 & 2.70 & 2.67 & 2.62 & $2.62 \mathrm{E}+02$ & $4.88 \mathrm{E}+06$ \\
\hline 11 & 1.00 & 1.28 & 5.24 & 62.40 & $1.15 \mathrm{E}+04$ & $2.30 \mathrm{E}+08$ \\
\hline 12 & 1.00 & 1.43 & 3.02 & 2.95 & $3.33 \mathrm{E}+02$ & $1.60 \mathrm{E}+06$ \\
\hline 13 & 1.00 & 2.29 & 6.51 & 257.02 & $1.38 \mathrm{E}+04$ & $8.52 \mathrm{E}+07$ \\
\hline 14 & 1.00 & 1.00 & 1.01 & 1.01 & $3.26 \mathrm{E}+01$ & $2.29 \mathrm{E}+07$ \\
\hline 15 & 1.00 & 1.00 & 4.06 & 3.99 & $3.85 \mathrm{E}+00$ & $2.26 \mathrm{E}+08$ \\
\hline 16 & 1.00 & 1.00 & 1.01 & 3.22 & $4.94 \mathrm{E}+02$ & $9.26 \mathrm{E}+03$ \\
\hline 17 & 1.00 & 11.91 & 2156.05 & 1591.38 & $5.71 \mathrm{E}+04$ & $8.33 \mathrm{E}+03$ \\
\hline 18 & 1.00 & 4.07 & 4.01 & 3.92 & $2.79 \mathrm{E}+01$ & $1.47 \mathrm{E}+02$ \\
\hline 19 & 1.00 & 1.00 & 1.00 & 1.14 & $7.26 \mathrm{E}+00$ & $8.89 \mathrm{E}+01$ \\
\hline 20 & 1.00 & 1.00 & 1.00 & 420.33 & $9.30 \mathrm{E}+04$ & $4.83 \mathrm{E}+07$ \\
\hline 21 & 1.00 & 1.00 & 1.30 & 5.58 & $1.83 \mathrm{E}+02$ & $2.02 \mathrm{E}+04$ \\
\hline 22 & 1.00 & 1.00 & 1.00 & 6.38 & $5.59 \mathrm{E}+00$ & $3.51 \mathrm{E}+05$ \\
\hline 23 & 1.00 & 1.00 & 4.49 & 4.21 & $3.61 \mathrm{E}+00$ & $1.03 \mathrm{E}+04$ \\
\hline 24 & 1.00 & 1.00 & 1.01 & 23.59 & $2.22 \mathrm{E}+01$ & $1.75 \mathrm{E}+06$ \\
\hline 25 & 1.00 & 1.00 & 1.01 & 6.36 & $5.77 \mathrm{E}+00$ & $1.87 \mathrm{E}+04$ \\
\hline 26 & 1.00 & 1.00 & 1.00 & 1.00 & $1.41 \mathrm{E}+00$ & $1.63 \mathrm{E}+02$ \\
\hline 27 & 1.00 & 1.28 & 1.27 & 1.27 & $4.87 \mathrm{E}+01$ & $1.90 \mathrm{E}+03$ \\
\hline 28 & 1.00 & 1.00 & 4.02 & 3.92 & $4.57 \mathrm{E}+01$ & $1.45 \mathrm{E}+07$ \\
\hline 29 & 1.00 & 0.13 & 1.20 & 2.04 & $2.81 \mathrm{E}+00$ & $3.83 \mathrm{E}+02$ \\
\hline 30 & 1.00 & 1.21 & 1.20 & 1.20 & $2.63 \mathrm{E}+00$ & $9.26 \mathrm{E}+01$ \\
\hline 31 & 1.00 & 7.14 & 107.95 & 870066.87 & $1.11 \mathrm{E}+08$ & $4.39 \mathrm{E}+11$ \\
\hline 32 & 1.00 & 1.00 & 69.07 & 63.64 & $5.42 \mathrm{E}+01$ & $9.09 \mathrm{E}+06$ \\
\hline 33 & 1.00 & 1.00 & 1.91 & 1.88 & $1.29 \mathrm{E}+01$ & $6.22 \mathrm{E}+02$ \\
\hline 34 & 1.00 & 1.00 & 3.04 & 2.97 & $2.77 \mathrm{E}+00$ & $7.87 \mathrm{E}+00$ \\
\hline 35 & 1.00 & 1.00 & 1.00 & 1.01 & $3.30 \mathrm{E}+00$ & $2.32 \mathrm{E}+02$ \\
\hline
\end{tabular}


Table 36: Loss-of-life Expectancy for each transformer for scenarios 7 and 8 as a percent of Base

Case (x100)

\begin{tabular}{|c|c|c|c|c|c|c|}
\hline \multicolumn{7}{|c|}{ Scenario 7 Tx Percent Loss-Of-Life (X100) } \\
\hline \multirow[b]{2}{*}{ Tx I.D } & \multicolumn{6}{|c|}{ \% PEV Penetration } \\
\hline & & 2 & 5 & 10 & 20 & 50 \\
\hline 1 & 1.00 & 1.00 & 1.09 & 1.11 & 9.19 & $7.64 \mathrm{E}+02$ \\
\hline 2 & 1.00 & 1.05 & 1.15 & 2.06 & 23.07 & $4.57 \mathrm{E}+05$ \\
\hline 3 & 1.00 & 1.00 & 2.04 & 44.43 & 1019.81 & $2.35 \mathrm{E}+10$ \\
\hline 4 & 1.00 & 1.00 & 1.00 & 8.10 & 8.09 & $9.02 \mathrm{E}+04$ \\
\hline 5 & 1.00 & 2.00 & 2.13 & 4.69 & 73.66 & $1.41 \mathrm{E}+04$ \\
\hline 6 & 1.00 & 2.74 & 2.71 & 70.46 & 1979.23 & $1.33 \mathrm{E}+07$ \\
\hline 7 & 1.00 & 1.00 & 1.00 & 1.08 & 1.21 & $2.94 \mathrm{E}+00$ \\
\hline 8 & 1.00 & 1.00 & 1.14 & 1.12 & 1.76 & $1.94 \mathrm{E}+01$ \\
\hline 9 & 1.00 & 1.00 & 1.76 & 3.80 & 23.07 & $1.21 \mathrm{E}+06$ \\
\hline 10 & 1.00 & 1.56 & 2.60 & 2.56 & 59.43 & $1.09 E+04$ \\
\hline 11 & 1.00 & 1.17 & 2.18 & 6.92 & 233.66 & $4.34 \mathrm{E}+05$ \\
\hline 12 & 1.00 & 1.15 & 1.55 & 1.72 & 11.06 & $5.63 \mathrm{E}+03$ \\
\hline 13 & 1.00 & 1.55 & 2.17 & 20.80 & 637.08 & $4.43 \mathrm{E}+06$ \\
\hline 14 & 1.00 & 1.00 & 1.00 & 1.01 & 2.03 & $2.64 \mathrm{E}+03$ \\
\hline 15 & 1.00 & 1.00 & 1.50 & 1.84 & 2.81 & $3.19 \mathrm{E}+04$ \\
\hline 16 & 1.00 & 1.00 & 1.01 & 1.71 & 12.37 & $8.32 \mathrm{E}+02$ \\
\hline 17 & 1.00 & 1.52 & 330.15 & 330.15 & 24003.79 & $2.40 \mathrm{E}+04$ \\
\hline 18 & 1.00 & 1.41 & 1.76 & 2.16 & 13.43 & $2.27 \mathrm{E}+01$ \\
\hline 19 & 1.00 & 1.00 & 1.00 & 1.07 & 1.54 & $4.17 \mathrm{E}+00$ \\
\hline 20 & 1.00 & 1.00 & 0.99 & 20.67 & 771.39 & $1.66 \mathrm{E}+06$ \\
\hline 21 & 1.00 & 1.00 & 1.10 & 1.76 & 9.52 & $6.09 \mathrm{E}+02$ \\
\hline 22 & 1.00 & 1.00 & 1.00 & 1.79 & 1.76 & $3.14 \mathrm{E}+03$ \\
\hline 23 & 1.00 & 1.00 & 1.73 & 1.73 & 2.18 & $1.52 \mathrm{E}+02$ \\
\hline 24 & 1.00 & 1.00 & 1.01 & 2.26 & 1.70 & $4.76 \mathrm{E}+03$ \\
\hline 25 & 1.00 & 1.00 & 1.00 & 1.65 & 1.45 & $1.06 \mathrm{E}+02$ \\
\hline 26 & 1.00 & 1.00 & 1.00 & 1.00 & 1.17 & $5.35 E+00$ \\
\hline 27 & 1.00 & 1.16 & 1.23 & 1.23 & 4.65 & $4.40 \mathrm{E}+01$ \\
\hline 28 & 1.00 & 1.00 & 1.89 & 3.11 & 7.34 & 1.37E+04 \\
\hline 29 & 1.00 & 0.21 & 0.16 & 1.37 & 0.54 & $5.12 \mathrm{E}+00$ \\
\hline 30 & 1.00 & 1.09 & 1.09 & 1.14 & 1.74 & $4.97 \mathrm{E}+00$ \\
\hline 31 & 1.00 & 2.17 & 5.74 & 1081.73 & 86901.02 & $5.35 \mathrm{E}+09$ \\
\hline 32 & 1.00 & 1.00 & 3.43 & 10.09 & 9.47 & $1.67 \mathrm{E}+05$ \\
\hline 33 & 1.00 & 1.00 & 1.33 & 1.45 & 3.20 & $4.45 \mathrm{E}+01$ \\
\hline 34 & 1.00 & 1.00 & 1.40 & 1.37 & 1.72 & $6.26 \mathrm{E}+00$ \\
\hline 35 & 1.00 & 1.00 & 1.00 & 1.00 & 1.47 & $5.31 \mathrm{E}+00$ \\
\hline
\end{tabular}

\begin{tabular}{|c|c|c|c|c|c|c|}
\hline \multicolumn{7}{|c|}{ Scenario 8 Tx Percent Loss-Of-Life (X100) } \\
\hline \multirow{2}{*}{ Tx I.D } & & \multicolumn{7}{|c|}{ \%EV Penetration } \\
\hline 1 & 1.00 & 1.00 & 1.18 & 1.18 & 12.21 & $8.51 \mathrm{E}+02$ \\
\hline 2 & 1.00 & 1.10 & 1.23 & 2.81 & 30.68 & $5.08 \mathrm{E}+05$ \\
\hline 3 & 1.00 & 1.00 & 2.89 & 46.34 & 1198.23 & $3.51 \mathrm{E}+10$ \\
\hline 4 & 1.00 & 1.00 & 1.00 & 15.60 & 15.60 & $1.41 \mathrm{E}+05$ \\
\hline 5 & 1.00 & 2.00 & 7.64 & 19.82 & 482.50 & $6.29 \mathrm{E}+04$ \\
\hline 6 & 1.00 & 3.74 & 3.68 & 93.21 & 2366.80 & $1.47 \mathrm{E}+07$ \\
\hline 7 & 1.00 & 1.00 & 1.00 & 1.19 & 1.59 & $7.29 \mathrm{E}+00$ \\
\hline 8 & 1.00 & 1.00 & 1.18 & 1.23 & 2.15 & $3.03 \mathrm{E}+01$ \\
\hline 9 & 1.00 & 1.00 & 1.82 & 3.97 & 34.80 & $1.70 \mathrm{E}+06$ \\
\hline 10 & 1.00 & 2.59 & 2.69 & 2.66 & 74.61 & $1.77 \mathrm{E}+04$ \\
\hline 11 & 1.00 & 1.22 & 2.31 & 7.23 & 294.88 & $5.72 \mathrm{E}+05$ \\
\hline 12 & 1.00 & 1.38 & 1.96 & 2.23 & 17.27 & $6.31 \mathrm{E}+03$ \\
\hline 13 & 1.00 & 1.61 & 2.29 & 23.80 & 806.71 & $5.42 \mathrm{E}+06$ \\
\hline 14 & 1.00 & 1.00 & 1.01 & 1.01 & 6.78 & $5.50 \mathrm{E}+03$ \\
\hline 15 & 1.00 & 1.00 & 2.32 & 2.30 & 3.96 & $4.59 \mathrm{E}+04$ \\
\hline 16 & 1.00 & 1.00 & 1.01 & 2.27 & 15.59 & $9.97 \mathrm{E}+02$ \\
\hline 17 & 1.00 & 12.15 & 2455.87 & 2455.00 & 96321.91 & $9.63 \mathrm{E}+04$ \\
\hline 18 & 1.00 & 1.91 & 1.92 & 3.99 & 35.16 & $5.16 \mathrm{E}+01$ \\
\hline 19 & 1.00 & 1.00 & 1.00 & 1.12 & 1.94 & $6.43 \mathrm{E}+00$ \\
\hline 20 & 1.00 & 1.00 & 1.01 & 44.42 & 2167.15 & $3.27 \mathrm{E}+06$ \\
\hline 21 & 1.00 & 1.00 & 1.24 & 2.43 & 15.75 & $8.75 \mathrm{E}+02$ \\
\hline 22 & 1.00 & 1.00 & 1.00 & 2.73 & 2.67 & $3.75 \mathrm{E}+03$ \\
\hline 23 & 1.00 & 1.00 & 3.10 & 3.03 & 4.04 & $2.96 \mathrm{E}+02$ \\
\hline 24 & 1.00 & 1.00 & 1.01 & 4.54 & 3.60 & $1.95 \mathrm{E}+04$ \\
\hline 25 & 1.00 & 1.00 & 1.01 & 2.47 & 2.21 & $7.49 \mathrm{E}+02$ \\
\hline 26 & 1.00 & 1.00 & 1.00 & 1.00 & 1.29 & $6.92 \mathrm{E}+00$ \\
\hline 27 & 1.00 & 1.21 & 1.27 & 1.27 & 5.06 & $5.94 \mathrm{E}+01$ \\
\hline 28 & 1.00 & 1.00 & 2.11 & 4.00 & 9.10 & $1.99 \mathrm{E}+04$ \\
\hline 29 & 1.00 & 0.78 & 1.20 & 1.39 & 1.66 & $1.71 \mathrm{E}+01$ \\
\hline 30 & 1.00 & 1.19 & 1.20 & 1.20 & 2.16 & $7.81 \mathrm{E}+00$ \\
\hline 31 & 1.00 & 7.17 & 18.14 & 4907.95 & 326504.89 & $9.40 \mathrm{E}+09$ \\
\hline 32 & 1.00 & 1.00 & 3.65 & 15.03 & 14.08 & $2.78 \mathrm{E}+05$ \\
\hline 33 & 1.00 & 1.00 & 1.43 & 1.51 & 3.88 & $7.18 \mathrm{E}+01$ \\
\hline 34 & 1.00 & 1.00 & 1.49 & 1.59 & 2.94 & $1.30 \mathrm{E}+01$ \\
\hline 35 & 1.00 & 1.00 & 1.00 & 1.01 & 1.94 & $1.08 \mathrm{E}+01$ \\
\hline
\end{tabular}




\subsection{Stochastic Impacts}

The outcome from the stochastic analysis is calculated by finding the average of all the simulated results from the Monte Carlo process.

$$
\text { stochastic result }=\frac{\sum_{i=1}^{N} \text { result for simulation }}{N}
$$

Where $\mathrm{N}$ is the number of simulation runs (20).

Stochastic impact analysis helps predict more actual impacts of PEV on the electric distribution grid compared to the sensitivity scenario. The methodology and assumptions used for the stochastic analysis are explained in section 4.4 above.

\subsubsection{Voltage Drop}

The result from the stochastic approach predicts that at 50\% PEV penetration, about 20 percent of the households on the distribution circuit will experience below tolerable voltage levels, which is about 16 percent increase from the base case. Figure 33 illustrates that at low level PEV penetration level, a high percent of PEV owners will be affected with voltage drop issues. Keeping in mind that from the base case power flow ( $0 \%$ PEV penetration), some of the households experienced voltage issues before purchasing PEV. As determined from the sensitivity impact, the stochastic analysis also shows that majority of the PEV owners with voltage issues own fast charger. At 50 percent PEV penetration level, 73 percent of PEV owners experience voltage issues. 
Table 37: Households with Voltage Drop Issue from Stochastic Analysis

\begin{tabular}{|c|c|c|c|c|c|c|}
\hline \multicolumn{7}{|c|}{ Average \# of Residents with Voltage Drop Issues (Stochastic Analysis) } \\
\hline \% PEV Penetration & 0 & $\mathbf{2}$ & $\mathbf{5}$ & $\mathbf{1 0}$ & $\mathbf{2 0}$ & $\mathbf{5 0}$ \\
\hline \# of Households within Tolerable Voltage Range & 13 & 15.2 & 18 & 20.7 & 31.75 & 62.15 \\
\hline \# of Households Below Tolerable Voltage Range & 15 & 16.45 & 17.85 & 21.4 & 30.3 & 74.5 \\
\hline PEV Households with Voltage Drop Issues & 3 & 8.75 & 12.5 & 28.2 & 58 & 175 \\
\hline
\end{tabular}

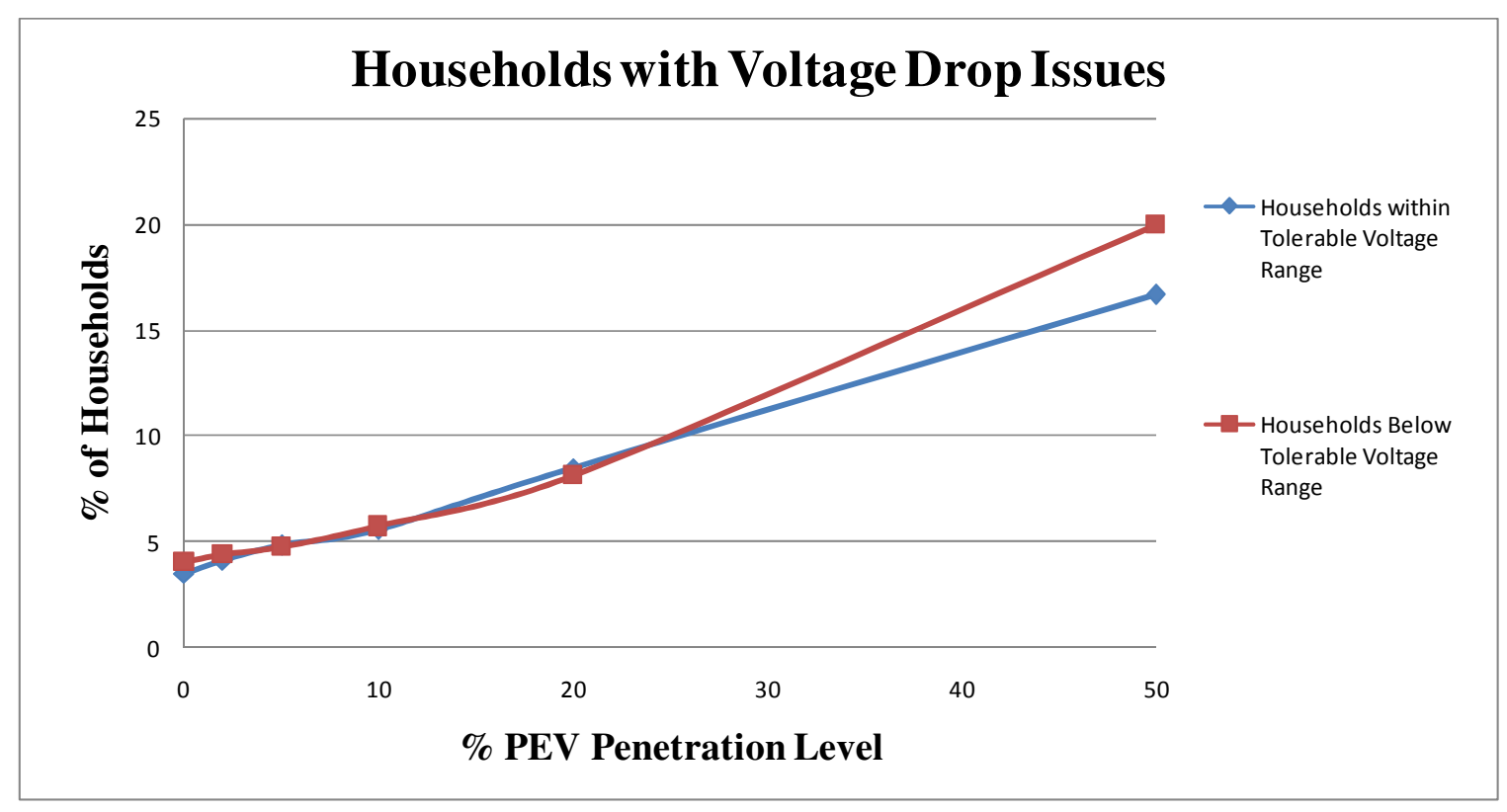

Figure 32: Percent of Households with Voltage drop issues from stochastic analysis

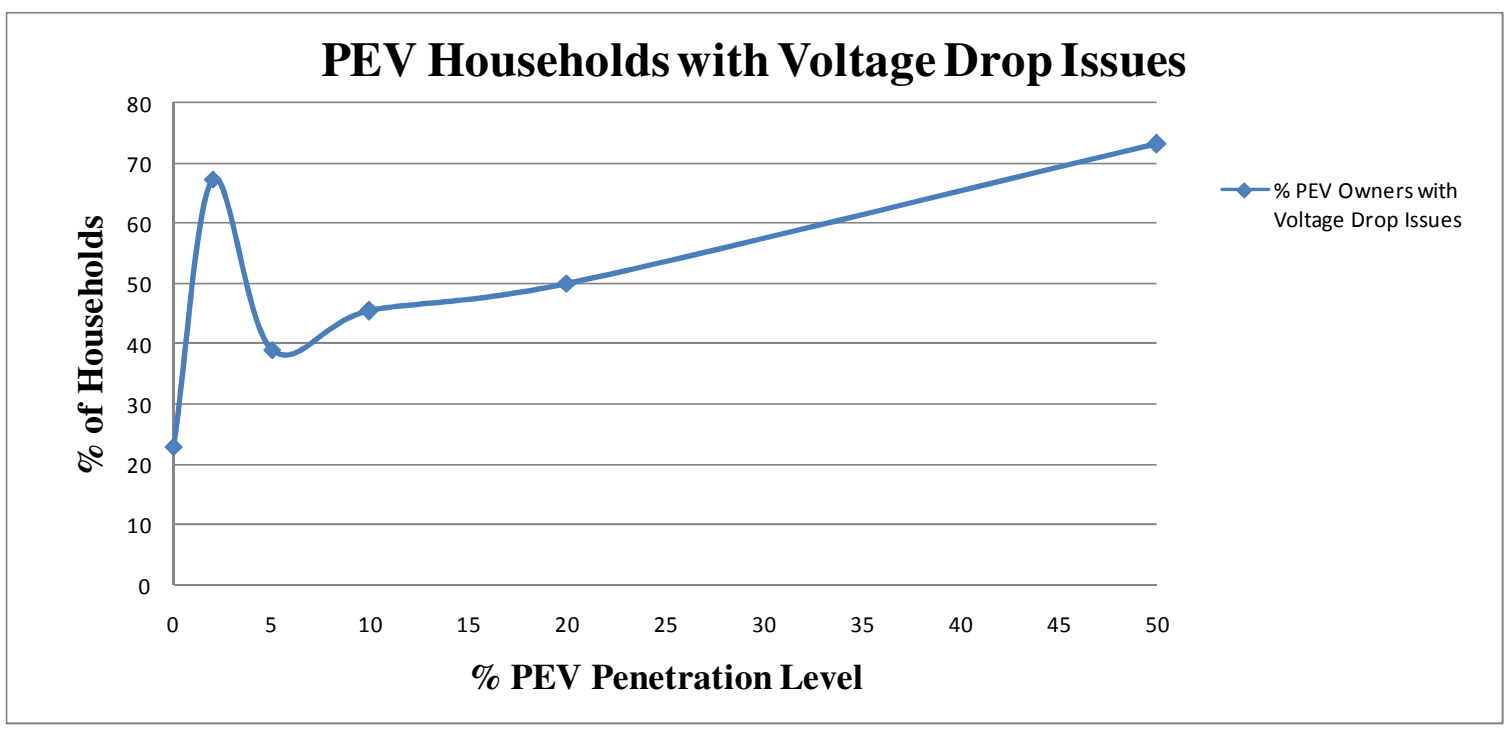

Figure 33: PEV Households with Voltage Drop Issues 
Similar to the sensitivity scenarios, note that the curve for percent of PEV owners with voltage drop issues is not linear as PEV penetration level increases. This is because the percentage is obtained from the number of households with PEV for each penetration level. For instance, at 2\% PEV penetration, about 9 households have voltage issues out of 13 households with PEV, while at 5 percent PEV penetration, about 13 households have voltage issues out of 32 households with PEV. Though the number of households with voltage issues increases with increasing PEV penetration level, the percentage of household does not increase linearly. This is because the ratio of the number of households with PEV and voltage issues to the total number of households with PEV is non-linear.

\% of PEV Households with voltage drop issues

$$
=\frac{\text { number of Households with PEV and voltage drop issues }}{\text { Total Households with PEV }} \times 100
$$

\subsubsection{Service Transformer Overloads}

Table 38 below contains the average number of service transformers that are overloaded or at risk of overload from the stochastic analysis results. As expected the number of service transformers that are either overloaded or at risk of overload increases with PEV penetration level. From base case to $50 \%$ PEV penetration level, the number of transformers at risk of overload increase from $8.5 \%$ to $33.1 \%$, while overloaded transformers increase from $2.9 \%$ to $21.6 \%$. 
Table 38: Average Transformer Overload for Stochastic Analysis

\begin{tabular}{|c|c|c|c|c|c|c|}
\hline & \multicolumn{4}{|c|}{ Average Tx Overload (Stochastic Analysis) } \\
\hline \% PEV Penetration & 0 & $\mathbf{2}$ & $\mathbf{5}$ & $\mathbf{1 0}$ & $\mathbf{2 0}$ & $\mathbf{5 0}$ \\
\hline \# of Tx at Risk of Overload (Average) & $\mathbf{3}$ & 3.35 & 3.5 & 3.8 & 6.45 & 11.6 \\
\hline \# of Overloaded Tx (Average) & 1 & 1.05 & 1.4 & 1.75 & 2.5 & 7.55 \\
\hline
\end{tabular}

$\%$ of overloaded service transformers

$$
=\frac{\text { number of transformer loaded above emergency }}{\text { total number of transformers }} \times 100
$$

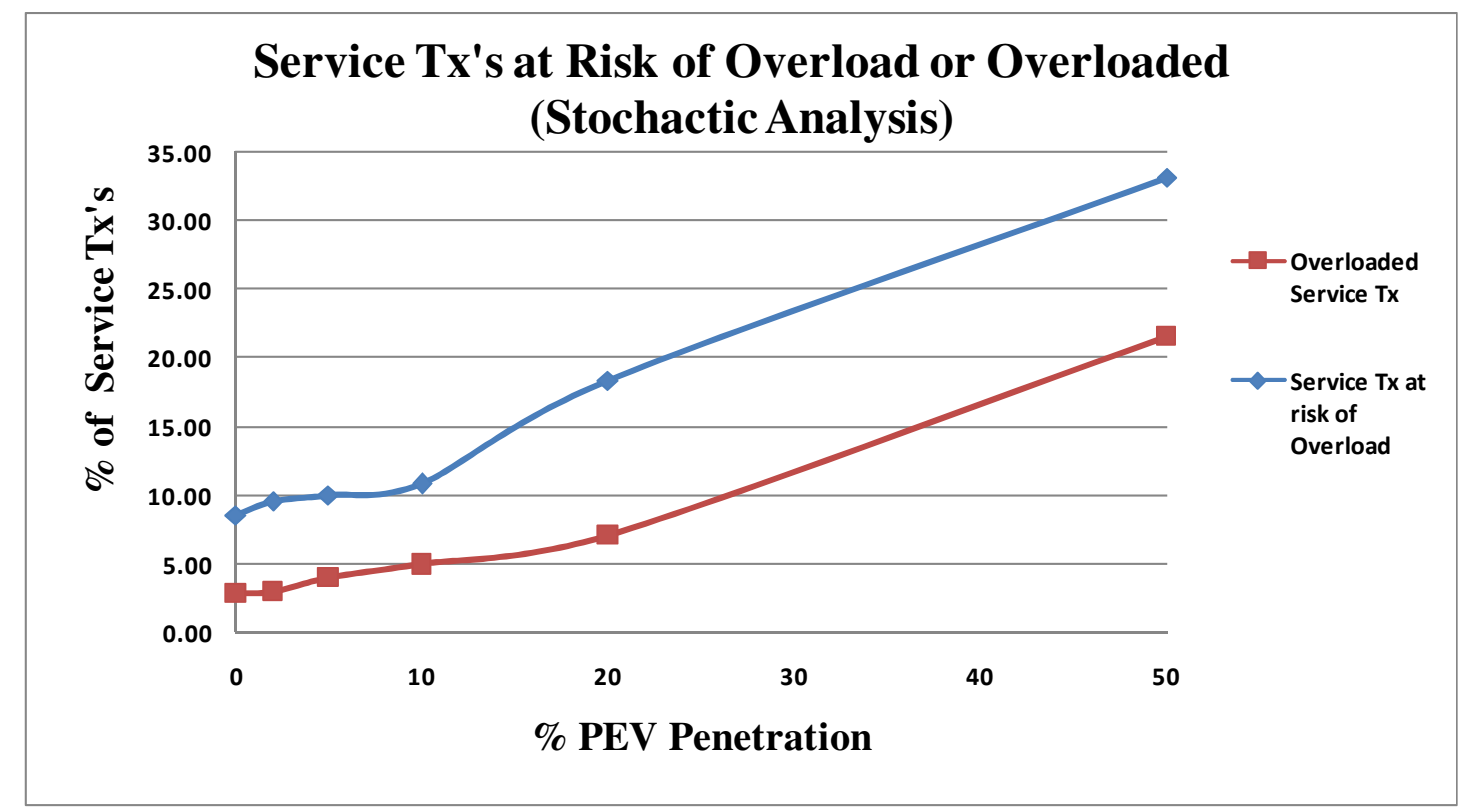

Figure 34: Percent Transformer Overloads from Stochastic Analysis

Table 39 shows the average number of transformer overloads by kVA. In

alignment with the results from the sensitivity analysis, the stochastic approach predicts that the low rated transformers $(10 \mathrm{kVA})$ are more susceptible to overload conditions. The $75 \mathrm{kVA}$ transformer overloads because it serves about 34 households and 36 PEVs at 50\% penetration level. 
Table 39: Percent of Service Transformer Overload by kVA rating for Stochastic Analysis

\begin{tabular}{|c|c|c|c|c|c|c|c|}
\hline \multirow{2}{*}{ Tx kVA } & & & \multicolumn{5}{|c|}{ Average Tx Overloads by kVA (Stochastic Analysis) } \\
\cline { 4 - 8 } & Count & Base Case & $\mathbf{2}$ & $\mathbf{5}$ & $\mathbf{1 0}$ & $\mathbf{2 0}$ & $\mathbf{5 0}$ \\
\hline 10 & 3 & 33.33 & 35.00 & 46.67 & 46.67 & 55.00 & 63.33 \\
\hline 15 & 3 & 0.00 & 0.00 & 0.00 & 0.00 & 0.00 & 48.33 \\
\hline 25 & 15 & 0.00 & 0.00 & 0.00 & 2.33 & 5.67 & 28.00 \\
\hline 50 & 13 & 0.00 & 0.00 & 0.00 & 0.00 & 0.00 & 0.00 \\
\hline 75 & 1 & 0.00 & 0.00 & 0.00 & 0.00 & 0.00 & 90.00 \\
\hline
\end{tabular}

\subsubsection{Service Transformer Loss-of-Life Expectancy}

Average hours of Tx at risk of overload $=\frac{\sum_{j=1}^{N} \sum_{i=1}^{M} \text { hours within risk of overload }}{\text { Total hours within } 7 \text { months of simulation } \times N}$

Where $\mathrm{M}$ is the number of service transformers and $\mathrm{N}$ is the number of simulation runs.

$\%$ transformer loss of life as a percent of base case

$$
=\frac{\text { transformer loss of live at PEV penetration level }}{\text { transformer loss of life at base case }} \times 100
$$

Table 40: Average Hours of Service Transformers Overload or at Risk of Overload (For 7 Months)

\begin{tabular}{|c|c|c|c|c|c|c|}
\hline \multicolumn{6}{|c|}{ Average Hours of all Service Tx at Risk of Overload or Overloaded As a Percent of Base Case } \\
\hline \% PEV Penetration & 0 & 2 & 5 & 10 & 20 & 50 \\
\hline At Risk of Overload & 100.00 & 105.36 & 169.17 & 425.02 & 901.77 & 3095.88 \\
\hline Overloaded & 100.00 & 101.85 & 108.48 & 272.17 & 828.48 & 5438.37 \\
\hline
\end{tabular}




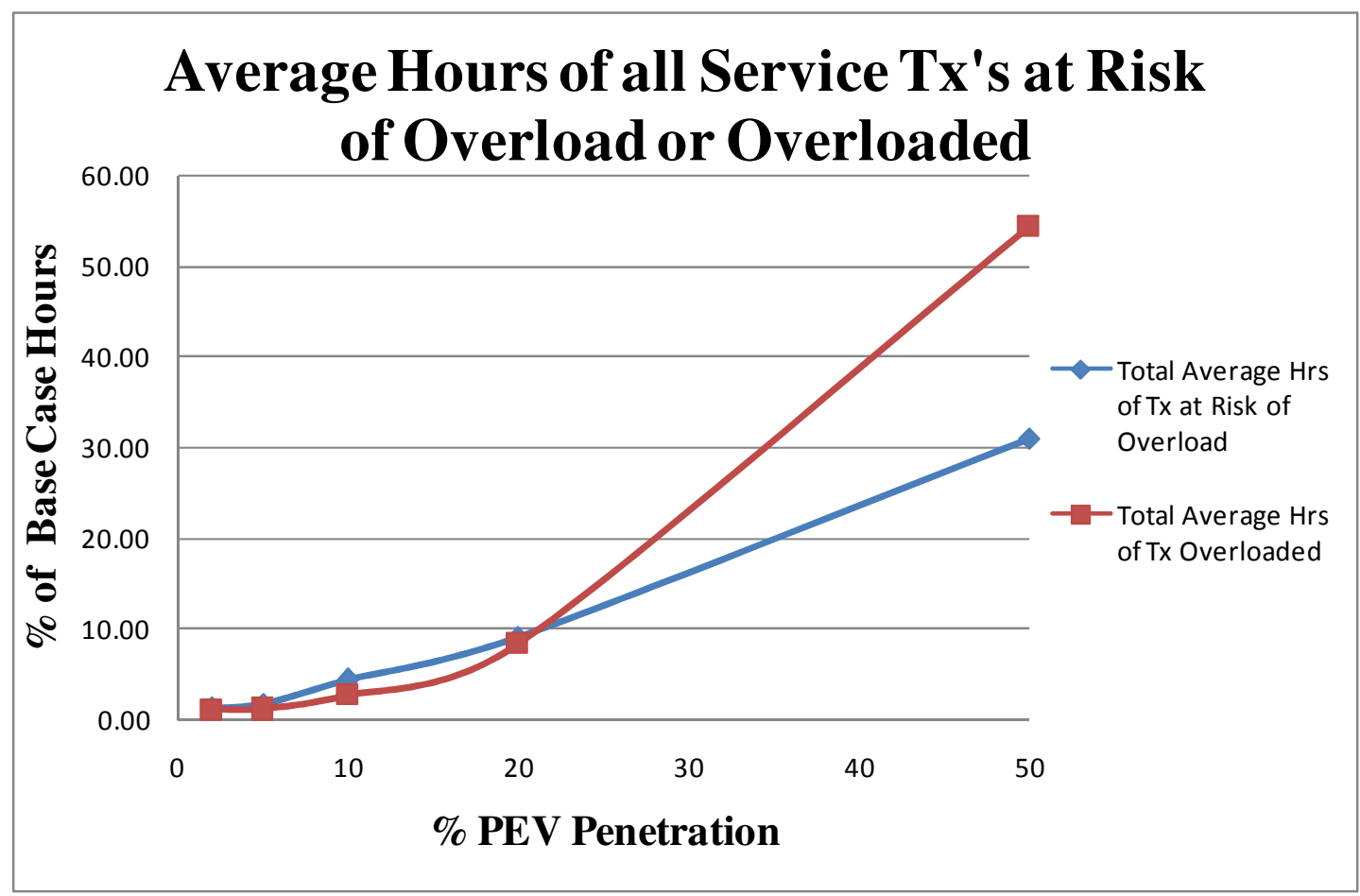

Figure 35: Average Hours of Service Transformers Overload or at Risk of Overload as a Percent of the Base Case

Table 40 and figure 35 show the average hours of transformers at risk of overload or overloaded as a percent of the base case. The total hours which the transformers are loaded above nameplate rating are reflected on the results for the loss-of-life calculation shown in table 41 below. At higher PEV penetration, services transformers are more likely to be overloaded than to be at risk of overload. Small size transformers with PEV load lose their life expectancy at greater than $200 \%$ rate of their base case at low PEV penetration level. The table showing the transformers by size and number of connected PEV is shown in table 42 of the appendix section. Results from both the stochastic and sensitivity approach show that transformer life expectancy will be greatly impacted by PEV load consumption, especially small size transformers. 
Table 41: Transformer Loss-of-Life Expectancy for Stochastic approach

\begin{tabular}{|c|c|c|c|c|c|c|}
\hline \multicolumn{7}{|c|}{ Tx Percent Loss-Of-Life for Stochastic Analysis (x100) } \\
\hline \multirow{2}{*}{ Tx I.D } & \multicolumn{7}{|c|}{$\%$ PEV Penetration } \\
\cline { 2 - 7 } & & 2 & 5 & 10 & 20 & 50 \\
\hline 1 & 1.00 & 20.00 & 22.11 & 21.84 & 68.05 & $4.93 \mathrm{E}+02$ \\
\hline 2 & 1.00 & 20.75 & 21.95 & 32.15 & 60.25 & $1.30 \mathrm{E}+04$ \\
\hline 3 & 1.00 & 20.01 & 82.87 & 329.59 & 29960.11 & $5.50 \mathrm{E}+08$ \\
\hline 4 & 1.00 & 20.00 & 20.00 & 2115.90 & 3446.12 & $3.99 \mathrm{E}+07$ \\
\hline 5 & 1.00 & 42.20 & 41.61 & 93.52 & 360.80 & $2.61 \mathrm{E}+05$ \\
\hline 6 & 1.00 & 35.78 & 44.91 & 153.52 & 1877.49 & $2.52 \mathrm{E}+06$ \\
\hline 7 & 1.00 & 20.00 & 20.00 & 21.62 & 24.09 & $4.11 \mathrm{E}+01$ \\
\hline 8 & 1.00 & 20.00 & 21.92 & 22.23 & 29.25 & $8.26 \mathrm{E}+01$ \\
\hline 9 & 1.00 & 20.02 & 34.75 & 68.36 & 252.55 & $8.72 \mathrm{E}+05$ \\
\hline 10 & 1.00 & 33.09 & 26.59 & 30.21 & 219.09 & $2.46 \mathrm{E}+04$ \\
\hline 11 & 1.00 & 23.26 & 30.56 & 43.42 & 177.86 & $1.37 \mathrm{E}+04$ \\
\hline 12 & 1.00 & 21.90 & 26.64 & 26.64 & 113.76 & $1.60 \mathrm{E}+03$ \\
\hline 13 & 1.00 & 25.74 & 30.25 & 58.73 & 290.26 & $1.61 \mathrm{E}+04$ \\
\hline 14 & 1.00 & 20.04 & 20.11 & 20.20 & 83.11 & $1.46 \mathrm{E}+04$ \\
\hline 15 & 1.00 & 20.03 & 36.33 & 36.63 & 31.92 & $7.43 \mathrm{E}+04$ \\
\hline 16 & 1.00 & 20.04 & 20.09 & 36.86 & 162.57 & $1.55 \mathrm{E}+03$ \\
\hline 17 & 1.00 & 178.38 & 5166.39 & 5075.43 & 130032.32 & $1.11 \mathrm{E}+05$ \\
\hline 18 & 1.00 & 29.35 & 31.76 & 36.54 & 156.86 & $3.87 \mathrm{E}+02$ \\
\hline 19 & 1.00 & 20.00 & 20.00 & 21.47 & 26.44 & $4.14 \mathrm{E}+01$ \\
\hline 20 & 1.00 & 20.00 & 19.99 & 312.63 & 6263.82 & $1.33 \mathrm{E}+06$ \\
\hline 21 & 1.00 & 20.00 & 22.16 & 27.87 & 49.92 & $3.38 \mathrm{E}+02$ \\
\hline 22 & 1.00 & 20.00 & 20.01 & 53.61 & 36.56 & $5.92 \mathrm{E}+04$ \\
\hline 23 & 1.00 & 19.98 & 34.63 & 39.60 & 41.65 & $1.68 \mathrm{E}+03$ \\
\hline 24 & 1.00 & 20.03 & 20.07 & 33.54 & 43.91 & $2.16 \mathrm{E}+04$ \\
\hline 25 & 1.00 & 20.03 & 20.09 & 37.33 & 45.63 & $4.69 \mathrm{E}+03$ \\
\hline 26 & 1.00 & 20.00 & 20.01 & 20.01 & 23.65 & $7.20 \mathrm{E}+01$ \\
\hline 27 & 1.00 & 22.50 & 22.36 & 22.35 & 51.27 & $1.53 \mathrm{E}+02$ \\
\hline 28 & 1.00 & 20.02 & 33.18 & 33.13 & 73.35 & $3.98 \mathrm{E}+04$ \\
\hline 29 & 1.00 & 18.49 & 13.66 & 22.32 & 35.01 & $7.17 \mathrm{E}+01$ \\
\hline 30 & 1.00 & 21.91 & 21.61 & 21.95 & 26.19 & $4.90 \mathrm{E}+01$ \\
\hline 31 & 1.00 & 30.30 & 137.15 & 3442.25 & 19793.42 & $1.98 \mathrm{E}+08$ \\
\hline 32 & 1.00 & 20.01 & 58.82 & 64.28 & 60.61 & $1.40 \mathrm{E}+04$ \\
\hline 33 & 1.00 & 20.00 & 25.26 & 24.25 & 32.26 & $7.51 \mathrm{E}+01$ \\
\hline 34 & 1.00 & 20.01 & 29.67 & 29.67 & 25.17 & $5.76 \mathrm{E}+01$ \\
\hline 35 & 1.00 & 20.01 & 20.03 & 20.06 & 29.89 & $1.87 \mathrm{E}+02$ \\
\hline
\end{tabular}




\section{SUMMARY OF FINDINGS, RECOMMENDATIONS, FUTURE STUDIES}

\subsection{Summary of Findings}

The study finds that PEVs are likely to impact both PEV owners and utility infrastructures. At lower PEV penetration level, PEV owners with fast chargers are likely to experience voltage drop issues. In addition, PEV owners located farther from the service transformer, and with fast chargers, are even more susceptible to voltage drop issues because of the power losses in the service lines. However, systemwide voltage drop concerns should be expected at higher PEV penetration levels.

While the base loading of transformers without PEV load is crucial, small size service transformers with PEVs are more likely to be overloaded in the short term. Additional PEV loads are likely to deteriorate service transformer life expectancy by over $200 \%$ at higher penetration level. Small size transformers with PEVs loads lose their life expectancy by over $200 \%$ at lower PEV penetration. Finally, slow chargers and fast chargers increase energy losses on the circuit over time compared to middle sized chargers. 


\subsection{Recommendations}

\subsubsection{Smart Charging}

- $\quad$ PEV chargers and EVSE (Electric Vehicle Supply Equipment) with programmable capability would help PEV owners set timers for charge time and charge rate. This functionally allows off peak charging of PEVs and could possibly prevent overloading of distribution service transformers. If all PEVs were to charge at the same off-peak time, it could lead to variation in load profile and possibly new peak time. Utility should be aware of the possible effect of uncontrolled charging.

- Utility control capability allows utilities to control the time and rate at which PEVs are charged, especially during overnight charging. The remote control capability would be performed by operators with access to real time monitoring data of distribution transformers. This capability would be valuable for utilities especially during high PEV penetration levels.

\subsubsection{Rates/Energy pricing}

- $\quad$ TOU (Time-of-Use) rates could serve as an effective tool to manage the PEV charging. A TOU schedule offers reduced rates per $\mathrm{kWh}$ on a pro-rated basis for off-peak charging, with incremental increases for vehicle charging during partial peak and on peak demand times. Many utilities now offer TOU rates to customers. Each PEV TOU tariff is either for a bundled household and vehicle 
load, or just a segregated vehicle load. This segregated vehicle load rate requires separate metering.

- Demand Response (DR) is another potential dynamic benefit related to PEV load. With DR, the utility may be able to interrupt PEV demand during high demand hours to mitigate PEV load impacts [15].

\subsubsection{Distribution Infrastructure Upgrade}

- $\quad$ Another method which utilities could employ to mitigate the voltage drop conditions is by adopting service transformers with tap changer and upgrading the size of secondary and service lines. This would help boost the voltage level at the secondary side of the transformer and reduce losses on the secondary and service lines.

\subsubsection{Effective Interaction between Utilities and Customers}

- $\quad$ Effective and efficient communication medium between customers and utilities would help customers to inform the utilities about their intention to purchase PEVs. This allows the utilities to initiate plans to accommodate the new PEV load. Utility response to this issue could include increasing the size of service transformer, installing a new transformer next to the customer, or increasing the size of the secondary and service conductor.

\subsection{Future Studies}

- Harmonics Impact of PEVs on Distribution Transformers should be of concern to utilities due to the non linear characteristics of the power converters of 
the PEV chargers. Upcoming PHEV charging technologies may contribute to high harmonic distortion in the distribution systems during simultaneous charging periods. According to the California Energy Commission Public Energy Report [16], a battery charger's input current total harmonic distortion (THD) may vary from $2.36 \%$ to $28 \%$ through a charging cycle. Harmonic effects from PEV chargers may cause overloads of distribution equipments like transformers, cables, breakers, and fuses [17].

- $\quad$ V2G (Vehicle to Grid) and G2V (Grid to Vehicle) modes of operation allow PEVs to operate as a load, distributed energy storage, or stand alone energy source. Various applications of V2G mode of operation that need to be further explored include peak shaving, electric service reliability, communication requirements, ancillary services such as voltage support, scheduling and dispatch, and load following. 


\section{CONCLUSION}

Electric vehicles offer various benefits like reducing green house gases and dependency on fossil fuels. Some studies also prove that PEVs are more economical than gasoline engines. While PEV offers great benefits, the short term and long term impacts of PEV charging on the electric distribution system should be of concern to PEV owners and utility industries. This study concludes that the type of PEV charger used is more likely to contribute to voltage drop than the time of plug-in. PEV owners with fast chargers are susceptible to low voltage conditions even at low PEV penetration levels. At higher penetration levels, PEV loads are likely to cause low voltage levels at the secondary side of the service transformer. For non-PEV owners connected to the same service transformer as PEV owners, the low voltage at the secondary side of the transformer coupled with the voltage drop from their service lines will increase the likelihood of voltage drop issues as well. Utilities should also be aware of the impacts of PEVs on service transformers. While the chances of service transformer overload depend on the number of connected customers and number of PEVs, smaller size transformers are more likely to overload even at low penetration levels. In addition, at high PEV penetration level, the number of overloaded transformers drastically depends on the type of PEV charger.

PEVs significantly affect the life expectancy of service transformers, especially at high penetration levels. In some cases, $\mathrm{PEV}$ s reduce the life expectancy of transformers already serving household loads by over $200 \%$. Even in the short term, the life expectancy of small size transformers with PEV loads significantly deteriorates. Utilities 
should take note of the number of customers and number of connected PEVs for each service transformer.

Communication medium should be established between customers and utilities for customers to inform utilities about their plans to purchase PEVs. This would help the utilities better prepare for the additional load. Utilities should consider increasing the size of service transformers with PEV loads or installing new service transformers next to households with PEV. In some cases, it would be beneficial to use transformers with tap changers, or upgrade the sizes of secondary and service lines to reduce voltage drop.

Overall, in the short term, PEVs are likely to create voltage drop issues for customers with PEVs only and overload small size service transformers with fast chargers. However, systemwide impact of PEVs on the distribution infrastructures and all households, including PEV owners and non-PEV owners, should be of concern in the long term at higher penetration level. 


\section{BIBLIOGRAPHY}

[1] C. H. Stephan and J. Sullivan. Environmental and energy implications of plug-in hybrid-electric vehicles. Environ. Sci. Technol. 42(4), pp. 1185-1190, 2008.

[2] J. Salihi, "Eenrgy Requiremnts for Electric Cars and Their Impact on Electric Power Generation and Distribution Systems" IEEE Transaction on Industry Application, vol. 9, No. 5, pp. 516-532, Sept/Oct 1973.

[3] KEMA, Inc. and ISO/RTO Council, (2010), "Assessment of plug-in electric vehicle integration with ISO/RTO Systems.” Retrieved from http://www.isorto.org/site/c.jhKQIZPBImE/b.2604461/k.6151/Documents_and_Issues.ht $\underline{\mathrm{m}}$

[4] "Environmental Assessment of Plug-in Hybrid Electric Vehicles Volume 1: Nationwide Greenhouse Gas Emissions,” EPRI TR-1015325, July 2007.

[5] Open Distribution Simulator Software (OpenDSS) Media Brief, 2011. Retrieved from http://www.electricenergyonline.com/?page=show_news\&id=104572

[6] J. Gonder, A. Simpson., "Measuring and Reporting Fuel Economy of Plug-in Hybrid Electric Vehicles,” National Renewable Energy Laboratory, pp 4 - 5, November 2006.

[7] A. Simpson., "Cost-Benefit Analysis of plug-in Hybrid Electric Vehicle Technology," National Renewable Energy Laboratory, pp 62 - 63, November 2006.

[8] L. Kelly., "Probabilistic Modeling of Plug in Hybrid Electric Vehicle Impacts on Distribution Networks in British Columbia," pp 82 - 83, 2005.

[9] PacifiCorp Engineering Hand book, 1C.2.1 - Voltage Level and Range, June 2004. Retrieved from http://www.rockymountainpower.net/content/dam/pacific_power/doc/Contractors_Suppli ers/Power_Quality_Standards/1C_2_1.pdf

[10] E. Benedict, T. Collins, D. Gotham, S. Hoffman, D. Karipides, S. Pekarek, and R. Ramabhadran., "Losses in Electric Power Systems," pp 15 - 17, December 1992.

[11]What is Sensitivity Analysis? April 2009, Retrieved from http://www.medicine.ox.ac.uk/bandolier/painres/download/whatis/What_is_sens_analy.p $\underline{\mathrm{df}}$

[12] J. Perez., "Fundamental Principles of Transformer thermal loading and protection," pp 1 - 4, May 2010. 
[13] EPRI, M. Duvall, M. Alexander., "Transportation Electrification, A Technology Overview," pp 46, 2011.

[14] P.K. Sen, S. Pansuwan, K. Malmedal., "Transformer overloading and assessment of loss of life for liquid-filled transformers (PSERC)," pp 35 - 40, February 2011.

[15] J. Perez., "Fundamental Principle of Transformer Thermal Loading and Protection," pp 5-8, 2010.

[16] M. M. Morcos, C. R. Mersman, G. D. Sugavanam, and N. M. Diliman., "Battery chargers for electric vehicles," IEEE Power Engineering Review, vol. 20, no. 11, pp. 811, Nov. 2000.

[17] J. C. Gomez and M. M. Morcos, "Impact of EV battery chargers on the power quality of distribution systems," IEEE Transactions on Power Delivery, vol. 18, no. 3, pp. 975-981, July 2003

[18] J. J. Winders, Jr, "Power Transformers, Principles and Applications," pp. 114-116, 2002 


\section{APPENDICES}

\section{Connected PEV to each Service Transformer at Increasing PEV}

\section{Penetration Level}

Table 42: Number of Connecter PEV to each Service Transformer at increasing PEV Penetration level

\begin{tabular}{|c|c|c|c|c|c|c|}
\hline \multirow[b]{2}{*}{$\mathrm{Tx} \#$} & \multirow[b]{2}{*}{ Size (kVA) } & \multicolumn{5}{|c|}{ Number of Connected PEV } \\
\hline & & $2 \%$ & $5 \%$ & $10 \%$ & $20 \%$ & $50 \%$ \\
\hline 1 & 50 & 0 & 1 & 1 & 9 & 16 \\
\hline 2 & 75 & 1 & 2 & 7 & 13 & 36 \\
\hline 3 & 15 & 0 & 1 & 2 & 4 & 10 \\
\hline 4 & 10 & 0 & 0 & 2 & 2 & 4 \\
\hline 5 & 25 & 1 & 1 & 2 & 3 & 7 \\
\hline 6 & 25 & 1 & 1 & 3 & 6 & 13 \\
\hline 7 & 50 & 0 & 0 & 1 & 2 & 6 \\
\hline 8 & 50 & 0 & 1 & 1 & 3 & 8 \\
\hline 9 & 25 & 0 & 1 & 2 & 3 & 12 \\
\hline 10 & 25 & 1 & 1 & 1 & 3 & 8 \\
\hline 11 & 50 & 1 & 3 & 5 & 9 & 20 \\
\hline 12 & 50 & 1 & 2 & 2 & 6 & 14 \\
\hline 13 & 50 & 2 & 3 & 6 & 9 & 19 \\
\hline 14 & 25 & 0 & 0 & 0 & 2 & 9 \\
\hline 15 & 25 & 0 & 1 & 1 & 1 & 10 \\
\hline 16 & 25 & 0 & 0 & 1 & 3 & 5 \\
\hline 17 & 10 & 1 & 2 & 2 & 3 & 3 \\
\hline 18 & 25 & 1 & 1 & 1 & 2 & 3 \\
\hline 19 & 50 & 0 & 0 & 1 & 4 & 7 \\
\hline 20 & 10 & 0 & 0 & 2 & 4 & 9 \\
\hline 21 & 50 & 0 & 1 & 3 & 6 & 11 \\
\hline 22 & 15 & 0 & 0 & 1 & 1 & 4 \\
\hline 23 & 25 & 0 & 1 & 1 & 1 & 5 \\
\hline 24 & 15 & 0 & 0 & 1 & 1 & 5 \\
\hline 25 & 25 & 0 & 0 & 1 & 1 & 5 \\
\hline 26 & 50 & 0 & 0 & 0 & 1 & 6 \\
\hline 27 & 50 & 1 & 1 & 1 & 5 & 9 \\
\hline 28 & 25 & 0 & 1 & 1 & 2 & 8 \\
\hline 29 & 50 & 0 & 0 & 2 & 3 & 10 \\
\hline 30 & 50 & 1 & 1 & 1 & 3 & 7 \\
\hline 31 & 25 & 1 & 2 & 6 & 9 & 19 \\
\hline 32 & 25 & 0 & 2 & 2 & 2 & 7 \\
\hline 33 & 50 & 0 & 2 & 2 & 4 & 8 \\
\hline 34 & 25 & 0 & 1 & 1 & 1 & 2 \\
\hline 35 & 25 & 0 & 0 & 0 & 1 & 3 \\
\hline \multicolumn{2}{|c|}{ Total PEV } & 13 & 33 & 66 & 132 & 328 \\
\hline
\end{tabular}


Table 43: Number of Connected Household to each Service Transformer

\begin{tabular}{|c|c|c|c|}
\hline Transformer \# & KVA & $\begin{array}{l}\text { Connected } \\
\text { Customers }\end{array}$ & KVA/Customer \\
\hline 1 & 50 & 16 & 3.13 \\
\hline 2 & 75 & 34 & 2.21 \\
\hline 3 & 15 & 15 & 1.00 \\
\hline 4 & 10 & 2 & 5.00 \\
\hline 5 & 25 & 11 & 2.27 \\
\hline 6 & 25 & 8 & 3.13 \\
\hline 7 & 50 & 10 & 5.00 \\
\hline 8 & 50 & 15 & 3.33 \\
\hline 9 & 25 & 14 & 1.79 \\
\hline 10 & 25 & 8 & 3.13 \\
\hline 11 & 50 & 15 & 3.33 \\
\hline 12 & 50 & 18 & 2.78 \\
\hline 13 & 50 & 17 & 2.94 \\
\hline 14 & 25 & 17 & 1.47 \\
\hline 15 & 25 & 13 & 1.92 \\
\hline 16 & 25 & 6 & 4.17 \\
\hline 17 & 10 & 3 & 3.33 \\
\hline 18 & 25 & 5 & 5.00 \\
\hline 19 & 50 & 8 & 6.25 \\
\hline 20 & 10 & 7 & 1.43 \\
\hline 21 & 50 & 9 & 5.56 \\
\hline 22 & 15 & 4 & 3.75 \\
\hline 23 & 25 & 5 & 5.00 \\
\hline 24 & 15 & 8 & 1.88 \\
\hline 25 & 25 & 7 & 3.57 \\
\hline 26 & 50 & 11 & 4.55 \\
\hline 27 & 50 & 13 & 3.85 \\
\hline 28 & 25 & 11 & 2.27 \\
\hline 29 & 50 & 12 & 4.17 \\
\hline 30 & 50 & 9 & 5.56 \\
\hline 31 & 25 & 16 & 1.56 \\
\hline 32 & 25 & 10 & 2.50 \\
\hline 33 & 50 & 7 & 7.14 \\
\hline 34 & 25 & 2 & 12.50 \\
\hline \multirow[t]{2}{*}{35} & 25 & 7 & 3.57 \\
\hline & 1175 & 373 & \\
\hline
\end{tabular}




\section{PEV Location on the Electric Distribution Circuit at Increasing \\ Penetration level}

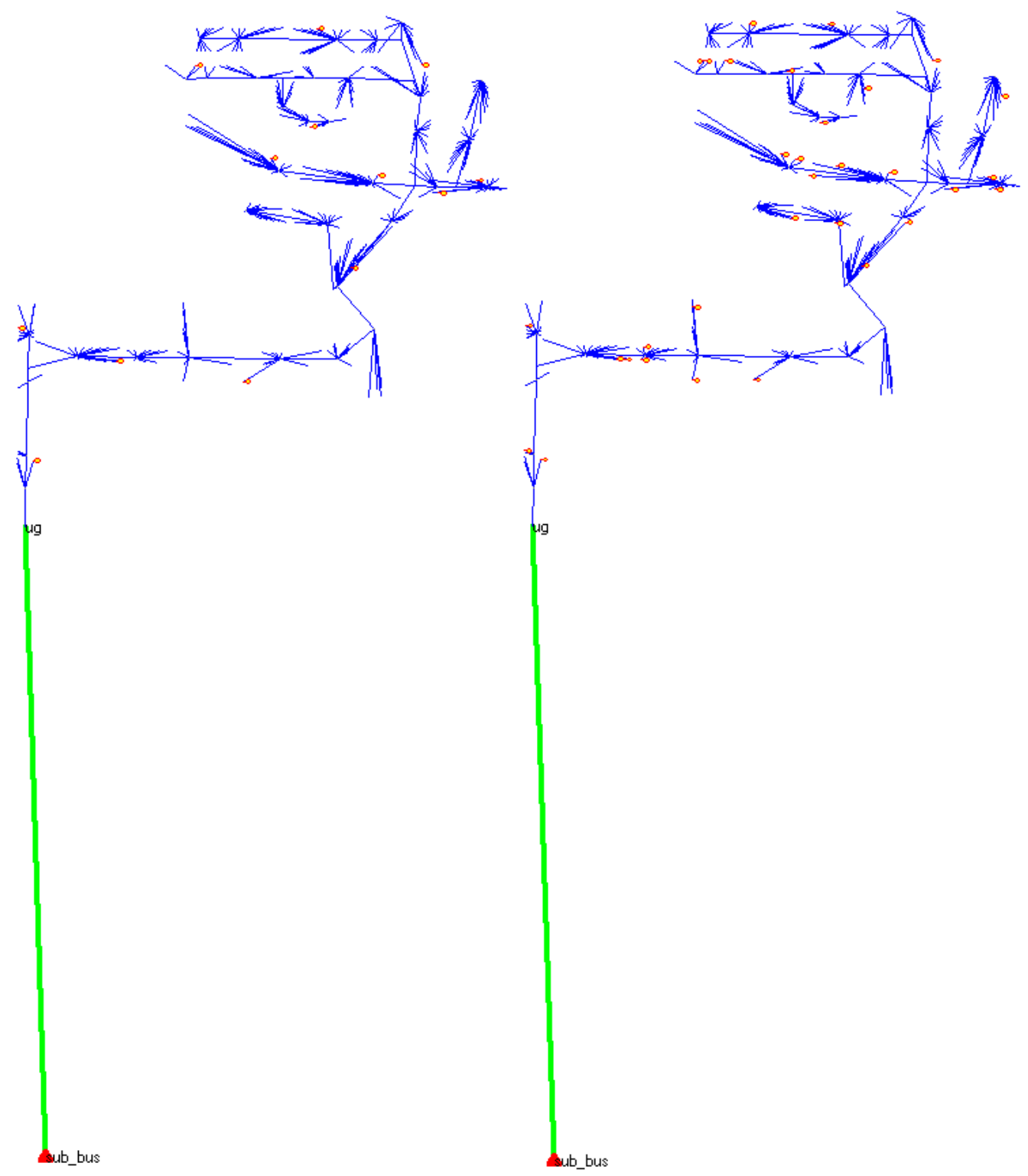

Figure 36: PEV Locations on the Distribution circuit at 2\% and 5\% Penetration Level 


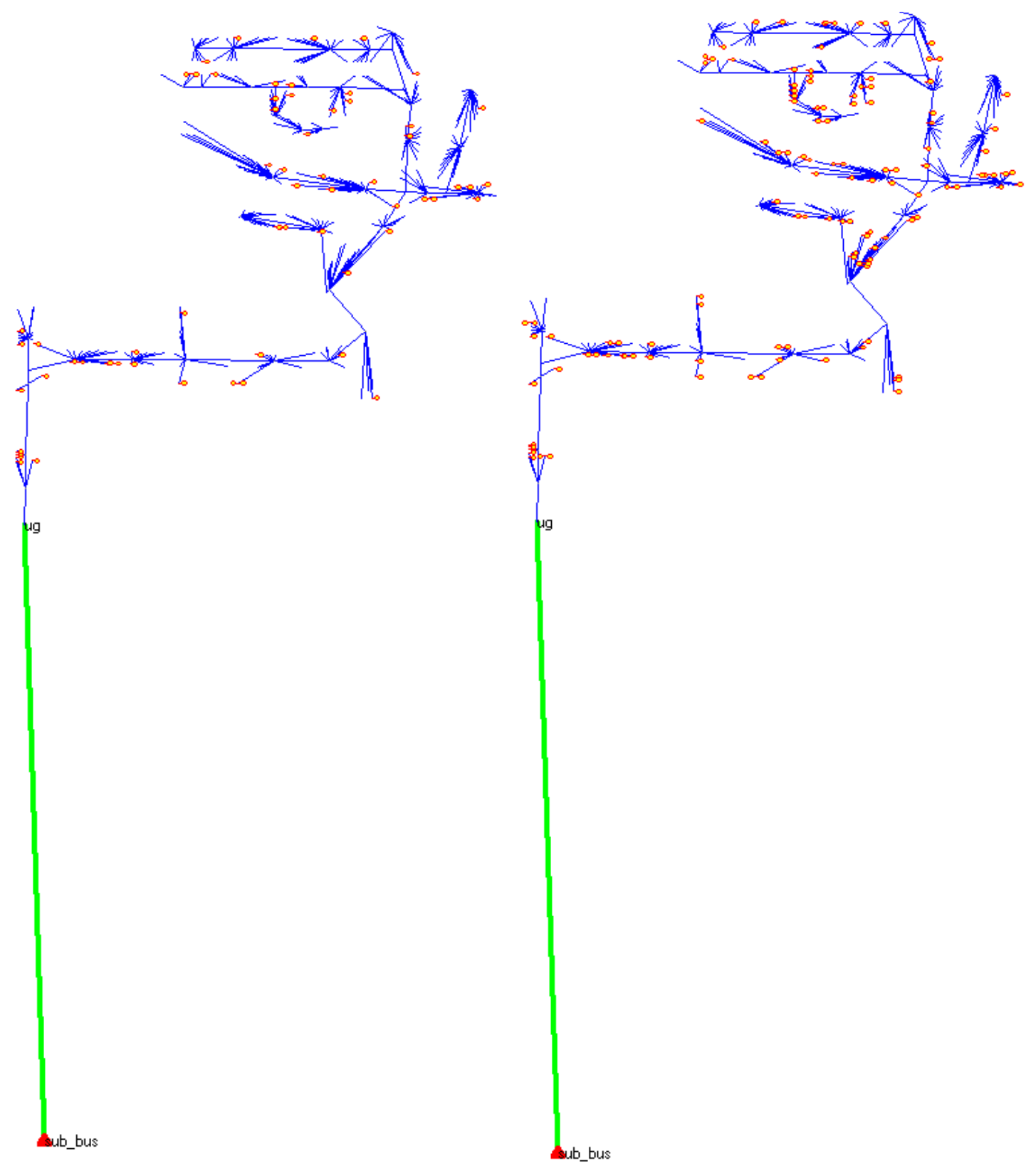

Figure 37: PEV Locations on the Distribution Circuit at $10 \%$ and $20 \%$ Penetration Level 


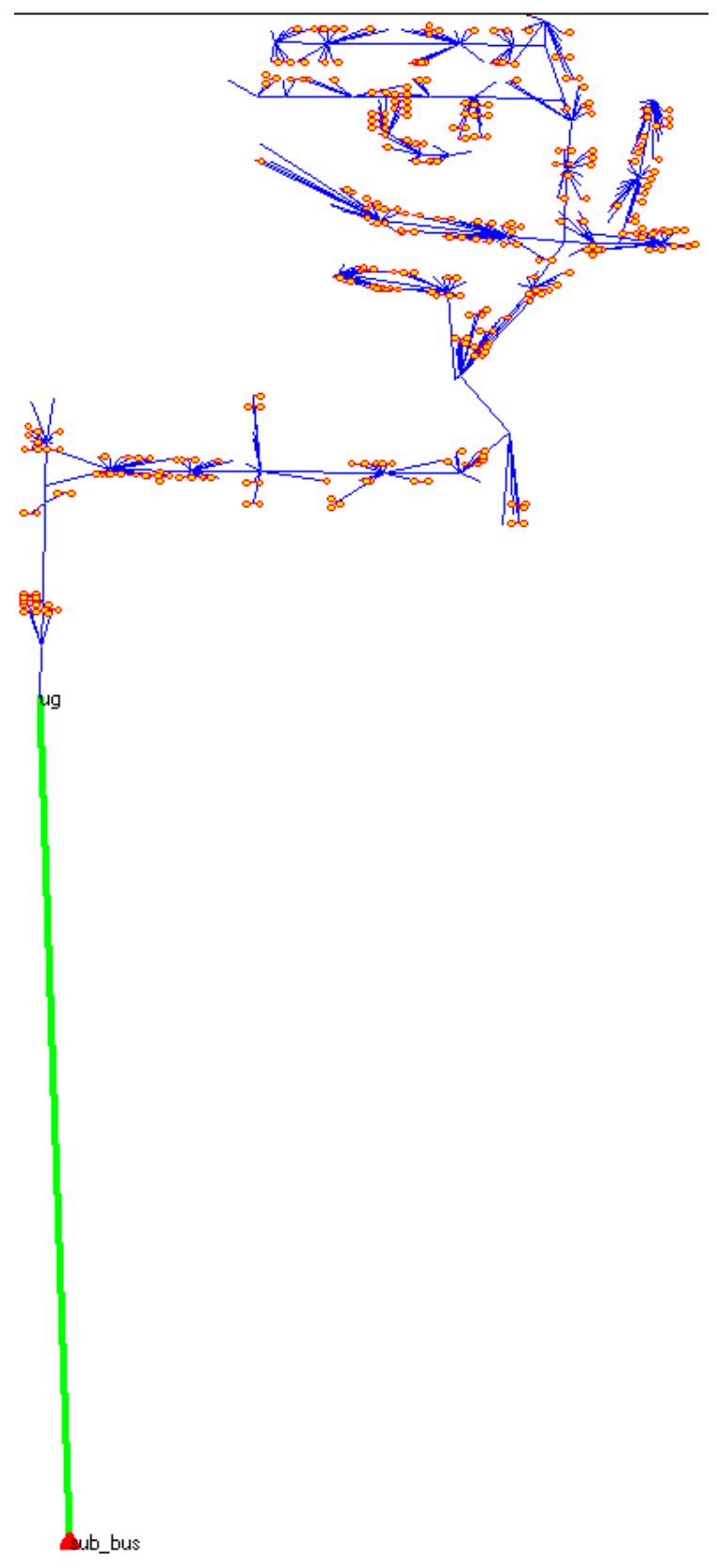

Figure 38: PEV Locations on the Distribution Circuit at 50\% Penetration Level 


\section{Nomenclature}

\begin{tabular}{|c|c|}
\hline PEV & Plug-in Electric Vehicle \\
\hline UG & Under Ground \\
\hline $\mathrm{OH}$ & Over Head \\
\hline ACSR & Aluminum Conductor Steel Reinforced \\
\hline SOC & State of Charge \\
\hline NHTS & National Household Travel Survey \\
\hline Tx & Transformer \\
\hline $\mathrm{HEV}$ & Hybrid Electric Vehicle \\
\hline $\mathrm{CV}$ & Conventional Vehicle \\
\hline UL & Underwriters Laboratories \\
\hline IC & Internal Combustion \\
\hline EPRI & Electric Power Research Institute \\
\hline OpenDSS & Open Distribution System Simulator \\
\hline ISO & Independent System Operator \\
\hline SCADA & Supervisory Control and Data Acquisition \\
\hline \# & Number \\
\hline AMI & Advanced Metering Infranstructure \\
\hline $\mathrm{CDF}$ & Cumulative Distribution Frequency \\
\hline EVSE & Electric Vehicle Supply Equipment \\
\hline THD & Total Harmonic Distortion \\
\hline TOU & Time of Use \\
\hline $\mathrm{kVA}$ & Kilo Volt Amps \\
\hline $\mathrm{kW}$ & Kilo Watt \\
\hline
\end{tabular}


kVAR

pf

p.u

BEV

EREV

PHEV
Kilo Volt Amp Reactive

Power Factor

Per Unit

Battery Electric Vehicle

Extended Range Electric Vehicle

Plug-in Hybrid Electric Vehicle 


\section{Service Transformer Loss-of-Life Calculation Using IEEE "Classical Thermal Model"}

\section{Hot Spot Temperature:}

$\theta_{H}=\theta_{A}+\Delta \theta_{\mathrm{TO}}+\Delta \theta_{H}$

Where

$$
\theta_{A}=\text { Ambient Temperature }
$$

$\Delta \theta_{\mathrm{TO}}=$ Temperature gradient of the top oil temperature over the ambient temperature $\Delta \theta_{H}=$ Temperature gradient of the hot spot over the top oil temperature

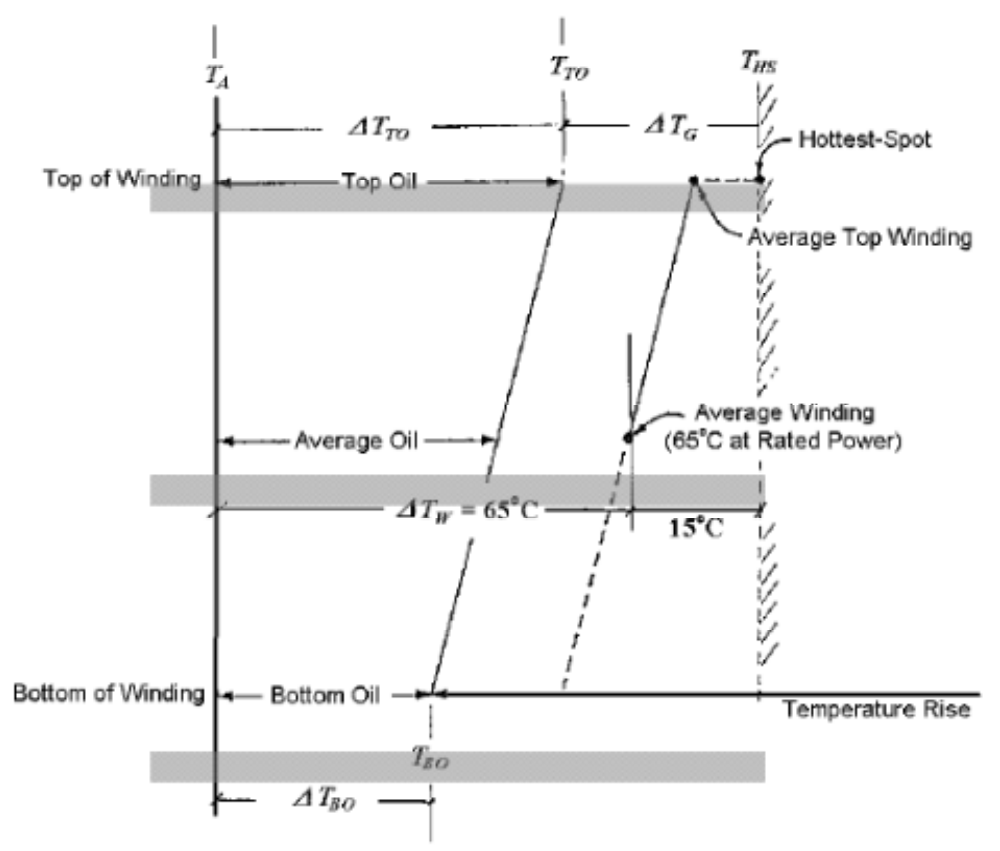

Figure 39: Transformer's Temperature profile for IEEE classical thermal model [14]

The top oil temperature $\Delta \theta_{\text {То }}$ is calculated as follows:

$$
\Delta \theta_{\mathrm{TO}}=\left(\Delta \theta_{\mathrm{TO}, U}-\Delta \theta_{\mathrm{TO}, i}\right)\left(1-e^{-\mathrm{t} / \tau_{\mathrm{TO}}}\right)+\Delta \theta_{\mathrm{TO}, i}
$$


Where

$\Delta \theta_{\mathrm{TO}, U}=$ ultimate steady-state top oil temperature gradient

$\Delta \theta_{\mathrm{TO}, i}=$ initial top oil temperature gradient

$\mathrm{t}=$ duration of the load change, $\mathrm{h}$

$\tau_{\mathrm{TO}}=$ oil time constant, $\mathrm{h}$

$$
\Delta \theta_{\mathrm{TO}, i}=\Delta \theta_{\mathrm{TO}, R}\left(\frac{K_{i}^{2} R+1}{R+1}\right)^{n}
$$

Where

$\mathrm{R}=$ ratio of load losses at rated load to no-load losses from the test report

$K_{i}=$ ratio of the initial load to the rated load

$\Delta \theta_{\mathrm{TO}, R}=$ top oil temperature gradient at rated load from the test report

$n=$ an empirical exponent that depends on the cooling class $(0.8$ for Oil Air cooling transformers)

$$
\Delta \theta_{\mathrm{TO}, U}=\Delta \theta_{\mathrm{TO}, R}\left(\frac{K_{U}^{2} R+1}{R+1}\right)^{n}
$$

Where

$K_{U}=$ the ratio of the ultimate (final) load to the rated load

\section{Winding hot-spot temperature gradient is calculated as follows:}

$$
\Delta \theta_{H}=\left(\Delta \theta_{H, U}-\Delta \theta_{H, i}\right)\left(1-e^{-t / \tau_{W}}\right)+\Delta \theta_{H, I}
$$

Where 
$\Delta \theta_{H, U}=$ ultimate steady-state hot spot temperature gradient

$\Delta \theta_{H, i}=$ initial hot spot temperature gradient

$\mathrm{t}=$ duration of load change, $\mathrm{h}$

$\tau_{W=\text { winding time constant, } \mathrm{h}}$

$\Delta \theta_{H, i}=\Delta \theta_{H, R} \times K_{i}^{2 m}$

Where

$\Delta \theta_{H, R}=$ the hot-spot temperature gradient at rated load

$\mathrm{m}=$ empirical exponent depending on the cooling class $(\mathrm{m}=0.8$ for oil air cooled transformer)

Oil time constant $\tau_{\mathrm{TO}}=\tau_{\mathrm{TO}, R} \times \frac{\Delta \theta_{\mathrm{TO}, U} / \Delta \theta_{\mathrm{TO}, R}-\Delta \theta_{\mathrm{TO}, i} / \Delta \theta_{\mathrm{TO}, R}}{\left(\Delta \theta_{\mathrm{TO}, U} / \Delta \theta_{\mathrm{TO}, R}\right)^{1 / n}-\left(\Delta \theta_{\mathrm{TO}, i} / \Delta \theta_{\mathrm{TO}, R}\right)^{1 / n}}$

$$
\tau_{\mathrm{TO}, R}=\mathrm{C} \times \frac{\Delta \theta_{\mathrm{TO}, R}}{P_{\mathrm{T}, R}}
$$

$P_{T, R}=$ total loss at rated load

$\mathrm{C}$ is thermal capacity of the transformer

$$
C=0.06 \times W_{\mathrm{CC}}+0.04 \times W_{\mathrm{TF}}+1.33 \times \mathrm{GO} \mathrm{Wh} /{ }^{\circ} \mathrm{C}
$$

Where

$W_{\mathrm{CC}}=$ weight of the core and coil assembly

$W_{\mathrm{TF}}=$ weight of the tank and fittings

$\mathrm{GO}=$ total gallons of oil that cools the transformer [18].

\section{Aging Acceleration Factor}

$F_{\mathrm{AA}}=e^{15000 / 383-15000 /\left(\theta_{H}+273\right)}=e^{39.16-15000 /\left(\theta_{H}+273\right)}$ 


\section{Loss of life:}

The equivalent aging of a transformer, ${ }_{E Q A}$, is calculated as

$$
F_{E Q A}=\frac{\sum_{n=1}^{N} F_{A A, n} \Delta t_{n}}{\sum_{n=1}^{N} \Delta t_{n}}
$$

Where $\mathrm{n}$ is the index of time interval $\mathrm{t}$, and $\mathrm{N}$ is the total number of time intervals, and $F_{A A, n}$, is the aging acceleration factor for the temperature at time interval $\Delta t_{n}$. 